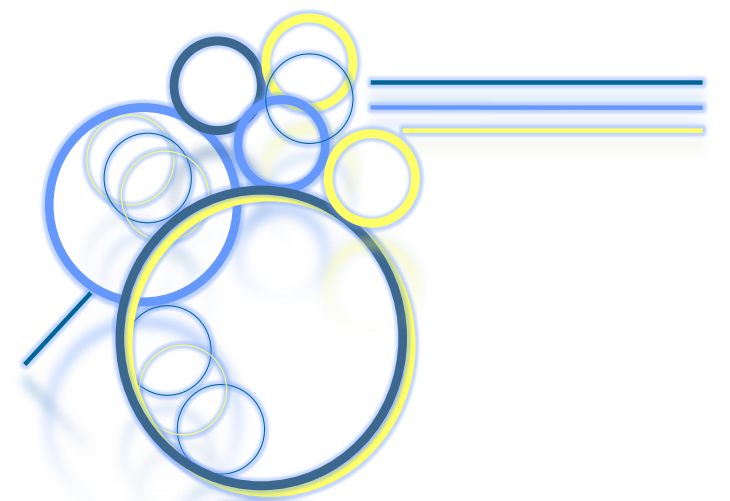

\title{
ON THE USE OF IMAGINATION BY ENTREPRENEURS
}

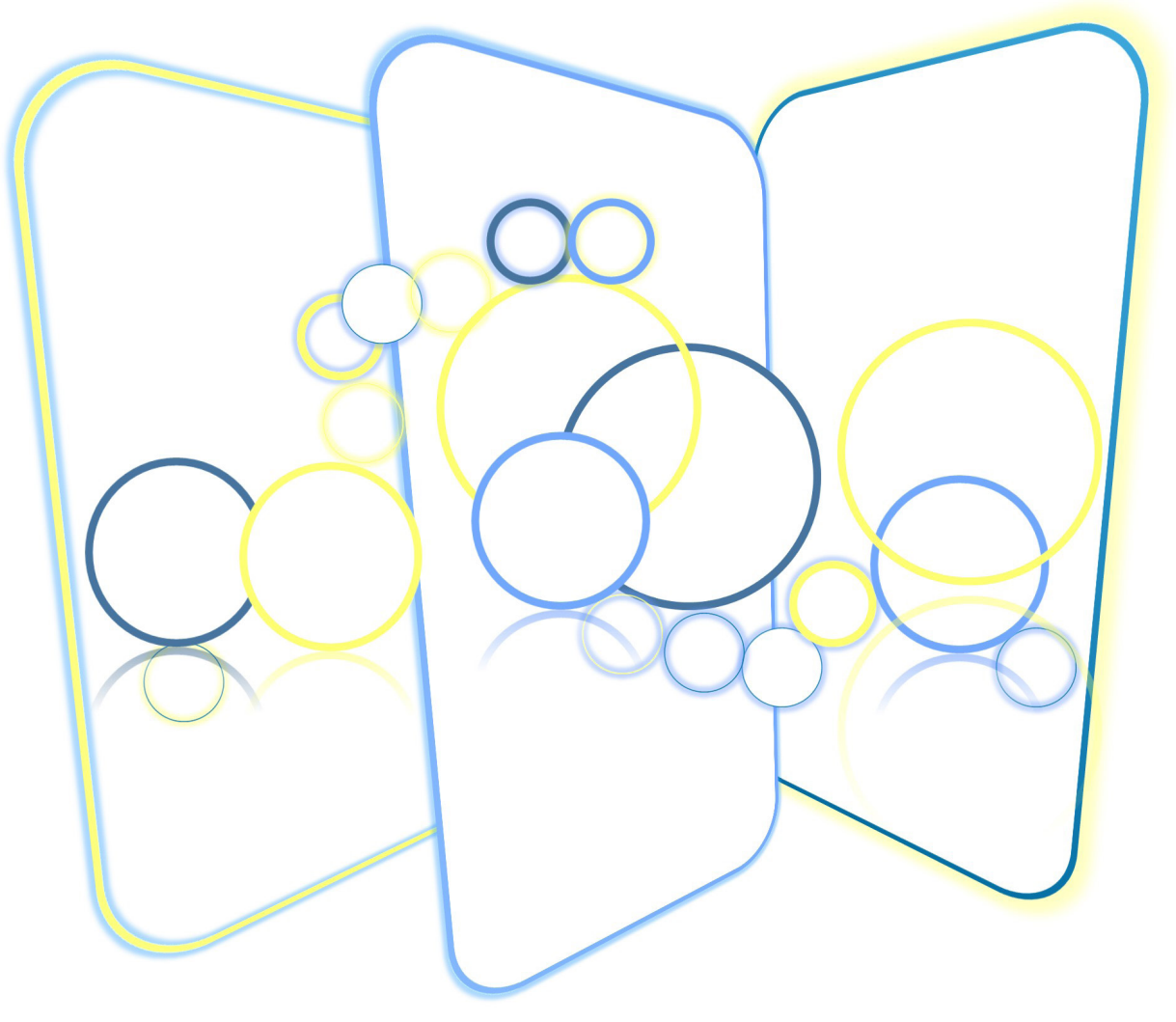

Arjan Frederiks 

On The Use of Imagination by Entrepreneurs

Arjan Frederiks 
Graduation committee:

Prof. dr. Th.A.J. Toonen (chair) University of Twente

Prof. dr. A.J. Groen (supervisor) University of Twente

Dr. M.L. Ehrenhard (co-supervisor) University of Twente

Prof. dr. T. Elfring VU University Amsterdam

Prof. dr. B.G. Englis Berry College

Prof. dr. P.D. Englis Berry College

Dr. I.R. Hatak University of Twente

Prof. dr. D.A. Shepherd Indiana University

Prof. dr. ir. P.C. de Weerd-Nederhof University of Twente

$\begin{array}{ll}\text { Year of publication: } & 2016 \\ \text { ISBN: } & 978-90-365-4003-2 \\ \text { DOI: } & \text { 10.3990/1.9789036540032 } \\ \text { URL: } & \text { http://dx.doi.org/10.3990/1.9789036540032 } \\ \text { Cover design: } & \text { Sílvia Fernandes Costa, Boston, MA, United States } \\ \text { Printed by: } & \text { Gildeprint, Enschede, The Netherlands } \\ \text { Typeset by: } & \text { LATEX } 2 \varepsilon \\ \text { Number of pages: } & \text { xxii, } 228 \text { pages } \\ \text { Number of copies: } & 200\end{array}$


ON THE USE OF IMAGINATION BY ENTREPRENEURS

\section{DISSERTATION}

to obtain

the degree of doctor at the University of Twente,

on the authority of the rector magnificus

Prof. dr. H. Brinksma,

on account of the decision of the graduation committee,

to be publicly defended

on Thursday, January 14, 2015 at 14.45 .

by

Albert Jan-Pieter Frederiks
born on July 27, 1986
in Alkmaar, the Netherlands. 
This dissertation is approved by:

Prof. dr. A.J. Groen (supervisor)

Dr. M.L. Ehrenhard (co-supervisor)

ISBN: 978-90-365-4003-2

Copyright: (C) 2016 by Albert J. Frederiks, Boston, MA, United States. 


\section{Contents}

Contents $\quad$ v

List of Figures $\quad$ xiii

List of Tables $\quad$ Xv

Acknowledgements $\quad$ xvii

1 Introduction 1

1.1 Preface .............................. 1

1.1.1 An Entrepreneurial Cognition Perspective . . . . . . . . . 2

1.1.2 The Need for Imagination in Entrepreneurship Research . . 6

1.2 Research Approach . . . . . . . . . . . . . . . . 8

1.2.1 Philosophical Positioning of this Dissertation . . . . . . . . 9

1.2.2 Research Objective and Academic and Practical Relevance . 12

1.2.3 Scope of this Dissertation . . . . . . . . . . . . 13

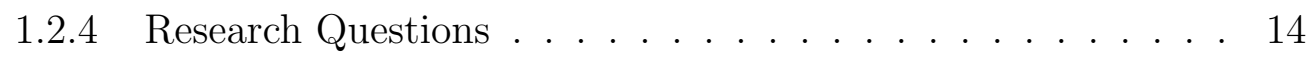

1.3 Structure of this Dissertation _. . . . . . . . . . . . . 18 


\section{Conceptualizing Imagination and Its Effective Use in Entrepreneur-} ship

2.1 Summary . . . . . . . . . . . . . . . . . . . 22

2.2 Introduction . . . . . . . . . . . . . . . . 22

2.3 What is Imagination? . . . . . . . . . . . . . . . 25

2.3.1 Processes . . . . . . . . . . . . . . . . . . . . . 28

2.3.1.1 Prospective Thinking . . . . . . . . . . 30

2.3.1.2 Counterfactual Thinking . . . . . . . . . . . 32

2.3.1.3 Perspective Taking . . . . . . . . . . . . . 33

2.3.1.4 Remembering .............. 34

2.3.2 Challenges in Understanding Imagination . . . . . . . . . . . 35

2.3.3 Positioning Imagination . . . . . . . . . . . . . . 36

2.4 Conditions Influencing the Effectiveness of Imagination . . . . . . . 38

2.4.1 Situational Factors . . . . . . . . . . . . . . . . 39

2.4.1.1 Imagination Task . . . . . . . . . . . . . 40

2.4.1.2 Environmental Dynamism . . . . . . . . . 43

2.4 .2 Individual Factors . . . . . . . . . . . . . . . . . . . . 44

2.4.2.1 Domain-relevant Knowledge . . . . . . . . . . . 44

2.4.2.2 Affect . . . . . . . . . . . . . 46

2.4.2.3 Self-esteem . . . . . . . . . . . . 47

2.5 Discussion and Implications _. . . . . . . . . . . . . . . 48

2.5.1 Beyond Entrepreneurship . . . . . . . . . . . . . . . 49

2.5.2 Further Research . . . . . . . . . . . . . . 50

2.5.3 Practical Implications _. . . . . . . . . . . . 52

2.5.4 Conclusion . . . . . . . . . . . . . . . . 53 
3 Exploring the Use of Imagination by Experienced High-tech $\begin{array}{ll}\text { Entrepreneurs } & 55\end{array}$

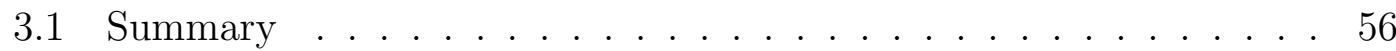

3.2 Introduction . . . . . . . . . . . . . . . . 56

3.3 Theoretical Background . . . . . . . . . . . . . . 58

3.3 .1 Imagination . . . . . . . . . . . . . . . . . 58

3.3.2 Recognizing Business Opportunities . . . . . . . . . . . 58

3.3.3 Developing Business Strategies . . . . . . . . . . . . . . . . 59

3.4 Methods . . . . . . . . . . . . . . . . . . . 60

3.4 .1 Sample . . . . . . . . . . . . . . . . . 60

3.4 .2 Data Collection . . . . . . . . . . . . . . 61

3.4 .3 Data Analysis . . . . . . . . . . . . . . . . 64

3.5 Findings . . . . . . . . . . . . . . . . . . 65

3.5.1 What is Imagination? . . . . . . . . . . . . 65

3.5.2 Prospective Thinking . . . . . . . . . . . . . . 71

3.5.3 Counterfactual Thinking . . . . . . . . . . . . 73

3.5.4 Perspective Taking . . . . . . . . . . . . . . . . 75

3.5.5 Relation with Information . . . . . . . . . . . . . 77

3.5.6 Relation with Prior Knowledge and Experience . . . . . . 79

3.6 Discussion . . . . . . . . . . . . . . . . . . . 80

3.7 Conclusion . . . . . . . . . . . . . . . . . . . . . 84

4 How Do Nascent Entrepreneurs Use Imagination In The Venture Creation Process? A Weekly Diary Study 85

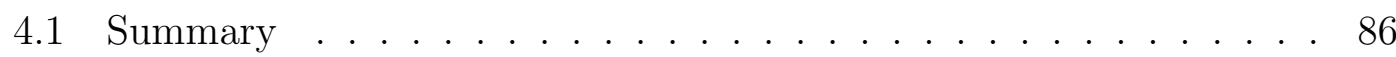


4.2 Introduction . . . . . . . . . . . . . . . 86

4.3 Theoretical framework . . . . . . . . . . . . . . . . 88

4.3.1 Imagination Processes . . . . . . . . . . . . . . . . . 88

4.3.2 Business Related Uses of the Imagination Processes . . . . . 90

4.3 .3 Main Hypothesis . . . . . . . . . . . . . . . . 91

4.3.4 Hypothesis Building . . . . . . . . . . . . . . . 92

4.4 Methods . . . . . . . . . . . . . . . . . . . . . 95

4.4.1 Measurements . . . . . . . . . . . . . . . 95

4.4.2 Sampling ...................... . . . 96

4.4.3 Research Design and Procedures . . . . . . . . . . . . . . 97

4.5 Results . . . . . . . . . . . . . . . . . . . . . . 98

4.5.1 Co-occurrences . . . . . . . . . . . . . . . . 98

4.5.2 Imagination Over Time . . . . . . . . . . . . . . . . . 102

4.5.3 Pursuit of the Business Idea Explained by Imagination . . . 103

4.6 Discussion . . . . . . . . . . . . . . . . . . . . . . 107

4.6.1 Implications . . . . . . . . . . . . . . . . 107

4.6 .2 Limitations . . . . . . . . . . . . . . . . . . 109

4.6 .3 Further Research . . . . . . . . . . . . . . . . . 111

4.7 Conclusion . . . . . . . . . . . . . . . . . . . 113

5 Using Imagination to Better Identify Business Opportunities? $\begin{array}{ll}\text { An Experimental Study } & 115\end{array}$

5.1 Summary . . . . . . . . . . . . . . . . . 116

5.2 Introduction . . . . . . . . . . . . . . . . . . . 116

5.3 Theoretical Framework . . . . . . . . . . . . . . . 118 
5.3.1 Business Opportunities . . . . . . . . . . . . . . . . 118

5.3 .2 Imagination . . . . . . . . . . . . . . . . . . . . 121

5.3.2.1 Prospective Thinking . . . . . . . . . . . 122

5.3.2.2 Counterfactual Thinking . . . . . . . . . . 123

5.3.2.3 Perspective Taking . . . . . . . . . . . . . . . 123

5.3.3 The Use of Imagination and the Quality of the Business

Opportunity . . . . . . . . . . . . . . . . 124

5.4 Methods . . . . . . . . . . . . . . . . . 126

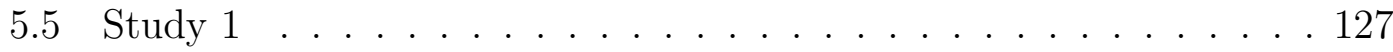

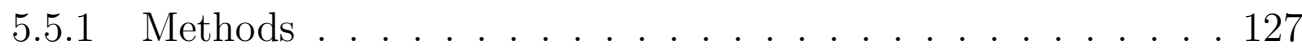

5.5.1.1 Participants .................. 127

5.5.1.2 Manipulation Task . . . . . . . . . . . . 128

5.5.1.3 Experimental Task . . . . . . . . . . . . . 132

5.5.1.4 Measures ................. . . 133

5.5.1.5 Procedures ................. 136

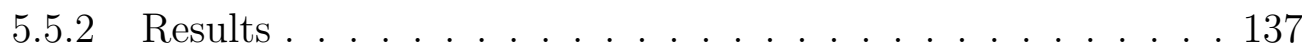

5.6 Study $2 \ldots \ldots \ldots$. . . . . . . . . . . . . . . . . 140

5.6 .1 Methods . . . . . . . . . . . . . . . . . 141

5.6.1.1 Participants . . . . . . . . . . . . . . 141

5.6.1.2 Manipulation Task . . . . . . . . . . . . . . 141

5.6.1.3 Experimental Task . . . . . . . . . . . . . 145

5.6.1.4 Measures ................. . 146

5.6.1.5 Procedures ................. . . . . . . . . . .

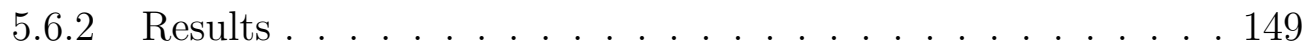

5.7 Discussion . . . . . . . . . . . . . . . . . . . 152 
5.7 .1 Implications . . . . . . . . . . . . . . . . . 153

5.7.2 Limitations and Further Research . . . . . . . . . . . . . 154

5.8 Conclusion . . . . . . . . . . . . . . . . . . . . 155

6 Discussion and Conclusion $\quad 157$

6.1 Summary of Key Findings . . . . . . . . . . . . . . . . 158

6.1.1 Research Question 1 . . . . . . . . . . . . . . 158

6.1 .2 Research Question 2 . . . . . . . . . . . . . . . 162

6.1.3 Research Question 3 . . . . . . . . . . . . . . . . . . 164

6.1.4 Research Question $4 \ldots \ldots$. . . . . . . . . . 167

6.2 Main Theoretical Contributions . . . . . . . . . . . . . . 168

6.3 Implications for Practice . . . . . . . . . . . . . . . 170

6.4 Research Limitations . . . . . . . . . . . . . . . . . . 172

6.5 Future Research Agenda . . . . . . . . . . . . . . . . . . 174

$\begin{array}{ll}\text { A Interview Questions } & 177\end{array}$

B Example of a Diary Entry $\quad 179$

C Codebook "Imagination in Diaries" 183

$\begin{array}{ll}\text { D Coding Sample } & 187\end{array}$

$\begin{array}{ll}\text { Bibliography } & 191\end{array}$

Summary: On the Use of Imagination by Entrepreneurs 217

Samenvatting: Over het gebruik van voorstellingsvermogen door ondernemers 221 
CONTENTS

About the Author 


\section{List of Figures}

1.1 Structure of this dissertation . . . . . . . . . . . . . . . . . . . 19

2.1 Different Imagination Processes . . . . . . . . . . . . . . . . . . . 30

2.2 Conceptual Model . . . . . . . . . . . . . . . . . . . . . 39

5.1 Conceptual Model . . . . . . . . . . . . . . . . . . . . 126 


\section{List of Tables}

1.1 Overview Research Questions Entrepreneurial Cognition . . . . . . . . 4

1.2 Outline of this Dissertation . . . . . . . . . . . . . 15

2.1 Definitions of Imagination . . . . . . . . . . . . . . 26

3.1 Interview Sample . . . . . . . . . . . . . . . . . . . . . . . 62

3.2 What is Imagination? . . . . . . . . . . . . . . . . . 66

4.1 Table of Co-occurrences . . . . . . . . . . . . . . . . . . 99

4.2 Predicting Amount of Imagination _ . . . . . . . . . . . . . . 102

4.3 Summary of Multinomial Logistic Regression Analysis for Imagination Processes Predicting Pursuit of Business Idea After Approximately Three Years. . . . . . . . . . . . . . . . . . . 105

4.4 Summary of Multinomial Logistic Regression Analysis for Imagination Outcomes Predicting Pursuit of Business Idea After Approximately Three Years. . . . . . . . . . . . . . . . . . 106

5.1 Overview Samples and Sample Differences Study 1 . . . . . . . . . . 129

5.2 Overview Conditions and Condition Differences Study 1 . . . . . . . 130

5.3 Overview Manipulation Check Study 1 . . . . . . . . . . . . . . . 134 
5.4 Correlation Table Study $1 \ldots$. . . . . . . . . . . . . 138

5.5 Overview Results Study 1 . . . . . . . . . . . . . . . . . . . 139

5.6 Overview Samples and Sample Differences Study 2 . . . . . . . . . . 142

5.7 Overview Conditions and Condition Differences Study 2 . . . . . . 143

5.8 Overview Manipulation Check Study 2 . . . . . . . . . . . . . . . . 147

5.9 Correlation Table Study $2 \ldots \ldots$. . . . . . . . . . . . . . 150

5.10 Overview Results Study 2 . . . . . . . . . . . . . . . . 151

C.1 Codebook for imagination processes . . . . . . . . . . . . . . . 184

C.2 Codebook for imagination outcomes . . . . . . . . . . . . . . . 185

D.1 Coding sample . . . . . . . . . . . . . . . . . . . . . . . 187 


\section{Acknowledgements}

In life, the journey is often more important than the destination. The beauty of a journey is that it hardly evolves as one had imagined upfront. One meets new people, challenges long-hold truths, develops new ideas, and creates memories that will last a lifetime. This does not mean that reaching the destination is unimportant. Quite the contrary actually. Reaching the destination gives one the chance to look back on this trip and be thankful for everything one has experienced.

When you read this, you are holding my doctoral dissertation, the destination of my five-year long journey. I am proud to have reached the final destination, but that is mainly due to the incredible journey that preceded it. I have met many people that traveled with me on this voyage. Some traveled very close by me, others on a distance, some already traveled with me on previous journeys, others I met along the way. Now I have reached this destination, I would like to take the opportunity to thank everyone who has travelled with me. I am very grateful for having the opportunity to have every single one of you as a companion on this journey. Thank you, it has been a trip of a lifetime that I will never forget!

Although many people have been part of this journey, there are some people that I would like to thank explicitly. First I would like to express my gratitude to my two supervisors: Aard Groen and Michel Ehrenhard. Aard, thank you for 
believing in me, challenging my ideas, and supporting me. Five years ago you welcomed me in your group. In hindsight I may not have had a very clear idea of what pursuing a doctoral degree entailed, but from the beginning you have supported my ideas. Although I had little experience, you believed in me and let me coordinate an undergraduate course of 150 students. On certain moments you kept your distance, allowing me to pursue my own research ideas, make mistakes, and improve my line of thought by myself. On other moments you critically and constructively challenged my thoughts to help me become a better researcher and teacher. Thank you for your support throughout these years.

Michel, our discussions on a wide variety of topics helped me shape my thoughts on a wide variety of topics. Whether we discussed local, national or international politics, the causes of the (lack of) performance of our favorite football teams FC Twente and AZ Alkmaar, or the topic of research of this dissertation, you helped me see all issues from even more points of view. Thanks to you I improved my thinking, my writing, my presentation skills and my teaching. Thank you for being such a dedicated supervisor!

Additionally, I would like to thank the committee members for reading and approving my dissertation. I look forward to having you present at my defense, and to potential future collaborations.

Subsequently, many thanks to Monique for everything you have arranged regarding the defense ceremony. You were a great help in all the administrative processes.

Additionally, I would like to thank my two paranymphs, Björn Kijl and Marc Bos, for making the journey to this doctoral dissertation, each in their own way, a very pleasant time. Björn, our 'apple breaks' were not only healthy to the body, 
but also to the mind. Our conversations on your company, stocks, the financial system, and politics taught me a lot. And all of that in the time it takes to eat an apple.

Marc, you provided me with the necessary breaks and distance from my work. We had great weekends in Enschede, Amersfoort and Utrecht and I'll never forget our adventures in France, Germany, Russia, and Switzerland. You were always there for me to challenge my thoughts on so many different topics, and provide me with invaluable advice combined with beer and whiskey. Thank you for being such a great friend!

Many thanks to my colleagues at the Netherlands Institute for Knowledge Intensive Entrepreneurship (NIKOS) at the University of Twente: Annemarie, Ari, Ariane, Basil, Björn, Efthymios, Ellen, Gabi, Isabella, Jaap, Jann, Jeroen, Jolande, Joyce, Kasia, Liqin, Mariska, Marlies, Martin, Monique, Natalie, Patrick, Paula, Petra, Rainer, Raja, Raymond, Rik, Ruud, Sandor, Sílvia, Tamara, and Tijs. And my colleagues from other departments of BMS: Anna, Anna, Erwin, Frederik, Jeroen, Jorrit, Maarten, Matthias, Michiel, Milana, Niels, Petra, Tanya. Thank you for giving me a great time at the University of Twente. A big thank you to the colleagues with whom I shared an office and whom had to endure me through all these years: Björn, Ellen, and Sílvia. Thank you for keeping up with me all this time and for our great conversations on all kinds of different topics.

Um grande Obrigado à minha família Portuguesa! Estou muito honrado e agradecido pelo vosso apoio e interesse no meu trabalho. Embora por vezes tenha tido de trabalhar algumas horas enquanto passava férias em Portugal, espero poder aproveitar ainda mais o bonito país e a vossa companhia agora que terminei a tese. Muito obrigado. 
E um grande Obrigado aos meus amigos do ISCTE-IUL: Professor Caetano, por todas as interessantes ideias de investigação partilhadas. À Ana Margarida Graça, por todas as aventuras em viagem por vários países. E à Susana Santos, pela amizade incondicional, todo o apoio e por toda a sua felicidade e entusiasmo contagiantes. Muito obrigado todas a pessoas do ISCTE-IUL proporcionarem momentos e conferencias interessantes!

Ook wil ik graag mijn ouders, Bert en Nel, en mijn zus Tineke bedanken: zonder jullie hulp en steun had ik geen proefschrift kunnen schrijven. Jullie hebben altijd alles gedaan en gegeven zodat ik mij verder kon ontwikkelen. Iedere stap die ik heb gezet, hebben jullie gesteund. Met het afronden van dit proefschrift heb ik weer een stap gezet, die alleen mogelijk was dankzij jullie onvoorwaardelijke liefde! Dank jullie wel!

The biggest evidence that the journey towards this dissertation is more important than the dissertation itself, are you, Sílvia. We met on a research conference in Seville and since then we have travelled together. From a fellow-researcher, you became my friend, my colleague, my girlfriend, my office-mate, my critical reviewer - but never reviewer 2 -, my wife, my co-author, and my most important travel companion. Thank you for your support in everything I do, your constructive critical feedback on my work, and your love. Pursuing a doctoral degree has taught me a lot, but having met you, and now having our little baby on the way, showed me that "All I know, and all I need to know, is there is no end to love" (U2, 2014).

Arjan Frederiks

Boston, MA, December 6, 2015. 



\section{Chapter 1}

\section{Introduction}

\subsection{Preface}

The concept of imagination is popular in both practice-oriented entrepreneurship literature (e.g., Faucette, 2012) and academic literature on entrepreneurship (Keating and McLoughlin, 2010). Also in entrepreneurship education the concept of imagination is becoming more and more important (e.g., Seelig, 2015). This is not surprising, because using their imagination is important for entrepreneurs (e.g., Cornelissen and Clarke, 2010; Gartner, 2007; Sarasvathy, 2002; Witt, 1998, 2007). However, what imagination is and how entrepreneurs use it, remain unknown from both practice-oriented and academic literature. Understanding what imagination is, and how entrepreneurs use their imagination effectively, is important. First, this will help entrepreneurship scholars to better understand the entrepreneurial process, for example, how entrepreneurs imagine opportunities (Cornelissen and Clarke, 2010). Second, it will help entrepreneurs to make better user of their imagination and therefore better develop their business ideas (Witt, 2007). Third, this 
will help entrepreneurship support organizations and entrepreneurship educators to prepare potential entrepreneurs to make more effective use of their imagination.

In this dissertation we treat the use of imagination by entrepreneurs. Imagination has been studied in multiple fields, such as biology, neurolog and psychology (Markman et al., 2009). Across these fields imagination has been conceptualized as a faculty, an outcome, or a process (Markman et al., 2009). In this dissertation we will take the perspective that imagination is a cognitive process, because this perspective gives insights into how entrepreneurs can use their imagination more effectively.

We start our introduction by placing the use of imagination in a broader discussion of entrepreneurial cognition. We then present the objective and the scope of this dissertation, and the research questions that will be answered in this dissertation. Subsequently, we outline the structure of this dissertation.

\subsubsection{An Entrepreneurial Cognition Perspective}

Entrepreneurial cognition is an important stream of research within the field of entrepreneurship (e.g., Grégoire et al., 2011; Ireland and Webb, 2007; Mitchell et al., 2004, 2007). Entrepreneurial cognition has been defined as follows: "entrepreneurial cognitions are the knowledge structures that people use to make assessments, judgments, or decisions involving opportunity evaluation, venture creation, and growth. In other words, research in entrepreneurial cognition is about understanding how entrepreneurs use simplifying mental models to piece together previously unconnected information that helps them to identify and invent new products or services, and to assemble the necessary resources to start and grow 
businesses" (Mitchell et al., 2002, p. 97, italics in original). The starting point of entrepreneurial cognition was the question: "How do entrepreneurs think?" (Mitchell et al., 2007, p. 3). Scholars within the stream of entrepreneurial cognition research have addressed this issue via multiple questions. In Table 1.1 we have provided an overview of the most important questions in entrepreneurial cognition research (based on Baron and Ward, 2004; Baron, 2004; Mitchell et al., 2004). Although these are all intriguing questions, for now we will focus on the set of questions related to why some people, but not others, recognize opportunities. The reason for this is that by focusing on the combination of entrepreneurial cognition and opportunities (e.g., Costa et al., 2016), we focus on the core of entrepreneurship research: the nexus between opportunities and enterprising individuals (Shane and Venkataraman, 2000; Venkataraman, 1997).

In addressing the question why some people, but not others, recognize opportunities, current research has mainly followed a Kirznerian approach (Chiles et al., 2007). Prior knowledge (Shane, 2000) has been studied extensively as an important antecedent of opportunity recognition. The opportunity recognition process has been described with concepts as entrepreneurial alertness (Gaglio and Katz, 2001; Kirzner, 1979) and pattern recognition (Baron, 2006; Baron and Ensley, 2006). Entrepreneurial alertness "will exhibit itself in a continuous 'search' for information, through broad and undirected scanning that will take place at unconventional times and places, as opposed to a directed, rational search, which takes place in appropriate times [...] and expected places [...] where managerial search is more likely to occur" (Kaish and Gilad, 1991, p. 49).

An alternative explanation has been given by Baron (2006), who introduced the concept of pattern recognition. From a pattern recognition perspective, indi- 
Table 1.1: Overview Research Questions Entrepreneurial Cognition

\begin{tabular}{|c|c|c|}
\hline Baron (2004) & Baron and Ward (2004) & Mitchell et al. (2004) \\
\hline $\begin{array}{l}\text { Why are some en- } \\
\text { trepreneurs so much } \\
\text { more successful than } \\
\text { others? }\end{array}$ & & \\
\hline $\begin{array}{l}\text { Why do some persons } \\
\text { but not others choose to } \\
\text { become entrepreneurs? }\end{array}$ & & $\begin{array}{l}\text { Why do some people } \\
\text { and not others choose to } \\
\text { become entrepreneurs? }\end{array}$ \\
\hline \multirow[t]{5}{*}{$\begin{array}{l}\text { Why do some persons } \\
\text { but not others } \\
\text { recognize opportunities } \\
\text { for new products or } \\
\text { services that can be } \\
\text { profitably exploited? }\end{array}$} & $\begin{array}{l}\text { What cognitive factors play a role in } \\
\text { opportunity recognition? } \\
\text { Are entrepreneurs better than other } \\
\text { persons at recognizing complex pat- } \\
\text { terns - at "connecting the dots" } \\
\text { or seemingly unrelated factors and } \\
\text { events into identifiable opportuni- } \\
\text { ties? }\end{array}$ & $\begin{array}{l}\text { Why do some persons } \\
\text { but not others } \\
\text { recognize opportunities } \\
\text { for new products or } \\
\text { services that can be } \\
\text { profitably exploited? }\end{array}$ \\
\hline & $\begin{array}{l}\text { Are entrepreneurs subject to the } \\
\text { same cognitive biases and errors as } \\
\text { other persons? }\end{array}$ & \\
\hline & $\begin{array}{l}\text { Do the cognitions of entrepreneurs } \\
\text { differ from those of other persons? } \\
\text { Do entrepreneurs prefer heuristics } \\
\text { to systematic thinking? } \\
\text { Do entrepreneurs possess knowledge } \\
\text { structures that differ from those of } \\
\text { other persons [...] and do they ap- } \\
\text { ply that knowledge more effectively } \\
\text { in a wide rage of situations? } \\
\text { Do entrepreneurs have greater ca- } \\
\text { pacity than other persons to focus } \\
\text { their attention on pertinent infor- } \\
\text { mation? } \\
\text { Do entrepreneurs reason or make } \\
\text { decisions differently than other per- } \\
\text { sons? }\end{array}$ & $\begin{array}{l}\text { Do entrepreneurs think } \\
\text { differently than other } \\
\text { business people? }\end{array}$ \\
\hline & & $\begin{array}{l}\text { How do entrepreneurs } \\
\text { think and make strate- } \\
\text { gic decisions? How do } \\
\text { these differences lead to } \\
\text { competitive advantages } \\
\text { and disadvantages? }\end{array}$ \\
\hline & & $\begin{array}{l}\text { How can we mea- } \\
\text { sure[...] cognitive con- } \\
\text { cepts in non-laboratory } \\
\text { settings[?] }\end{array}$ \\
\hline
\end{tabular}


viduals possess cognitive frameworks to 'connect the dots' between environmental changes - "changes in technology, economic, political, social, and demographic conditions" (Baron, 2006, p. 107).

In this Kirznerian approach to entrepreneurship with entrepreneurial alertness (Gaglio and Katz, 2001; Kirzner, 1979) and pattern recognition perspectives (Baron, 2006; Baron and Ensley, 2006), opportunities are viewed from a discovery perspective (Shane, 2003). This perspective assumes opportunities to exist independent of the entrepreneur, and 'out there' to be recognized. Such opportunities exist ex ante, one can be alert to them and discover these opportunities, or one can recognize patterns that lead to the recognition of these opportunities. However, the Kirznerian approach of entrepreneurial alertness and pattern recognize is only a partial explanation to why some people, but not others, recognize opportunities (Alvarez and Barney, 2007).

Not all opportunities exist independent of the entrepreneur (Alvarez and Barney, 2007). Following a creation perspective instead (Venkataraman, 2003), Alvarez and Barney (2007) argue that other opportunities only come into existence because of entrepreneurial action. These opportunities do not exist ex ante, and only exist because of the entrepreneur (Alvarez and Barney, 2007). The Kirznerian approach does not fit with these assumptions, as this approach does not assume the possibility of entrepreneurs to create opportunities, and therefore we need to look into other approaches than the Kirznerian approach to entrepreneurship.

Before we look into these other approaches, we shortly want to reflect upon the question "why do some people, but not others, recognize opportunities?" Maybe the reason why answering the question is so difficult, could very well be due to the formulation of the question itself. By using the term 'recognize' we limit ourselves 
to opportunities that exist ex ante, and therefore can be recognized. We would like to extend this question to capture both opportunity recognition and opportunity creation by asking the question "why do some people, but not others, identify opportunities?" Opportunity identification is a more general term (DeTienne and Chandler, 2004), combining both opportunity recognition and opportunity creation (Zahra, 2008). This question opens up possibilities for research by scholars who either assume that opportunities are created through action, or who are indifferent on this matter. That type of research would be build upon an approach different from the Kirznerian approach and have a different set of assumptions. In the next section we will look into such an approach.

\subsubsection{The Need for Imagination in Entrepreneurship Research}

While Kirznerian discovery assumes that opportunities exist ex ante, and independent of the entrepreneur, Alvarez and Barney (2007) argue that other opportunities do not exist ex ante. These opportunities come into existence due to entrepreneurial action (Alvarez and Barney, 2007). Because the assumptions of the Kirznerian approach do not fit, we need to find a different approach to entrepreneurship that is build upon a different set of assumptions.

The Schumpeterian approach to entrepreneurship allows for entrepreneurs to create opportunities. Schumpeter (1934) argued that the entrepreneur is a special individual who combines resources into new products or services. These new combinations of resources lead, via creative destruction of industries, to innovation and wealth creation (Schumpeter, 1942). Schumpeter (1942) explains that these 
new combinations, or novelty, is spread through the market via 'creative destruction.' However, Schumpeter does not explain from where these new combinations originate, nor how novelty is created (e.g., Kirzner, 1973; Witt and Foster, 1992). To explain how new combinations come into existence, Chiles et al. (2007) argue for a Lachmannian approach to entrepreneurship, which assumes entrepreneurs use their imagination.

Whereas the Schumpeterian approach explains how entrepreneurs create novelty and does not explain where novelty comes from, a Lachmannian approach both assumes that entrepreneurs can create novelty and also explains that this novelty comes from the use of imagination. According to Lachmann (1986) entrepreneurs "form plans based on their subjective knowledge and expectations" (Chiles et al., 2007, p. 473, italics in original). These expectations are directed toward an unknown and unknowable future. Hence, entrepreneurs imagine possible futures and then choose a possible future upon which they will act. This makes the choice for a possible future a creative act that leads to novelty (Chiles et al., 2007).

The Lachmannian approach of creative imagination (Lachmann, 1986) differs from Kirznerian discovery (Kirzner, 1979), which assumes that opportunities already exist, and differs from Schumpeterian creative destruction (Schumpeter, 1942), which abstains from human subjectivity (Witt and Foster, 1992). In the Lachmannian approach to entrepreneurship imagination is at the core of the creation of novelty, and hence of opportunities (Chiles et al., 2007; Lachmann, 1986). Because imagination creates novelty, imagination can be a source of competitive advantage for entrepreneurs and their ventures, and therefore imagination could be regarded as a dynamic capability (Teece et al., 1997). As we will explain in subsection 1.2.3, in this dissertation we are more interested in the use of imagi- 
nation by entrepreneurs, and hence conduct our research on the individual level. Therefore our studies take a cognition perspective, instead of a capabilities perspective (Eggers and Kaplan, 2013).

Research on entrepreneurship focuses on the nexus between individuals and opportunities (Shane and Venkataraman, 2000). A Lachmannian approach to entrepreneurship assumes that these entrepreneurial individuals use their imagination to create the novelty that leads to opportunities. Therefore, entrepreneurship research should take the use of imagination by entrepreneurs into account.

Studying the use of imagination by entrepreneurs helps us not only to address the question "why do some people, but not others, identify an opportunity?", but also may contribute to finding an answer to other questions in the field of entrepreneurial cognition, like the questions shown in Table 1.1. For example, the use of imagination may contribute to an explanation whether entrepreneurs think differently than other business people (Mitchell et al., 2004). In this dissertation we do not aim to fully answer any of the questions in Table 1.1. Our objective is to increase our understanding of the use of imagination by entrepreneurs. By increasing our understanding of the use of imagination by entrepreneurs, we hope that future research may use the concept of imagination to answer questions of entrepreneurial cognition research.

\section{$1.2 \quad$ Research Approach}

From this introduction the need for a critical investigation of the use of imagination by entrepreneurs was explained. In this section we will present the philosophical positioning of this dissertation, the objective of this dissertation, the scope of our 
dissertation, and our research questions. We will end this chapter by presenting the structure of this dissertation.

\subsubsection{Philosophical Positioning of this Dissertation}

In this section we will briefly elaborate on the philosophical positioning of this dissertation. The philosophy of science literature has discussed many different approaches to science. For example, Johnson and Duberley (2000) distinguish between positivism, neopositivism, critical theory, critical realism and pragmatism, conventionalism, and postmodernism. The authors make this distinction based on a quadrant with objective versus subjective ontology on the one side, and objective versus subjective epistemology on the other side. In this dissertation we take a realist philosophy of science. We take this philosophy of science, because many studies in the field of entrepreneurship are conducted based on this philosophy of science (Alvarez and Barney, 2010; Alvarez et al., 2014) and we aim to contribute to existing work in this field.

Our choice for a realist philosophy of science implies that we presuppose an objective ontology and a subjective epistemology. Hence, we presuppose that "social and natural reality have an independent existence prior to human cognition" (Johnson and Duberley, 2000, p. 180), and that we only can access this external world subjectively. Although there are multiple approaches that presuppose an objective ontology and a subjective epistemology, for example critical realism and pragmatism, the differences between these approaches "seem differences of emphasis rather than irresolvable dispute" (Johnson and Duberley, 2000, p. 187). We therefore will not dive further into these differences. We refer the reader who is 
interested in knowing more about the different philosophical approaches to science to the book by Johnson and Duberley (2000).

The choice for a realist philosophy of science fits well with an engaged scholarship approach (van de Ven and Johnson, 2006; van de Ven, 2007), because engaged scholarship is build upon an evolutionary realist philosophy of science. In our research we take an engaged scholarship approach, because we aim to generate knowledge that is relevant for both theory and practice.

Our presupposition of a subjective epistemology means we assume that researchers can only know reality via subjective means (Johnson and Duberley, 2000). This means that we cannot completely and objectively know and study the use of imagination by entrepreneurs. It is precisely because we presuppose that we cannot fully and objectively know the reality that we study, that we choose to use multiple methods. By the use of multiple methods we try to understand the use of imagination in multiple ways which gives a more complete overview than when we would have used one single method only. Using a "pluralistic methodology for advancing knowledge" (van de Ven and Johnson, 2006, p. 803) is at the core of an engaged scholarship approach (van de Ven, 2007).

In chapter 3 we conduct interviews on the use of imagination by entrepreneurs. We analyse the answers of the entrepreneurs, who give their subjective interpretation and memories of the events we study. In such interviews the interaction between the interviewer and interviewee affects the data that is gathered. For example, based on the answers of the interviewee the interviewer may decide to focus more on one aspect or another. The researcher is here not the observing outsider, but part of the data gathering process. Also in the data analysis process the researcher is not an observing outsider. By reading, interpreting, coding, and 
reinterpreting the answers of the interviewees the researchers actively participate in the research process and in shaping the results and conclusions.

In chapter 4 we collect and analyse the weekly diaries that a group of entrepreneurs has filled out for one year. By coding for sentences and phrases that contain an expression of imaginative thoughts, we analyse the use of different imagination processes and the goals for which these imagination are used. As there is no interaction between researchers and entrepreneurs, the researchers keep their distance from the subject of the study in the data collection process. In this phase the researchers are more observing outsiders than an active part of the research process. In the data analysis phase, however, the researchers are active participants in interpreting and coding the writings of the entrepreneurs. In this phase the researchers become an active part in the research process and therefore in shaping the results and conclusions.

In chapter 5 we use an experimental design to study which imagination process leads to the identification of better business opportunities. Taking an experimental design, the researchers objective outsiders in the data collection and data analysis phases. The researchers do not intervene or influence these processes. In this study the researchers are more observing outsiders.

In this section we have shortly reflected upon our philosophical positioning. Our realist philosophy of science, engaged scholarship approach, and assumptions of an objective ontology and subjective epistemology have an influence on our research, its results, and conclusions, as we described above. By making these assumptions explicit, our research can be critically assessed and can be positioned among other works along the lines of its assumptions. 


\subsubsection{Research Objective and Academic and Practical Relevance}

Our research objective is to increase our understanding of the use of imagination by entrepreneurs. We will do so by systematically conceptualizing, exploring and testing how entrepreneurs use imagination to identify and develop their business idea.

Our research has three main contributions. The first contribution is that this dissertation conceptualizes what imagination is. Current entrepreneurship literature fails to analyze, or even describe, this important aspect of the entrepreneurial process. From both existing and recent research in entrepreneurship it became apparent that entrepreneurs use their imagination. However, what imagination is, is barely understood by entrepreneurship researchers. Hardly any scholar explains what is meant by "imagination" or "to imagine". By conceptualizing what imagination is, we hope to provide a framework for entrepreneurship scholars to be more precise in explaining what they mean by imagination if they study the use of imagination by entrepreneurs.

The second contribution is that we show the situations in which entrepreneurs use their imagination. From previous research we do not know in what situations entrepreneurs use their imagination. Knowing this enables entrepreneurship scholars to study the use of imagination in a better defined setting and provide practitioners with better contingency-based advice.

The third and last main contribution of our research is that we provide insights in how entrepreneurs can use their imagination more effectively. Knowing how the imagination can be used more effectively by entrepreneurs enables scholars 
to better understand how certain entrepreneurial processes can be optimized. Additionally, practitioners would be able to better educate (potential) entrepreneurs on how to start their businesses.

\subsubsection{Scope of this Dissertation}

In this dissertation we aim to achieve our objective to increase our understanding of the use of imagination by entrepreneurs within a certain scope. The unit of analysis of this dissertation is the individual entrepreneur. The reason that we chose to study the use of imagination by entrepreneurs on the individual level is that imagination is a cognitive process at the individual level. Not all cognitive process take place on the individual level (e.g., Hodgkinson and Healey, 2008; de Mol et al., 2015). One could argue that entrepreneurs use their imagination when thinking about ideas in a group (West III, 2007), for example, when participating in a brainstorming session, having a meeting with the co-founders, or working together in networks (Groen, 2005). We recognize that, for example, the business opportunities that were imagined advance by communicating them with others (Felin and Zenger, 2009), especially using metaphors (Cornelissen and Clarke, 2010). However, the imagination processes take place inside the head of an individual, before one can communicate these thoughts with others.

In this dissertation we mainly study the use of imagination by entrepreneurs in high-technology settings. We chose for high-technology settings because of two reasons. First, technological inventions are an important source of new business opportunities (Shane, 2001). This means that imagination may be used often in such a setting. Second, uncertainty is a pivotal element of entrepreneurial 
action (McMullen and Shepherd, 2006). High-technology industries uncertainty is high because these industries are changing rapidly and the future of these industries are unpredictable and unknowable. But although the future is unknowable, it is not unimaginable (Lachmann, 1976). Therefore, the use of imagination may be more imperative to high-technology entrepreneurs than to other types of entrepreneurs.

In this section we have discussed the scope in which our research takes place. In the next section we will focus on the research questions we aim to answer.

\subsubsection{Research Questions}

In this dissertation we treat the use of imagination by entrepreneurs. More specifically, we aim to understand what imagination is, and how entrepreneurs use their imagination effectively. Therefore, the main research question that we aim to answer in this dissertation is:

Main research question: How do entrepreneurs effectively use their imagination in the entrepreneurial process?

To be able to reach our research objective and to answer this question, we need to answer several underlying research questions. Four research questions form the basis of the four studies that we present in this dissertation. Before we elaborate on the four studies, we summarize the research questions, the contribution of each study in answering the main research question, and the research methods used in each study in Table 1.2.

First, we need to focus on the concept of imagination. To be able to conduct research on this concept, we need to make clear what imagination is. Therefore, we aim to conceptualize imagination, and position imagination in relation to closely 


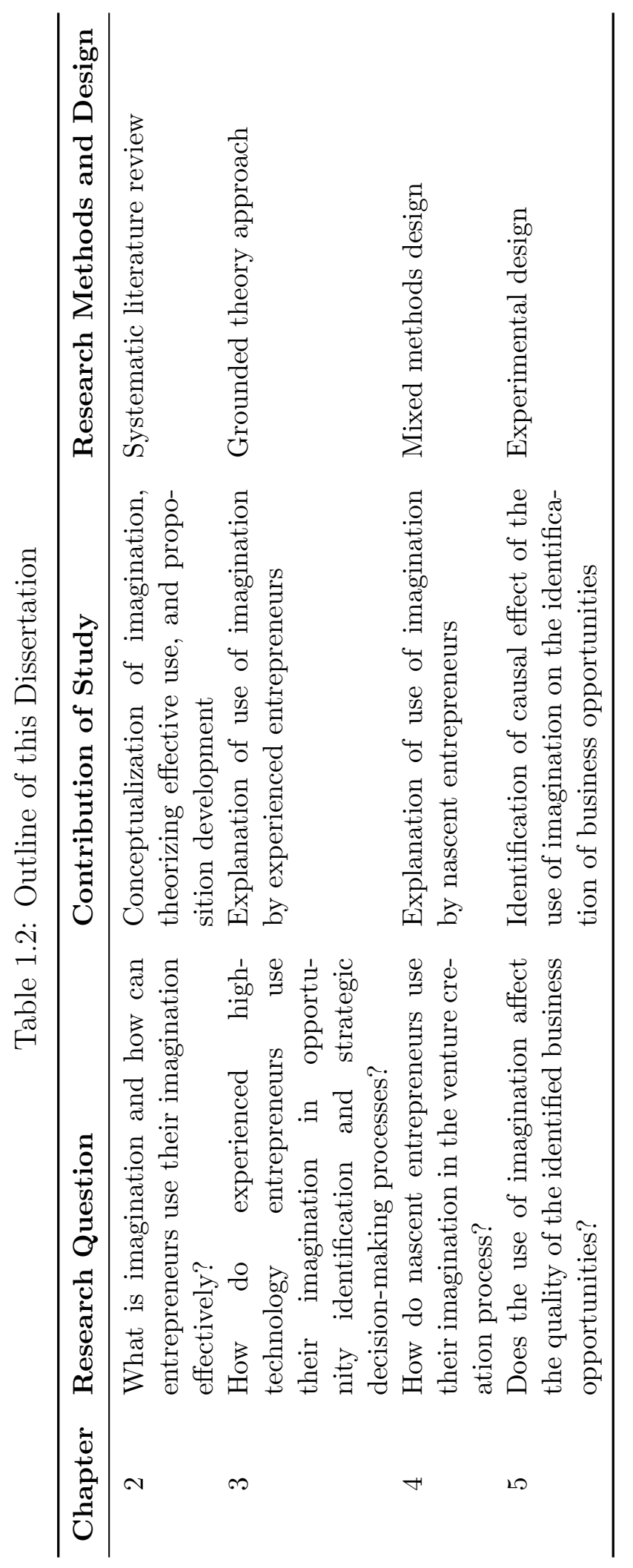


related concepts. After conceptualizing imagination, our aim is to theorize on the effective use of imagination by entrepreneurs. We will develop proposition on the effective use of imagination by entrepreneurs. These propositions will guide our empirical work in this dissertation. Hence, our first research question is:

Research question 1: What is imagination and how can entrepreneurs use their imagination effectively?

After we have conceptualized imagination and developed propositions, we can empirically study the use of imagination by entrepreneurs. An important finding in entrepreneurial cognition research is that there are significant differences between the way novice entrepreneurs and expert entrepreneurs think and act (e.g., Baron and Ensley, 2006; Mitchell et al., 2005; Sarasvathy, 2001). Therefore, we want to study the use of imagination by both nascent entrepreneurs and experienced entrepreneurs.

We first focus on the use of imagination by experienced entrepreneurs in the setting of opportunity identification and strategic decision making. We focus on opportunity identification and strategic decision making because the use of imagination by entrepreneur is often mentioned in relation to these two processes in the existing literature (e.g., Szulanski and Amin, 2001; Witt, 2007). Experienced entrepreneurs have been through these entrepreneurial processes multiple times and therefore will able to reflect upon their use of imagination in these processes. Therefore, we will conduct interviews with these entrepreneurs, to get an answer to our second research question:

Research question 2: How do experienced high-technology entrepreneurs use 
their imagination in opportunity identification and strategic decision-making processes?

After we have focused on the use of imagination by experienced entrepreneurs, we focus on its use by nascent entrepreneurs. We aim to learn how nascent entrepreneurs use their imagination, while most of them go through the venture creation process for the first time. By analyzing their weekly diary entries, which these entrepreneurs kept for a year, we aim to learn how nascent entrepreneurs use their imagination in the venture creation process. Hence, our third research question is:

Research question 3: How do nascent entrepreneurs use their imagination in the venture creation process?

We have studied the use of imagination by both experienced and nascent entrepreneurs in the previous two research questions. These studies will result in a causal explanation of the use of imagination by entrepreneurs. To identify causal relationships, not only a causal explanation is needed, but also a causal description. In the last study of our dissertation we choose to use an experimental design, because its unique strength is to find a causal description, which is "describing the consequences attributable to deliberately varying a treatment" (Shadish et al., 2002, p. 9). Our aim is to use an experimental design to identify the effect of the use of imagination by entrepreneurs on one specific task, the identification of business opportunities. More precisely, we aim to find whether the use of imagination leads to identifying business opportunities of higher quality. Hence, our fourth research question is: 
Research question 4: Does the use of imagination affect the quality of the identified business opportunities?

In this section we have introduced our main research question. We have developed four research questions that will guide us in the four studies in this dissertation, we have argued why we have developed these four studies, we have argued how the studies relate to each other, and we have summarized this in Table 1.2. In the next section we will present the structure of this dissertation.

\subsection{Structure of this Dissertation}

This dissertation, which contains four studies, consists of six chapters. In Figure 1.1 the graphical representation of the six chapters, the four studies, and their relations are presented.

In chapter 2 our main theoretical model is presented. The aim of this chapter is twofold. First, imagination is conceptualized and demarcated from related concepts. Second, theory is built on how entrepreneurs use their imagination more effectively. The propositions derived from theorizing are input for the rest of the dissertation.

In chapter 3 we study the use of imagination by experienced high-technology entrepreneurs. By interviewing experienced high-technology entrepreneurs we aim to better understand how they use their imagination.

In chapter 4 we study the use of imagination by nascent entrepreneurs in the venture creation process. By studying the diaries of such entrepreneurs we aim to better understand for which purposes nascent entrepreneurs use their imagination. 


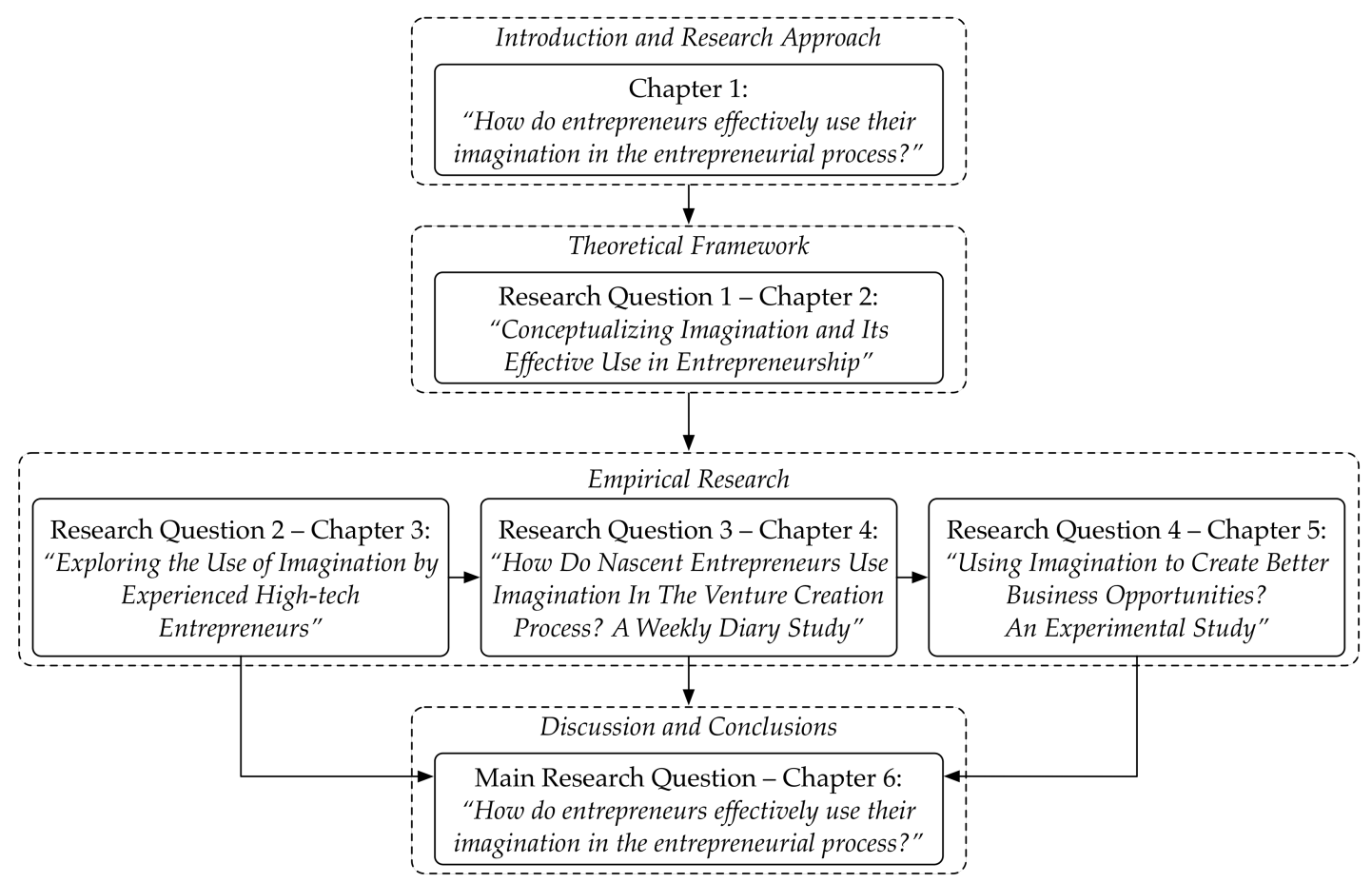

Figure 1.1: Structure of this dissertation

In chapter 5 we aim to test whether using one's imagination influences the quality of the business opportunity that is recognized. In an experimental setting we test the effect of the different imagination processes on the quality of the business opportunity.

In chapter 6 we bring together and discuss the overall findings of this dissertation, we draw implications for both theory and practice, and build an agenda for future research. 



\section{Chapter 2}

\section{Conceptualizing Imagination and}

\section{Its Effective Use in}

\section{Entrepreneurship}

Previous versions of this chapter have been presented at 1) the $74^{\text {th }}$ Annual Meeting of the Academy of Management, August 1-5, 2014 in Philadelphia, PA, United States of America; 2) the $72^{\text {nd }}$ Annual Meeting of the Academy of Management, August 3-7, 2012 in Boston, MA, United States of America; and 3) the $26^{\text {th }}$ Annual Meeting of the British Academy of Management, September 11-13, 2012 in Cardiff, United Kingdom. 


\section{$2.1 \quad$ Summary}

The use of imagination is important to entrepreneurs. Many entrepreneurship scholars state that entrepreneurs use imagination for, among others, identifying opportunities and developing strategies. However, what imagination is and how entrepreneurs use their imagination stay unexplained. Consequently, how entrepreneurs use their imagination most effectively remains unclear. This chapter aims both to provide more clarity on what imagination is from a business perspective, and to explain how entrepreneurs can use imagination more effectively. We review the concept of imagination and we conceptualize imagination as a combination of three mental simulation processes: prospective thinking, counterfactual thinking, and perspective taking. Additionally, we differentiate imagination from related concepts such as creativity. Subsequently, we develop a model and propositions on the effective use of imagination by entrepreneurs. We argue that individual factors, the type of imagination task, and environmental dynamism influence the effective use of imagination by entrepreneurs. Furthermore, we offer a research agenda for further research on the use of imagination by entrepreneurs, which focuses on opportunity identification, effectuation strategies, and expertise.

\subsection{Introduction}

The use of imagination is essential for entrepreneurs (e.g., Baron, 2006; Cornelissen and Clarke, 2010; Foss and Foss, 2008; Foss et al., 2008; Gartner, 2007; Kaish and Gilad, 1991; Lumpkin and Dess, 1996; Mathews, 2010; Sarasvathy, 2001, 2008; Witt, 1998, 2007). From previous research, we know what entrepreneurs imagine: 
specific goods or services (Baron, 2006; Boudreaux and Holcombe, 1989), opportunities (Chiles et al., 2010; Cornelissen and Clarke, 2010; Foss and Foss, 2008; Klein, 2008; Olson Jr, 1996), (new) combinations of existing resources (Chiles et al., 2010; Kraaijenbrink et al., 2009), market values of goods and resources (Kaish and Gilad, 1991), the future (Chiles et al., 2010; Lachmann, 1976), courses of action (Read et al., 2009; Wiltbank et al., 2009), ends or goals (Edelman and Yli-Renko, 2010), expansion (Lumpkin and Dess, 1996), business conception (Witt, 1998, 2007), and "all possible moves that unfold in the future" (Witt, 2007, p. 1128). Additionally, we know that entrepreneurs use their imagination in decision-making processes (Foss et al., 2008) and opportunity creation processes (Klein, 2008), because imagination is a low-cost way to generate, identify, and consider a diversity of entrepreneurial possibilities (Felin and Zenger, 2009).

However, what imagination is, how entrepreneurs use their imagination, and if imagination has an influence on venture success remain unclear from these studies. There are two main reasons that studying the use of imagination more extensively is complicated. The first is that there is no consensus among scholars on what imagination is. This lack of agreement over the concept of imagination manifests itself in four ways. Some scholars define imagination as the faculty in the brain responsible for imaginative thoughts (e.g., Loasby, 2001), other scholars define imagination as the mental processes in which new connections lead to new representations (e.g., Keating and McLoughlin, 2010), and again other scholars define imagination as the outcome of such mental processes: images (e.g., Gordon, 1985). Furthermore, when discussing the use of imagination, scholars mainly consider imagining possible futures (e.g., Chiles et al., 2007; Cornelissen and Clarke, 2010), but imagination can also be used to recreate the past (e.g., Van Boven et al., 
2009). Additionally, some scholars argue that imagination is non-abrasive (e.g., Chia, 1996; Szulanski and Amin, 2001), whereas other scholars argue that imagination is rational (e.g., Byrne, 2005). Finally, some scholars argue that everything can be imagined, because the imagination is unbounded (e.g., Hamel, 1999; Witt, 1998, 2007), whereas others have shown that one's imagination is bounded (e.g., Chiles et al., 2010). One goal of this chapter is, therefore, to provide conceptual clarity on what imagination is, and what it is not.

The second reason that complicates extensive research on the use of imagination in entrepreneurship is that the factors that influence the effective use of imagination are not clear. For example, scholars state that entrepreneurs use their imagination to come up with new business ideas (Chiles et al., 2010; Witt, 2007). However, using a little to no imagination may not lead to non-novel ideas, whereas too much imagination may lead to unrealistic ideas due to daydreaming or wild fantasies (Roos and Victor, 1999). Therefore, we need to better understand these factors that foster the effective use of imagination.

In this chapter we conceptualize imagination and we argue how entrepreneurs can use their imagination more effectively. We do this in two steps. First, we explore what imagination is, we argue, by bringing together cognitive and social psychology literature, that imagination consists of three imagination processes, and we explore the boundary conditions of imagination by discussing how imagination differs from related concepts such as creativity. Second, we introduce factors that influence the effective use of imagination in entrepreneurship settings. Additionally, we formulate propositions on the relations between these factors and the effective use of imagination in entrepreneurship. 


\subsection{What is Imagination?}

The verb "to imagine", and the interchangeably used nouns "imagination" and "mental simulation" have no commonly accepted definition. Table 2.1 provides an overview of definitions of imagination.

In Table 2.1 it is shown that scholars define imagination as a faculty, an outcome, or a process. A first group of scholars, including Aristotle (1907) and Kant (2010), have defined imagination as a faculty of the brain. Phrenology could not prove the existence of a faculty of imagination, nor the existence of any faculty at all (Knight, 2007). Neuroscience, however, has found that imagination takes place in multiple parts of the brain, depending on what exactly is being imagined (Hassabis et al., 2007; Mullally and Maguire, 2014; Schlegel et al., 2013; Wheeler et al., 1997). In this chapter we will not further discuss the biological foundations of imagination.

A second group of scholars defines imagination not as a faculty, but as the outcomes of imagination processes: "a cluster of images" (p. 11 Gordon, 1985). These clusters of images can be classified using image theory (Beach and Mitchell, 1987). Image theory distinguishes between four different images that can be imag-

ined: (1) the self image, with which principles are imagined; (2) the trajectory image, with which goals are imagined; (3) the action image, with which action and behavior is imagined; and (4) the projected image, with which the anticipated future is imagined (Beach and Mitchell, 1987).

A third group of scholars defines imagination neither as a faculty, nor as an outcome, but as processes instead. Imagination processes are studied in a wide range of fields, like biology, neurology, and different streams within psychology, 


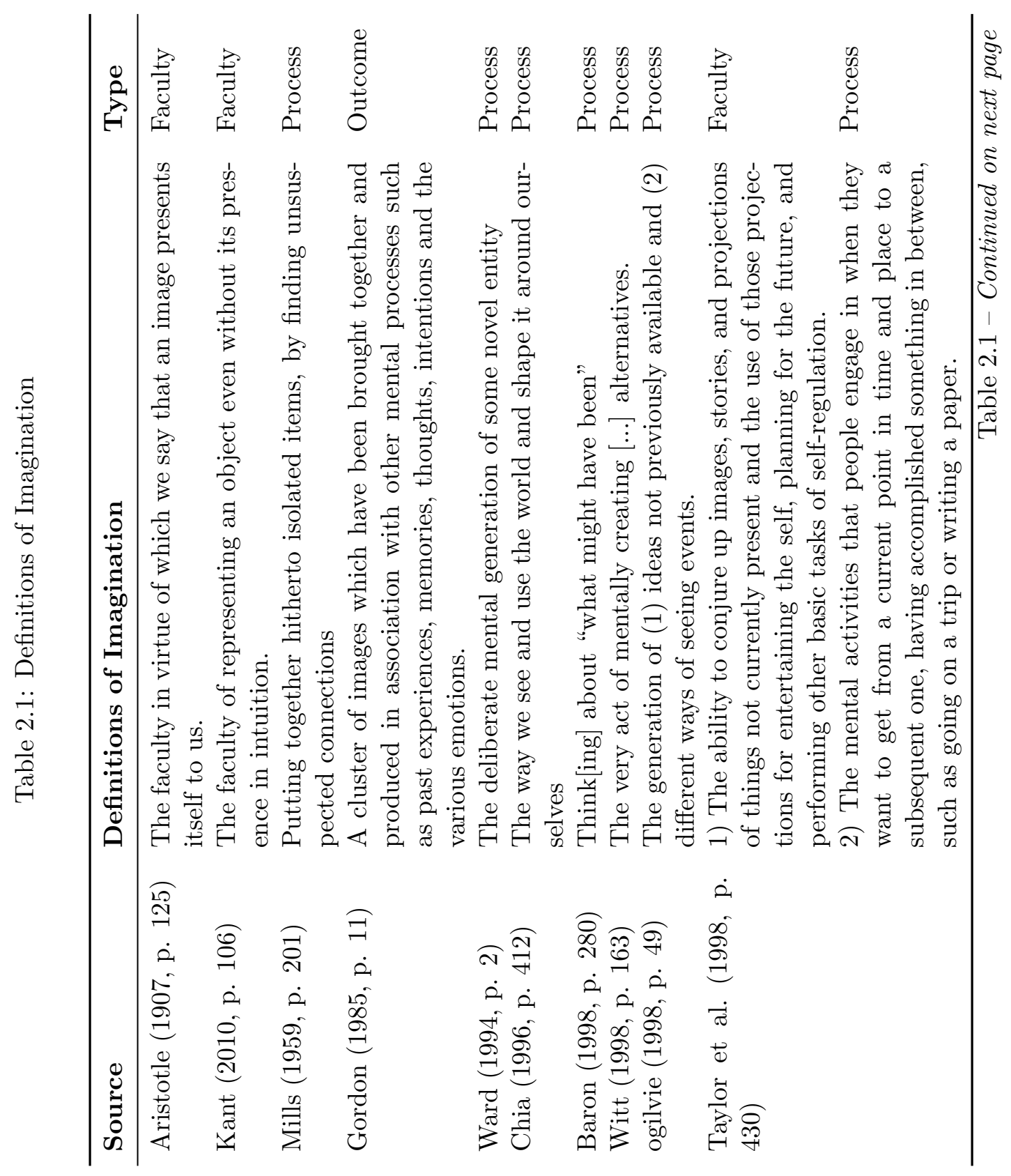




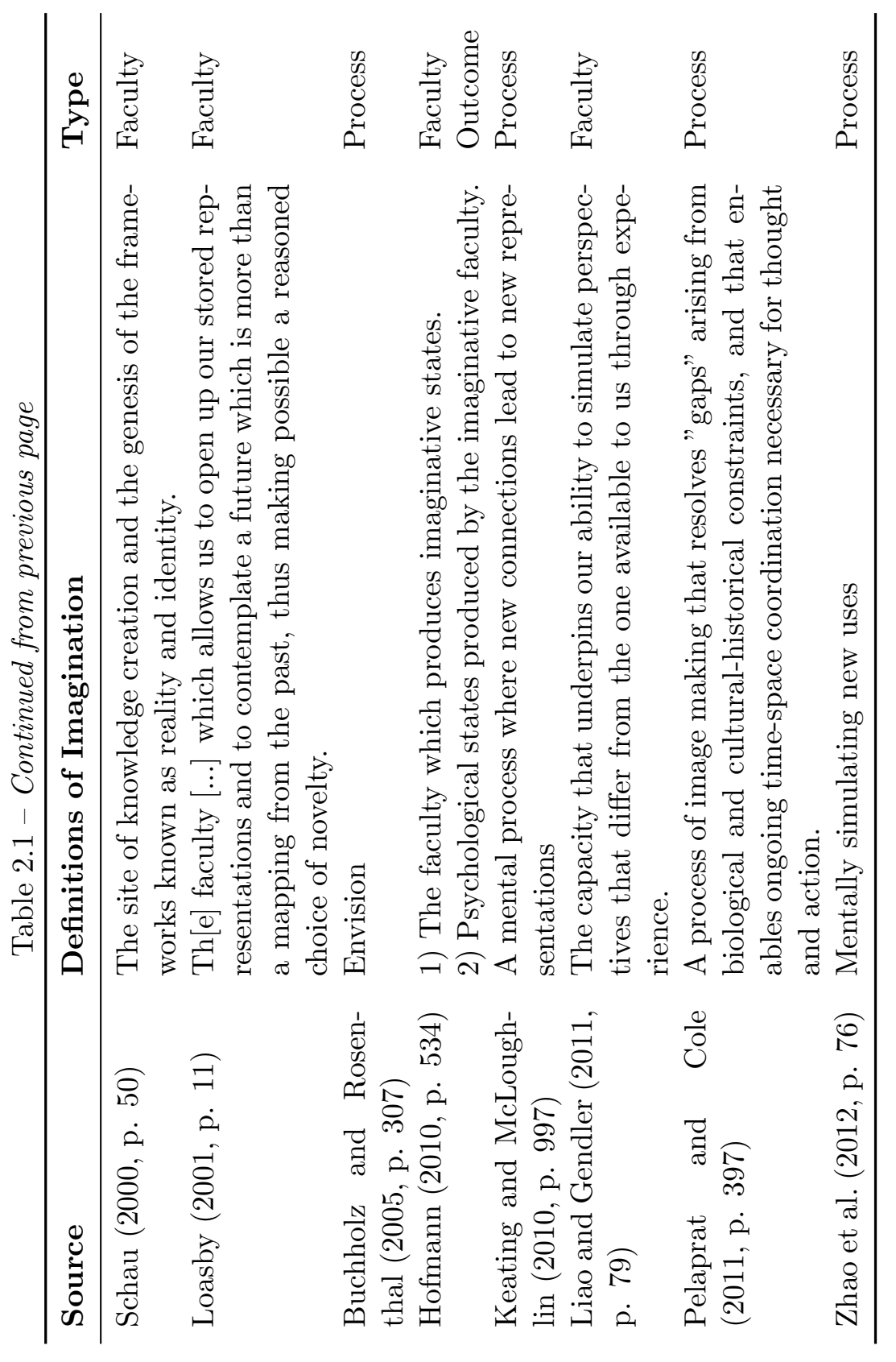


like developmental psychology, cognitive psychology, social psychology, and clinical psychology (Markman et al., 2009). Imagination research in biology and neurology have made important contributions to understanding how the various imagination processes physically work in the brain, yet these are not the focus of our study and more of a general interest. To fulfill the first goal of this chapter - providing conceptual clarity of what imagination is - we describe imagination more extensively based on its processes, because only a process approach gives the most complete insight into how entrepreneurs can use their imagination more effectively. We describe imagination as consisting of various mental processes. Mental processes can be trained (Baron, 2006) and therefore entrepreneurs can be trained to use imagination in the most effective ways. In this chapter we will draw on cognitive and social psychological streams of research, since these are most relevant to the effective use of entrepreneurial imagination specifically. We will discuss the different imagination processes in the following section.

\subsubsection{Processes}

Most scholars define imagination as a process. Mills (1959), for example, defines imagination as "putting together hitherto isolated items, by finding unsuspected connections" (Mills, 1959, p. 201), where these unsuspected connections bear a resemblance to Schumpeter's "new combinations" (Schumpeter, 1934). Imagination generates a simulation of a series of actions and events in concrete and specific form (Taylor et al., 1998). These events seem real due to the fact that imagination tends to be bounded by what is plausible (Kahneman and Miller, 1986; Taylor et al., 1998). Therefore, the outcomes of imagination can function as a plan and are 
plausible and relevant to real-world problem solving activities (Taylor et al., 1998). Previous research has shown that imagination processes only start to develop in human beings from the age of three or four years old on (Atance and O'Neill, 2005), are based on memory (Schacter et al., 2007), and are performed when the mind is not perceiving the present (i.e. the stimulus is not present) (Buckner and Carroll, 2007; Chiu, 1989). Imagination is used to construct and reconstruct the past and the future in the present (Johnson and Sherman, 1990). Construction refers to "creating a past and future in the present" and reconstruction refers to "altering (distorting) our memory for or anticipation of what has been created" (Johnson and Sherman, 1990, p. 483).

We build on work from cognitive psychology and social psychology by distinguishing between three different imagination processes. From cognitive psychology we look into prospective thinking (Gilbert and Wilson, 2007), and counterfactual thinking (Byrne, 2005). From social psychology we look into perspective taking (Batson et al., 2003; Batson, 2009). Based on the temporal distinction of past and future and the before mentioned distinction between construction and reconstruction (Johnson and Sherman, 1990), we distinguish between these imagination processes as follows: (1) prospective thinking, directed towards constructing future action and events; (2) counterfactual thinking, directed towards reconstructing future and past action and events; and (3) perspective taking, directed towards constructing future and past human behavior and thinking, see also Figure 2.1. Although these three imagination processes are distinctive on a conceptual level, they are used intertwined while one imagines. Constructing past action and events is remembering. Remembering is not necessarily imagination, but remembering and imagination are related concepts. In the sections below we will elaborate on 
each of these three distinctive processes and the link with remembering.

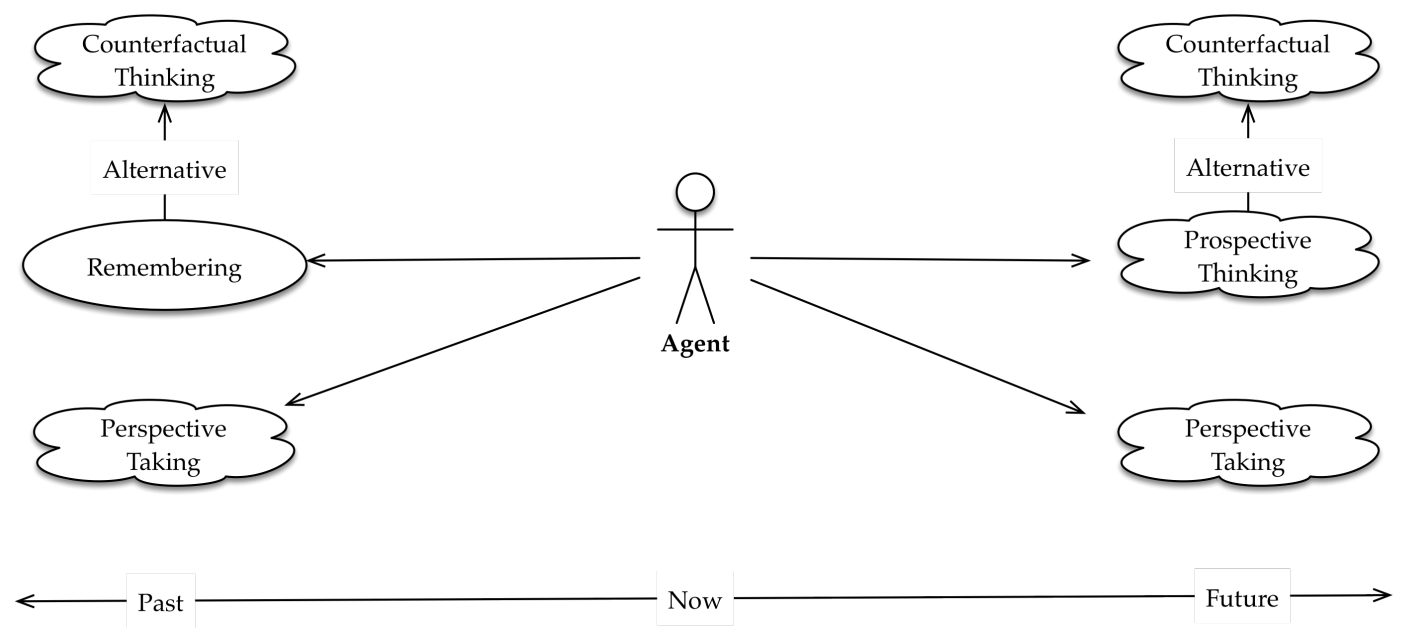

Figure 2.1: Different Imagination Processes

\subsubsection{Prospective Thinking}

The first type of imagination is prospective thinking. Other terms are prefactual thinking (Sanna, 1996; Sanna and Turley-Ames, 2000), forethought (Bandura, 2001), or future thinking (Chiu, 2012). Prospective thinking is the "ability to "preexperience' the future by simulating it in our minds" (Gilbert and Wilson, 2007, p. 1352).

Kahneman and Tversky (1982) distinguish three categories of prospective thinking. First, prospective thinking can be used to predict situation or events. Prediction starts from the current, specified state and generates the most likely future state. For instance, one can imagine how two people that you know well, but have never met before - for instance, your business partner and a potential customer - might get along. How can you 'know' whether these people will or will not like each other (Kahneman and Tversky, 1973, 1982)? 
Second, prospective thinking is used to assess the probability of a specified event. Assessing the probability of a specified event differs from prediction because in this case a future state is specified. For example, how do entrepreneurs assess the likelihood of having sold their products a certain number of times within the coming three years? One needs to obtain a measure of the ease with which this future state can be reached, within the constraints of a realistic model of the economic situation and market conditions. When imagining a specific situation is easy, the perceived likelihood of that situation to become true increases (Carroll, 1978; Tversky and Kahneman, 1973).

Third, prospective thinking is used to assess conditioned probabilities. Assessing conditioned probabilities differs from the previous two categories because in this category of prospective thinking, the mental simulation starts from a specified, initial state, which needs to be reached before the simulation can be run. For example, entrepreneurs may ask themselves: "If the economy goes into a doubledip, what are the likely consequences for my company?" An interesting ambiguity exists for this category of prospective thinking: how should the current state be changed before that simulation can be run? If only a few, easy changes are needed, the probability that the simulation comes true increases (Kahneman and Tversky, 1982).

Two types of prospective thoughts can be distinguished. On the one hand there are upward prospective thoughts, which are an improvement of the current situation (Sanna, 1996). On the other hand, there are downward prospective thoughts, which are a deterioration of the current situation (Sanna, 1996).

Prospective thinking affects future outcomes via positive changes in attitudes, self-efficacy, intentions, and actual behavior (Ajzen, 1991; Anderson, 1983; Ban- 
dura, 1982; Carroll, 1978; Gregory et al., 1982) when one repeatedly imagines one's future behavior. "Future events cannot, of course, be causes of current motivation and action, because they have no actual existence. However, by represented cognitively in the present, foreseeable future events are converted into current motivators and regulators of behaviour" (Bandura, 2001, p. 7).

\subsubsection{Counterfactual Thinking}

The second imagination process, counterfactual thinking, is: "think[ing] about what might have been" (Byrne, 2005, p. 1) by comparing actual events to "alternatives that are constructed ad hoc rather than retrieved from past experience" (Kahneman and Miller, 1986, p. 136). Norm theory (Kahneman and Miller, 1986) "proposes that events evoke their own norms and that counterfactual alternatives to surprising occurrences are automatically available" (Kahneman, 2003, p. 702). Recent, misfortunate events (Baron, 1998; Byrne, 2005; Gilovich and Medvec, 1994) often cause counterfactual thoughts via the negative affect that surrounds such events (Roese, 1997). Counterfactual thinking often raises regret (Beike et al., 2008; Gilovich and Medvec, 1994) by targeting the causes of misfortunate events (Roese, 1997), and by comparing such events to what "normally" should have happened (Kahneman and Tversky, 1982).

Kahneman and Tversky (1982) distinguish two categories of counterfactual thinking to reconstruct the past or future. In the first category, counterfactual assessments, alternative past or possible future events are mentally modified to simulate both what would have happened and how that modified past event might have affected the present (Byrne, 2005; Roese, 1997). For example, what would have happened if we had not bought our competitor three years ago? 
Second, to assess whether event $A$ caused event $B$, we undo event $A$ in our mind and observe whether event $B$ still occurs in the simulation. Where counterfactual assessment focuses on how an unknown event $B$ might look like after event $A$ was changed, the assessment of causality focuses on whether a pre-specified event $B$ would still be possible even after event $A$ was changed (Kahneman and Tversky, 1982).

Just like prospective thoughts (Sanna, 1996), also counterfactual thoughts can be split in upward counterfactuals, which are alternatives that improve reality, and downward counterfactuals, which are alternatives that worsen reality (Markman et al., 1993). Upward and downward counterfactuals are generated to gain control over a situation (Nasco and Marsh, 1999). Upward counterfactuals result in improved subsequent performance (Baumeister et al., 2011; Markman et al., 1993; Roese, 1994). Using downward counterfactuals results in feeling better with a current situation (Roese, 1994).

\subsubsection{Perspective Taking}

The third imagination process, perspective taking, is defined as "the cognitive capacity to consider the world from another individual's viewpoint" (Galinsky et al., 2008, p. 378). Perspective taking is an imagination process, because one imagines how things look from the view point of another person, but does not literally look through another person's eyes or take another person's place (Batson, 2009). Perspective taking is related to - but distinct from - empathy: empathy is on a emotional level, whereas perspective taking is on a cognitive level (Galinsky et al., 2008). 
Batson (2009) distinguishes three categories of perspective taking. First, the "to see oneself through the other's eyes" perspective implies that one imaginatively sees oneself through the eyes and set of values of the other; i.e., you imagine how someone else thinks about you and what you have done. Second, the imagine-other perspective: "Imagine how another person sees his or her situation and feels as a result" (Batson, 2009, p. 267). Last, the imagine-self perspective in which you "imagine how you would see the situation were you in the other person's position and how you would feel as a result" (Batson, 2009, p. 267). Examples of the use of perspective taking in entrepreneurial settings are negotiating, where one needs to balance between self-interests and other-interests, and new product design, where one needs to define target markets and to identify stakeholders (McMullen, 2010). Also in the marketing literature, perspective taking is an important concept. For example, McBane (1995) found perspective taking to be important for salespersons.

\subsubsection{Remembering}

A memory is a mental representation of a past event. A memory can be distinguished from the mental representation of a present event, which is a perception, and the mental representation of a possible future event, which is prospection (Gilbert and Wilson, 2007). Imagining the future and alternatives situations is often based on the memories. For instance, amnesia patients cannot imagine how next year's Christmas party will be, because they cannot remember Christmas parties at all. However, the imagination can also influence memory. By misattributing simulations, some simulations are remembered as "memories" of the past, whereas the simulated events did not really occur (Lakshmanan and 
Krishnan, 2009). These misattributed simulations are called false memories. Especially in the field of advertising, there has been considerable research on false memory (e.g., Braun et al., 2002).

\subsubsection{Challenges in Understanding Imagination}

In the previous sections, we have described the three imagination processes. However, scholars disagree whether these imagination processes are rational or nonrational, and bounded or unbounded. In this section we argue that imagination can be rational and that imagination is bounded.

First, when talking about whether the imagination is 'rational', we mean that the line of reasoning used when one is imagining, is logically consistent. Some scholars argue that imagination is non-rational (e.g., Chia, 1996; Szulanski and Amin, 2001), whereas other scholars argue that imagination is rational (e.g., Byrne, 2005). (Szulanski and Amin, 2001) argue that imagination is unconscious and based on pure creative human spontaneity. Therefore imagination cannot be based on reasoning, they argue. Chia (1996) argues that imaginative thoughts are free thoughts, achieved in free minds. This does not mean, he argues, that the imagination is completely detached from facts. The imagination fills facts with meaning and possibilities. We, on the other hand, follow the three steps argument by Byrne (2005) to argue that imagination can be rational. First, "humans are capable of rational thought" (Byrne, 2005, p. 208), second, "the principles that underlie rational thought guide the sorts of possibilities that people think about" (Byrne, 2005, p. 208), and third "these principles underlie the [...] imagination" (Byrne, 2005, p. 208). This does not mean that the imagination only produces rational 
thoughts, as there are many examples of non-rational thoughts (Granovetter, 1985; Simon, 1956; Tversky and Kahneman, 1986), but it does show that the imagination can be rational. Additionally, we emphasize that, although there may be evidence that imaginative thoughts are free thoughts that happen in an unconscious state like Szulanski and Amin (2001) argue, our understanding of the imagination is that imagination is a conscious process, as people are aware of the simulations they create.

A second aspect of disagreement among scholars is whether everything can be imagined. Some scholars accept the idea that imagination is unbounded and that, therefore, everything can imagined (e.g., Hamel, 1999; Witt, 1998). They argue that new thoughts cannot be created due to our limited capacity for creating alternatives, due to our limited capacity for information processing and memorizing. Therefore, imagination must be unbounded to provide new alternatives that have not been thought of before. We, on the other hand, argue together with other scholars (e.g., Chiles et al., 2010) that imagination must be bounded. Imagination creates - until then unknown - resource combinations (Chiles et al., 2010) and imaginative thoughts and outcomes are constrained by what is plausible (Kahneman and Miller, 1986; Taylor et al., 1998). This boundedness to what is plausible makes imagination useful for preparing for the future (Taylor et al., 1998).

\subsubsection{Positioning Imagination}

Imagination is often considered to be an important part of creativity (Zhou, 2008; Hennessey and Amabile, 2010) and ideation (Graham and Bachman, 2004). Creativity "involves the production of novel, useful products" (Mumford, 2003, p. 
110). Creativity, which requires some kind of action, differs from imagination, which does not require action and is limited to thinking processes. Ideation is "generating, developing and communicating ideas, where 'idea' is understood as a basic element of thought that can be either visual, concrete, or abstract" (Jonson, 2005, p. 613). Ideation comprises all aspects of a thought cycle: from the idea, to development, to actualization (Graham and Bachman, 2004). The process of ideation is broader and more generic than the imagination process: generating and developing ideas can be done in more ways than via imagination only, and imagination does not involve the communication of ideas.

Dane (2011) refers to imagination as a state of attention with a relatively narrow attentional breadth and a low present moment orientation. He distinguishes imagination from mind wandering, which also has a low present moment orientation but has a relatively wide attentional breadth; absorption or flow, which also have a relative narrow attentional breadth, but have a high present moment orientation; and mindfulness, which is the opposite of imagination, due to its relatively wide attentional breadth and high present moment orientation (Dane, 2011).

However, imagination is not the only state of attention with a relatively narrow attentional breadth and a low present moment orientation. Fantasizing, for example, also has a relative narrow attentional breadth and a low present moment orientation (Dane, 2011; Oettingen et al., 2001; Oettingen and Mayer, 2002). Fantasies are "thoughts and images of future events or behaviors that appear in the mind (Klinger, 1990; Singer, 1966) independent of the likelihoods that these events or behaviors will actually occur" (Oettingen et al., 2001, p. 737). This differs from imagination, because imagination is typically bound to what is plausible (Kahneman and Miller, 1986; Taylor et al., 1998). To summarize, we define imagination 
as follows:

Imagination is a combination of three mental simulation processes - prospective thinking, counterfactual thinking, and perspective taking - that (1) require a narrow attentional breadth and a low present moment orientation; and that (2) create mental images - of principles, goals, action and behavior, and anticipated events and states - that are not currently present to the senses, and that are bounded by an individual's prior knowledge and experience, and by what is plausible.

In this section we have reviewed the concept of imagination. We have conceptualized imagination based on three processes, positioned it in relation to closely related concepts, and in the end defined the concept.

\subsection{Conditions Influencing the Effectiveness of Imagination}

In this section we discuss the factors that influence whether entrepreneurs use imagination most effectively. First, however, we need to state that scholars disagree whether the use of imagination is beneficial. Some scholars argue that the use of imagination leads to negative affect and demotivation (e.g., Byrne, 2005; Roese, 1997) and hence improved performance. Other scholars argue that imagination can lead to positive affect and hence improved performance (e.g., Markman et al., 1993; Roese, 1994), and that, for certain conditions, imagination may be as good as, or even superior to, more systematic approaches (Gaglio, 2004; ogilvie, 1998; Sarasvathy, 2001, 2008). 


\subsection{CONDITIONS INFLUENCING THE EFFECTIVENESS OF}

Based on our review, which focused on cognitive and social psychology literature, we argue that several factors determine when imagination is useful. Following Zhou (2008) who argue that both personal and contextual factors influence creative processes, we grouped these factors in two broad sets: (1) situational factors and (2) individual factors. These two sets and the factors are shown in Figure 2.2.

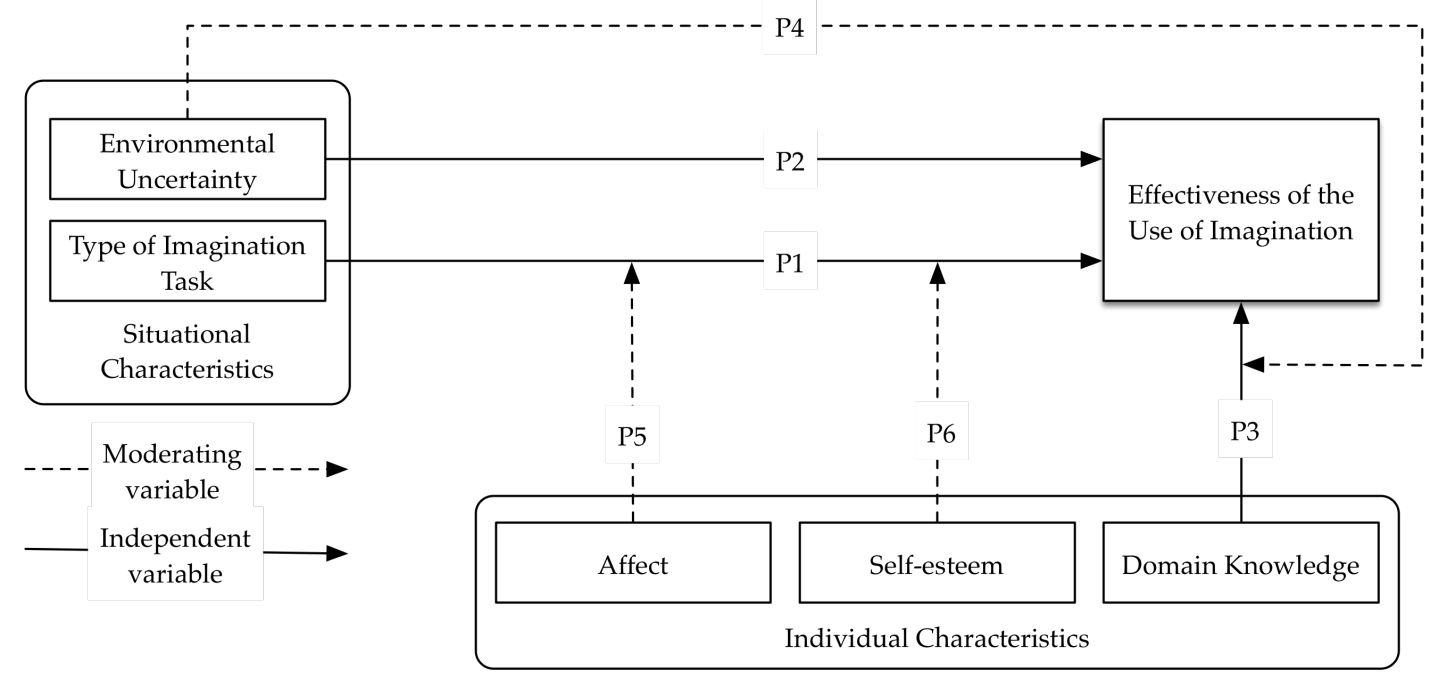

Figure 2.2: Conceptual Model

\subsubsection{Situational Factors}

Whether a task benefits from an imaginative approach depends on the structuredness of the problem that the task needs to solve. Problems can be placed on a continuum of structuredness (Dane and Pratt, 2007; Shapiro and Spence, 1997). For well-structured problems, for example dealing with accounts receivable, a task is readily available to be applied (Shapiro and Spence, 1997). For ill-structured problems no standard task is available. Therefore, imagination can be used more effectively to think of tasks to solve ill-structured problems than to think of tasks 
to solve well-structured problems (Chiles et al., 2007; Loasby, 2001; Sarasvathy, 2001, 2008). First, we discuss the influence of the characteristics of the imagination task itself. Second, based on literature from cognitive psychology, we discuss the influence of environmental dynamism on the effectiveness of imagination.

\subsubsection{Imagination Task}

According to our literature review entrepreneurs use their imagination for seven different tasks. First, entrepreneurs imagine business ideas and opportunities (e.g., Chiles et al., 2007; Felin and Zenger, 2009); second, they imagine the (inter)action of stakeholders (e.g., Hart and Sharma, 2004; Galinsky et al., 2008); third, they imagine the likelihood of success of the company and/or its products (e.g., Zhao et al., 2011, 2012); fourth, scenarios and strategies are imagined (e.g., Felin and Zenger, 2009; Szulanski and Amin, 2001); fifth, they imagine the future state of the company and/or its products (e.g., Chiles et al., 2007; ogilvie, 1998); sixth, they imagine the social impact of the company and/or its products (e.g., Buchholz and Rosenthal, 2005; McVea, 2009); and seventh and last, entrepreneurs imagine their personal development (e.g., Byrne, 2005). Yet which imagination process leads to which imagination outcome remains unknown, because scholars do not distinguish between the three processes of imagination. Although imaginative thoughts often are a combination of the three imagination processes, one can differentiate between the likelihood that an imagination process contributes to a specific task.

Many scholars who discuss the use of imagination by entrepreneurs focus on the recognition, discovery, identification or creation of opportunities and business ideas (e.g., Chiles et al., 2007; Cornelissen and Clarke, 2010; Felin and Zenger, 2009; Gaglio, 2004; Gartner, 2007; Sarasvathy, 2001; Witt, 2007). Most of these 


\subsection{CONDITIONS INFLUENCING THE EFFECTIVENESS OF}

IMAGINATION

scholars treat imagination as equal to prospective thinking. For example, Chiles et al. (2007) discuss how entrepreneurs create opportunities through expectations of an imagined future. Furthermore, Witt (2007) describes how imagined business opportunities are an important input for the realization of the venture. Alternatively, Gaglio (2004) states that counterfactual thinking is important for the identification of business opportunities. Grant and Berry (2011) found that perspective taking strengthens the association between intrinsic motivation and creativity. Perspective taking turns a person's intrinsic motivation towards not only novel, but also useful ideas (Grant and Berry, 2011). From this we conclude that prospective thinking, counterfactual thinking, and perspective taking are all three beneficial to imagining business opportunities.

To imagine business opportunities, we argue, one is mainly focusing on the future, because a new business opportunity is not being remembered (past) nor perceived (present), but simulated (future). Imagining opportunities may follow a pattern recognition process (Baron, 2006; Baron and Ensley, 2006) using the three categories of prospective thinking: First, future changes in the external world are predicted. A business idea is recognized while connecting the dots of the future changes. Second, the probability of such a specified business idea is mentally assessed. Third, if the probability seems high, the consequences (profit, employees, customers) are assessed via 'assessing conditioned probabilities'. Based on this line of argument, we conclude that mainly prospective thinking is an effective imagination process for imagining business opportunities.

Proposition 1a. For imagining business opportunities prospective thinking is more effective than counterfactual thinking and perspective taking. 
A second group of scholars discusses the use of imagination for creating strategies (e.g., Giraudeau, 2008; Szulanski and Amin, 2001). In rapidly changing environments, with little information, predicting the future is difficult and thus it is difficult to create strategies that successfully guide the venture into that future. Giraudeau (2008) argues that strategic plans are not static and inflexible, and do not give long-term stability to a company. Instead, strategic plans are flexible tools that can be changed easily. Strategic plans are like drafts of strategy. They provide food for thought to the imagination. Using their imagination, entrepreneurs improve these plans and develop innovative strategies. Szulanski and Amin (2001) argue that strategic plans are developed by combining imagination, to come up with several alternative plans, with discipline, to carefully select the useful plans. For strategy making the emphasis would be on projective thinking, as strategy makers need to imagine the future, on counterfactual thinking to be able to create and select from several possible alternative strategies, and on perspective taking to be able to "examin[e] reality from a variety of perspectives" (Szulanski and Amin, 2001, p. 548).

Szulanski and Amin (2001) argue that entrepreneurs use their imagination to come up with several plans. It can be argued that prospective thinking leads to multi plans by repeatedly predicting the future and assessing the probabilities of possible outcomes. However, we argue that mainly counterfactual thinking leads to multiple plans. After an initial plan is generated via prospective thinking, counterfactual assessment is used to mentally modify a part of that plan and to simulate what the effect of that plan would be. By repeatedly mentally modifying a different small part of the plan, many plans are generated. Additionally, via assessment of causality, one can mentally test the results of the plans to test whether final 


\subsection{CONDITIONS INFLUENCING THE EFFECTIVENESS OF}

IMAGINATION

success is still plausible when a plan is undone in one's mind. Therefore, we argue that counterfactual thinking is the most effective imagination process to create strategies.

Proposition 1b. For creating business strategies counterfactual thinking is more effective than prospective thinking and perspective taking.

\subsubsection{Environmental Dynamism}

Aside from the characteristics of the task, also environmental dynamism influences the effectiveness of the use of imagination. ogilvie (1998) found that the use of imagination for decision-making is more effective in a dynamic environment than in a stable environment. Besides decision making, we argue that imagination is effective in generating ideas in dynamic environments. Gaglio (2004) gives a good example of this, when she argues that opportunity finders will sooner engage in counterfactual thinking than non-finders, when they are confronted with the unexpected. The lack of, and the rapid change of, information in the dynamic environment causes people to think outside of the boarders which are shaped by that information, which results into new ideas. We, therefore, argue that the use of imagination is more effective in a dynamic environment and thus we propose that:

Proposition 2. The use of imagination is more effective in a dynamic environment than in a stable environment. 


\subsubsection{Individual Factors}

Besides aforementioned situational factors, also individual factors influence the effective use of imagination. In our review we found three individual factors influence the effectiveness of the use of imagination. First, based on literature from cognitive psychology, we discuss the influence of domain-relevant knowledge of individuals on the effective use of imagination. Second, based on literature from social psychology, we discuss the influence of affect and self-esteem.

\subsubsection{Domain-relevant Knowledge}

Experts differ from novices because experts have more domain-relevant knowledge (Wiley, 1998). This domain-relevant knowledge is an important precursor to the effective use of imagination (Ward, 2008). Individuals with domain-relevant knowledge generate more practical ideas than individuals that lack domain-relevant knowledge (Ward, 2008). Domain-relevant knowledge enables experts to make more reliable judgments about what is metaphysically possible or not (Hofmann, 2010). This suggests that when experts use their imagination, they generate more realistic ideas than novices.

Due to cognitive entrenchment (Dane, 2010), experts are more likely to stay with what they know and, therefore, do not come up with more original ideas (Ward, 2008). Their knowledge limits them to an area of the search space in which the solution is not available (Wiley, 1998). This suggests that novices tend to use more often their imagination than experts.

When generating ideas, the use of imagination is only effective when it results in ideas that are both novel and realistic. For non-novel ideas one does not need 


\subsection{CONDITIONS INFLUENCING THE EFFECTIVENESS OF}

IMAGINATION

to rely on one's imagination. Memory and analytical skills are superior tools for this. On the other hand, very novel but non-realistic ideas are not effective either. Experts are more likely to use their imagination to create non-novel but realistic ideas and novices are more likely to use their imagination to create novel but non-realistic ideas. Therefore, we argue that an optimum exists in the effective use of imagination when ideas are generated that are both quite novel and quite realistic. This implies that the use of imagination is most effect when an individual has moderate domain-relevant knowledge.

Proposition 3. The relation between domain-relevant knowledge and effective use of imagination has a inverted U-shape.

Due to the unpredictability of dynamic environments, experts who work in dynamic environments start doubting the cause-and-effect relationships within the knowledge they have (Locke et al., 2008). This doubt reduces behavioral habits, fosters creativity, and motivates the search for discovery (Dane, 2010; Locke et al., 2008). Experts in dynamic environments who are confronted with these doubts cannot stick to what they know and these doubts lower their cognitive entrenchment (Dane, 2010). Therefore, these experts need to imagine what they will do (Wiltbank et al., 2009). Their use of imagination leads to more alternatives, and fast decisions in dynamic environments based on more alternatives lead to superior performance (Eisenhardt, 1989). This suggests that the use of imagination by experts is more effectively in dynamic environments.

Proposition 4. The inverted U-shape relationship between domain-relevant knowledge and effective use of imagination will be moderated by environmental dynamism. 
More specifically:

Proposition 4a. The relation between domain-relevant knowledge and effective use of imagination should be initially lower in a dynamic environment than in a stable environment.

Proposition 4b. The curvilinearity of the relation between domain-relevant knowledge and effective use of imagination will be lower in a dynamic environment than in a stable environment.

\subsubsection{Affect}

Affect influences the effective use of imagination. Positive affect is likely to result in downward counterfactuals (Sanna, 1999), which leads to improved selfefficacy (Arora et al., 2013), which leads to improved performance (Ajzen, 1991; Bandura, 1977). Negative affect, however, does not result in upward counterfactuals (Sanna et al., 1999). Affect also has an effect on prospective thinking (Sanna, 1998). Positive affect is likely to result in downward prospective thoughts, whereas negative affect is likely to result in upward prospective thoughts (Sanna, 2000). Regarding perspective taking, individuals with a positive affect are less likely to use of perspective taking, whereas individuals with a negative affect are more likely to use of perspective taking (Converse et al., 2008). Therefore, the relations between affect and the effective use of imagination are mixed.

We argue that affect has a mediating effect on the relation between the imagination task and the effective use of imagination. If a suitable imagination process is used for the imagination task, but one is in the less advantageous mood, the use of imagination is not as effective as it could have been. Following Proposition 


\subsection{CONDITIONS INFLUENCING THE EFFECTIVENESS OF}

IMAGINATION

1a, if the use of prospective thinking is effective for coming with business ideas, a positive affect strengthens that effect, whereas a negative affect weakens that effect.

Proposition 5a. An individual's positive (negative) affect strengthens (weakens) the relation between imagination task and the effective use of prospective thinking.

Proposition 5b. An individual's positive (negative) affect strengthens (weakens) the relation between the imagination task and the effective use of counterfactual thinking.

Proposition 5c. An individual's positive (negative) affect weakens (strengthens) the relation between the imagination task and the effective use of perspective taking.

Affect does not only influence the effective use of imagination, the use of imagination also influences affect. For example, considering several outcomes may induce fear of what might come (Roese, 1997). Although we recognize that the use of imagination influences affect, in this section we limit our discussion to the factors that influence the effective use of imagination.

\subsubsection{Self-esteem}

Also self-esteem influences the effective use of imagination. High self-esteem people generate more downward counterfactuals, whereas low self-esteem people generate more upward counterfactuals (Sanna et al., 1999). Arora et al. (2013) have found that high levels of counterfactual thinking are beneficial to those with high selfesteem, high positive affect, and low negative affect, as it increases self-efficacy. This suggests that high self-esteem people use counterfactual thinking more effectively than low self-esteem people. For prospective thinking a similar effect 
is visible. Low self-esteem people generate downward prospective thoughts to cope with failure, whereas individuals with a high self-esteem generate upward prospective thoughts to keep positive affect high (Sanna, 2000). For perspective taking (Davis, 1983) found that individuals with a higher self-esteem also score higher on perspective taking. Therefore, the use of perspective taking is more beneficial for individuals with a high self-esteem than for individuals with a low self-esteem.

We argue that self-esteem has a mediating effect on the relation between the imagination task and the effective use of imagination. If a suitable imagination process is used for the imagination task, but and one has a high self-esteem, the use of imagination is more effective than when one has a low self-esteem. Therefore, we propose:

Proposition 6. An individual's high (low) self-esteem strengthens (weakens) the relation between the imagination task and the effective use of imagination.

\subsection{Discussion and Implications}

In the previous sections we have conceptualized imagination is and described which factors contribute to the effective use of imagination. In this section we discuss other issues concerning the use of imagination. Additionally, we present directions for further research on this topic and present practical implications concerning the use of imagination. We conclude this chapter by presenting our conclusions. 


\subsubsection{Beyond Entrepreneurship}

Up to now, we have mainly focused on the use of imagination by entrepreneurs. However, not only entrepreneurs use their imagination, customers do so as well. Customers imagine themselves using the product; they 'taste' and 'feel' the product. By imagining the use of the product, the product becomes more 'tangible' to customers. This enables them to make better decisions on whether or not to buy the product (Phillips, 1996). Imagining favorable consequences of the use of the product, accounts for more positive emotions, which results in a better liking of the product than when analytical tools were used (Escalas, 2004). Especially when thinking about buying a 'Really New Product', imagining the use of such a product takes away the uncertainty of a buyer (Hoeffler, 2003). This implies that when marketing 'Really New Products', the focus should be on uses customers have never experienced before. Making customers imagine usages they have not experienced, helps them to realize the value of the usage, which leads to a higher evaluation of the 'Really New Products' (Zhao et al., 2009).

Also in education imagination plays an important role (Chia, 1996; Hjorth, 2011; Mustar, 2009). According to Chia (1996, p. 409) "cultivation of the "entrepreneurial imagination' is the singular most important contribution university business schools can make to the business community." Business school professors should teach their students both analytical skills and how to use their imagination. This enables future managers and entrepreneurs to better cope with quick changing markets, little availability of information, and high uncertainty. 


\subsubsection{Further Research}

In this section we provide six directions for further research. First, we think a better understanding of the link between imagination and mindfulness is needed. So far we have presented the beneficial side of the use of imagination. However, the use of imagination also has disadvantages. With a low present moment orientation one keeps thinking and doubting about the future and the past. Therefore, with too much imagination one gets stuck in thinking about the future and the past and one does not turn ideas and strategies into action. Mindfulness, with its high present moment orientation, has a positive influence on task performance. Whereas Dane (2011) argues that experts in dynamic environments benefit from the use of mindfulness, we argue that experts in dynamic environments benefit from imagination. Research that empirically tests in which situations mindfulness, imagination, or their combination is more useful would bring this field a step forward.

Second, this chapter opened up the possibility for research into the link between imagination and effectuation versus causation (Sarasvathy, 2001, 2008). On the one hand, one can argue that imagination contributes to a more effectuation approach. By starting with the means (who am I, what I know and whom I know), an entrepreneur can imagine all kinds of possible future directions. On the other hand, one can argue that imagination contributes to a more causation approach. By imagining the ends, the image of the ideal company, one can see how such an image can be reached. Following these lines of arguments, imagination can be beneficial to both effectuation and causation. Further research that investigates the relation between imagination and effectuation/causation could help us to better 
understand how (expert) entrepreneurs work and think.

Third, we need to understand the precise relation between expertise and the effective use of imagination. We argue that there must be an optimum between on the one hand the use of imagination when having little expertise, which is likely to result in novel but often less realistic ideas, and on the other hand the use of imagination when having more expertise, which is likely to result in realistic, but often less novel ideas. A better understanding of the use of imagination in regard to this optimum would provide an interesting new perspective to the idea generation literature.

Fourth, the concept of imagination can play an important role in the opportunity recognition (e.g., Baron and Ensley, 2006; Grégoire et al., 2010) versus opportunity discovery (e.g., Hsieh et al., 2007; Klein, 2008; Shane, 2000) versus opportunity creation (e.g., Alvarez and Barney, 2007) debate. Imagination may play a role in recognizing the prototypes of opportunities (Baron and Ensley, 2006; Costa et al., 2013), in discovering potential customers for products or potential solutions for existing problems (Sarasvathy et al., 2003) or in creating opportunities through the (inter)actions of the entrepreneurs and their perceptions (Alvarez and Barney, 2007; Chiles et al., 2007).

Fifth, in this chapter we have not defined effectiveness for each of the seven imagination tasks, because the definition of effectiveness depends on the type of imagination task that needs to be performed. For imagining business ideas and opportunities we have defined the use of imagination as effective when the business idea is both novel and realistic. Further research should define the effectiveness of the use of imagination for the other seven business-related imagination tasks.

Sixth, so far we only discussed how an individual imagines. However, many 
companies and projects are lead by teams. Inter-personal dynamics may influence the imagination of individuals. This leads to opportunities for further research. For example, entrepreneurs may be able to build upon a collective imagination (Zhou, 2008). Does this lead to more creative ideas? Another possible opportunity for research on imagination on the team level is that entrepreneurs need to communicate what they imagine to other people (Cornelissen and Clarke, 2010). Cornelissen and Clarke (2010) discuss the use of metaphors, and Gartner (2007) discusses the use of narratives to communicate what has been imagined. The feedback one gets may cause a person to re-imagine and create better images. Empirical research on this topic is needed to better understand the influences of other people on the imagination of an individual. We need to extend our research beyond the single-person bias (Dimov, 2007).

\subsubsection{Practical Implications}

In this section we discuss three practical implications of our work. First, due to the proposed inverted U-shape relationship between domain-relevant knowledge and the effectiveness of imagination, we expect that collaboration between both novice and experts is an good way to use imagination effectively. For example, high-tech entrepreneurs could especially profit from the use of their imagination. Although these entrepreneurs are experts in their technical field, they are often non-experts in doing business. Therefore, we argue, what their imagination may not be realistic. A solution may be for inexperienced entrepreneurs to find experienced entrepreneurs to develop strategies and business ideas together. By talking to these experienced entrepreneurs, the inexperienced entrepreneurs will have to 
reason and justify their image (Cornelissen and Clarke, 2010; Felin and Zenger, 2009) and the input of the experienced entrepreneurs will make these images better fit to what is possible.

Second, in the rapid changing times that we live in, imagination is not only important for high-tech entrepreneurs. Many companies face continuous change in which the knowledge and experience of today are not so useful anymore for the challenges of tomorrow. In these changes experts in the 'previous' field are non-experts in the 'new' field. The importance of imagination therefore does not disappear once one has become an expert.

Third, we have also argued that to perform certain tasks, specific imagination processes are more effective than using others. By becoming more aware of one's thinking patterns, one can steer these patterns and, therefore, get more imaginative ideas, which could be the solution to one's problem.

\subsubsection{Conclusion}

In this chapter, we have discussed the use of imagination. As we mentioned at the beginning of this chapter, many scholars state that entrepreneurs use their imagination, but what imagination is, how it is used, when it is effectively, and its influence on venture success remains unclear from their articles. In this chapter we have (1) conceptualized imagination by discussing several definitions, the different imagination processes, and closely related concepts; and (2) theorized when entrepreneurs use their imagination effectively by exploring several factors of imagination.

Our discussion of the imagination may help to get more attention to the use of 
imagination by entrepreneurs. Our conceptualization gives a starting framework for future research to build upon. Additionally, our work helps entrepreneurship scholars to refer more specifically to the type of imagination when they study the use of imagination in entrepreneurship. The use of imagination is an important but under-researched topic in the field of entrepreneurship, and we hope that our discussion of this concept gives imagination the importance it deserves in the field of entrepreneurship. 


\section{Chapter 3}

\section{Exploring the Use of Imagination}

\section{by Experienced High-tech}

\section{Entrepreneurs}

A previous version of this chapter has been presented at the $34^{\text {th }}$ Babson College Entrepreneurship Research Conference, June 4-7, 2014 in London, Ontario, Canada. 


\subsection{Summary}

Using a grounded theory approach, we study how thirty-one high-technology entrepreneurs use their imagination in opportunity recognition processes and strategic decisions processes. We find that entrepreneurs are aware that they use their imagination, although they call it differently (e.g., creating a vision). They find it an important factor that contributes to their business success. Additionally, we find that the use of imagination is more important in high-uncertainty environments than low-uncertainty environments. Subsequently we find that the use of imagination is more important earlier in the entrepreneurial process, where information is often unknown, than later in the process when more information is gathered. Based on our findings we develop propositions for further research.

\subsection{Introduction}

Technological innovation is an important driver of economic growth (Schumpeter, 1942). To bring these technological innovations to the market, high-technology entrepreneurs need a business opportunity and make successful strategic decisions (Gans and Stern, 2003). Imagination is a necessary process for both recognizing business opportunities and making strategic decisions (e.g., Baron and Ensley, 2006; Cornelissen and Clarke, 2010; Gartner, 2007; Sarasvathy, 2001; Szulanski and Amin, 2001; Witt, 1998, 2007). Additionally, high-tech industries are rapidly changing industries and therefore it is very difficult for entrepreneurs to predict the future. This means that these entrepreneurs may use their imagination to imagine how the future may look like, instead of predicting it. Although the above 
mentioned literature states that imagination is used by high-tech entrepreneurs, it does not state how they use imagination. This led us to the research question: How do experienced high-tech entrepreneurs use their imagination in opportunity identification and strategic decision-making processes?

Having little understanding of the use of imagination by high-technology entrepreneurs has two very important implications for both practice and research. First, a lack of understanding of the use of imagination means that practitioners may not make the most of this inherent human capacity. Second, mentioning imagination, but not diving into the concept, means that researchers explain phenomena with very poor understood concepts. Therefore, the aim of this chapter is twofold. First, it captures the use of imagination of experienced high-tech entrepreneurs for recognizing business opportunities and developing strategies. Second, this chapter contributes to the entrepreneurship literature, specifically to the literature stream on opportunity recognition and strategy development by adding our understanding of the concept of imagination.

In this chapter we take a grounded theory approach, because there is hardly any theory on how entrepreneurs use their imagination. We therefore start with a short overview of the available information in the literature that steered us in our research. Next, we describe the research methods we used. Subsequently we present our findings. In the last sections we discuss our findings and present our conclusions. 


\subsection{Theoretical Background}

\subsubsection{Imagination}

'Imagination' and 'to imagine' are both words that are often used in everyday language and they do not have a common definition. In this chapter, we define imagination as a concept existing of three distinguishable processes (Markman et al., 2009): prospective thinking (Kahneman and Tversky, 1982), counterfactual thinking (Byrne, 2005), and perspective taking (Batson, 2009). Prospective thinking is "the ability to 'pre-experience' the future by simulating it in our minds" (Gilbert and Wilson, 2007, p. 1352). Counterfactual thinking is "thinking about what might have been" (Byrne, 2005, p. 1). Perspective taking is "perceiving the other's situation" (Batson, 2009), or putting yourself in someone else's shoes.

\subsubsection{Recognizing Business Opportunities}

In the entrepreneurship literature, there two distinct views on opportunities. In one view opportunities are objective phenomena that are to be discovered by individuals with the right knowledge and experience (e.g., Shane, 2000). In the other view, opportunities are created by the subjective view and creative actions of these individuals (e.g., Chiles et al., 2007). In this chapter we follow Grégoire et al. (2010), by stating that we do not focus on whether opportunities are objective or subjective phenomena, but that opportunities arise from changes. These changes can, for instance, be in the set of knowledge of individuals, or in the macro-environment. These changes themselves are not opportunities themselves. Opportunities are "courses of action that seek to derive benefits from these changes" (Grégoire et al., 
2010, p. 415). Opportunities for a new technology lie in applying this technology in the market (Grégoire et al., 2010).

How an individual recognizes these opportunities from changes is not clear. Baron (2006), building on mental prototyping, proposes that individuals try to recognize patterns in the changes they experience. By "connecting the dots" (Baron and Ensley, 2006, p. 1341), individuals make sense out of their surrounding changes until it fits their prototype of an opportunity. Grégoire et al. (2010) propose that individuals use structural alignment to recognize opportunities. They argue that people compare the new information with what they already know to see where this information could be useful.

Opportunity recognition exists of two phases (Grégoire et al., 2010; McMullen and Shepherd, 2006). The first phase regards the formation of subjective beliefs that there is an opportunity out there for people with the right skills and recourses to exploit them. The second phase regards whether this opportunity is an opportunity for the individuals themselves.

\subsubsection{Developing Business Strategies}

Strategic decisions are these decisions that comply to the following five characteristics (Harrison and Pelletier, 2001). First, the decision involves determining the relation between the company and its environment. Second, the decision affects the whole company. Third, the decision depends on input from all primary functional areas of the company. Fourth, the decision directly affects all administrative and operational actions. And last, the decision is essential to the long-term successfulness of the entire company. 
Strategic decision-making processes follow several steps. Although authors have proposed several processes with different amounts of steps (e.g., Harrison and Pelletier, 2001; Szulanski and Amin, 2001), the several decision-making processes have in common the following four main steps. In the first phase, the problem identification phase, the problem at hand is being analyzed. In the second phase multiple alternatives or solutions for the problem are being generated. In the third phase the different alternatives or solutions are being evaluated and the best option is selected. In the fourth and last phase the selected option is being implemented.

\subsection{Methods}

\subsubsection{Sample}

We focused in this research on experienced high-tech entrepreneurs. The rationale for this is threefold. First, high-tech entrepreneurs are often the ones within the company who have recognized the business opportunities and who make strategic decisions. Therefore, they are the ones that may have used their imagination. Second, as using one's imagination is not visible by others, the only ones who can share the experience of using their imagination are the high-tech entrepreneurs. Third, experienced entrepreneurs, defined by the fact that there company exists for more than two years (Mitchell, 1997), have been through the full entrepreneurship process (Baron and Ensley, 2006) and are thus better able to answer the interview questions than novice entrepreneurs.

We specifically focused on the four converging technologies (Roco and Bainbridge, 2003): nanotechnology, biotechnology, information technology and tech- 
nologies based in cognitive sciences. The reason for this is that these technologies both currently as well as in the future, could have an enormous impact on human abilities, societal outcomes and economic growth (Roco and Bainbridge, 2003). Within these sectors, we contacted twenty high technology entrepreneurs with more than five years of experience. The companies were all located in the Netherlands. Two entrepreneurs were female, seven entrepreneurs work in the information technology, four in biotech, two in nanotech, and seven entrepreneurs were in non-converting technology sectors. The average founding year is 2001 (SD $=10$ year). See also Table 3.1.

\subsubsection{Data Collection}

Multiple sources of data have been collected. Before the interviews we collected data about the company and its history to be able to verify the information of the interview with other sources. We did this to limit retrospective bias. Additional sources came from a venture incubator in which half of the companies participated. In this incubator the entrepreneurs were supported in starting their business and they got help in identifying opportunities and developing their strategies. The data from the incubator are the field notes of the first author who is a researcher and observant in this incubator. The main data source of this research, however, are the interviews that we conducted.

The first author and two interviewers conducted the interviews with 31 entrepreneurs. The interviews, which lasted between 30 and 60 minutes, were mostly conducted face-to-face; we conducted eleven interviews via telephone or Skype. All interviews were conducted in the interviewees' native language. The interviews 
Table 3.1: Interview Sample

\begin{tabular}{|c|c|c|c|c|c|}
\hline Name & Year & Gender & Language & Description & Industry \\
\hline Entrepreneur 1 & 2012 & Female & Dutch & $3 \mathrm{D}$ printing & IT \\
\hline Entrepreneur 2 & 2004 & Male & Dutch & Automotive electronics & Other high-tech \\
\hline Entrepreneur 3 & 1999 & Male & Dutch & Automotive software & IT \\
\hline Entrepreneur 4 & 2005 & Male & Dutch & Machine building & Non-high-tech \\
\hline Entrepreneur 5 & 2004 & Male & Dutch & Vehicles software & IT \\
\hline Entrepreneur 6 & 1981 & Male & Dutch & Automotive hardware & Other high-tech \\
\hline Entrepreneur 7 & 1990 & Male & Dutch & Automation & IT \\
\hline Entrepreneur 8 & 2004 & Male & Dutch & Artificial organ & Biotech \\
\hline Entrepreneur 9 & 1993 & Male & Dutch & Planning software & IT \\
\hline Entrepreneur 10 & 2006 & Male & Dutch & Particle measurement & Nanotech \\
\hline Entrepreneur 11 & 2006 & Female & Dutch & Soft tissue implants & Biotech \\
\hline Entrepreneur 12 & 2007 & Male & Dutch & Lab-on-a-chip & Biotech \\
\hline Entrepreneur 13 & 1994 & Male & Dutch & Mechatronics & Non-high-tech \\
\hline Entrepreneur 14 & 2007 & Male & Dutch & Domotica & IT \\
\hline Entrepreneur 15 & 2012 & Male & Dutch & Water power & Other high-tech \\
\hline Entrepreneur 16 & 2008 & Male & Dutch & Lab-on-a-chip & Nanotech \\
\hline Entrepreneur 17 & 1998 & Male & Dutch & Filter & Non-high-tech \\
\hline Entrepreneur 18 & 2005 & Male & English & Molecular imaging & Biotech \\
\hline Entrepreneur 19 & 2011 & Male & Dutch & Medical gas & Non-high-tech \\
\hline Entrepreneur 20 & 1970 & Male & Dutch & Motion control & Non-high-tech \\
\hline Entrepreneur 21 & 1999 & Male & Dutch & Simulation & IT \\
\hline Entrepreneur 22 & 2012 & Male & Dutch & Virtual reality & IT \\
\hline Entrepreneur 23 & 2007 & Male & Dutch & Logistics automation & Non-high-tech \\
\hline Entrepreneur 24 & 2008 & Male & Dutch & Breath analyses & Biotech \\
\hline Entrepreneur 25 & 2006 & Male & Dutch & Laser deposition & Nanotech \\
\hline Entrepreneur 26 & 1986 & Male & Dutch & ICT products retailer & Non-high-tech \\
\hline Entrepreneur 27 & 1993 & Male & Dutch & Voice technology & IT \\
\hline Entrepreneur 28 & 2009 & Male & Dutch & Heating systems & IT \\
\hline Entrepreneur 29 & 2011 & Male & Dutch & Micro bubbles & Nanotech \\
\hline Entrepreneur 30 & $<1996$ & Male & Dutch & Civil engineering & Non-high-tech \\
\hline Entrepreneur 31 & 2011 & Male & Dutch & Lab-on-a-chip & Biotech \\
\hline
\end{tabular}


were recorded and transcribed by the interviewers and the first author checked the transcriptions.

The interviews started by explaining the purpose of the study, why the interviewee was selected, and that the interviewee remains anonymous. The first question that was asked is what imagination is according to the interviewee. We asked this question to gain an understanding of how the entrepreneur sees imagination. This may help to interpret the answers of the entrepreneur. Subsequently we asked whether the entrepreneurs could think of business related situations in which they used their imagination. Next, to help entrepreneurs to get a more complete understanding of what imagination is, we explained that there are three different types of imagination. First, prospective thinking, is about imagining the future (Kahneman and Tversky, 1982); second, counterfactual thinking, is about imagining alternatives by changing the facts (Byrne, 2005); and third, perspective taking (Markman et al., 2009), is about putting oneself in someone's shoes.

Subsequently we focused on the process of opportunity recognition. We wanted to know how the entrepreneurs use their imagination to recognize their business opportunity. Following Cornelissen and Clarke (2010) and Felin and Zenger (2009), we asked additional questions concerning the influence of others on this process. Thereafter we focused on the process of strategic decision-making. Together with the entrepreneur we chose a recent, important strategic decision. By choosing a recent, important strategic decision, we limit the hindsight bias and have an event the entrepreneur remembers well. We then asked questions while following the process of decision-making. First we asked how the entrepreneur identified the problem that preceded the decision to get a better understanding of the background of this decision. Next, we asked whether the entrepreneur developed multiple scenarios 
after the problem identification. Hereafter we asked how the entrepreneurs used their imagination for evaluating the scenarios and whether other influenced their imaginations. We ended our questionnaire by asking whether the entrepreneurs are aware of other business related aspects in which they use their imagination. A complete overview of the interview questions can be found in Appendix A.

\subsubsection{Data Analysis}

Given that there is hardly any theory available on how entrepreneurs use their imagination, we want to identify patterns in our data that may show how entrepreneur use their imagination. Therefore, we have adopted a grounded theory methodology (Glaser and Strauss, 1967; O'Reilly et al., 2012). The analysis of the interviews has been an iterative process. We analyzed the data by going forth and back between the interviews and the themes that emerged from the data (Gioia et al., 2013; Miles and Huberman, 1994). Following Strauss and Corbin (1990), we attributed first-order codes (Van Maanen, 1979) to the data via open coding technique in the first step, until all the interviews were coded. Following Gioia et al. (2013) and Strauss and Corbin (1990), we used axial coding to generate secondorder themes (Gioia et al., 2013; Van Maanen, 1979). We generated conceptually clustered matrices (Miles and Huberman, 1994) and cognitive maps (Curşeu, 2008; Hodgkinson et al., 2004) to support us in the axial coding process. 


\subsection{Findings}

\subsubsection{What is Imagination?}

A first remarkable finding is that the question of whether or not they use their imagination was not equally understood by entrepreneurs, see also Table 3.2. Respondents 5 and 7 did not know what imagination had to do entrepreneurship and respondent 8 even called it a "vague research goal". They said they did not use imagination. However, later in the interview respondent 7 came to realize that he does use imagination: "Actually, this [= being an entrepreneur] involves a lot of imagination. This happens regularly, but it is not called imagination: one makes an assessment/estimation, that is also a kind of imagination" (Respondent 7).

On the other hand, the other respondents were very much aware that they use imagination. However, they often use different words for it. Or, as respondent 5 states: "Often, you don't think in these terms, one falls back to the terms that one [learned] at school". They describe it as a (full-color) image (Respondents 3 and 21), estimation (Respondent 7), projections (Respondent 10), visualizations (Respondent 11), ideas about the future (Respondents 12, 13 and 29), a type of creativity (Respondents 15 and 30), a possible solution (Respondents 17, 26 and 31), making associations (Respondent 24), seeing things from a different perspective (Respondent 20) or in a different context (Respondent 25), or a point on the horizon (Respondent 28). Hence, imagination is a concept that is described by different terms.

The respondents often state that they have actively used their imagination from an early age on and that they continuously use it. Respondent 10 said that all his life he imagined himself being an entrepreneur. He has imagined often what is 


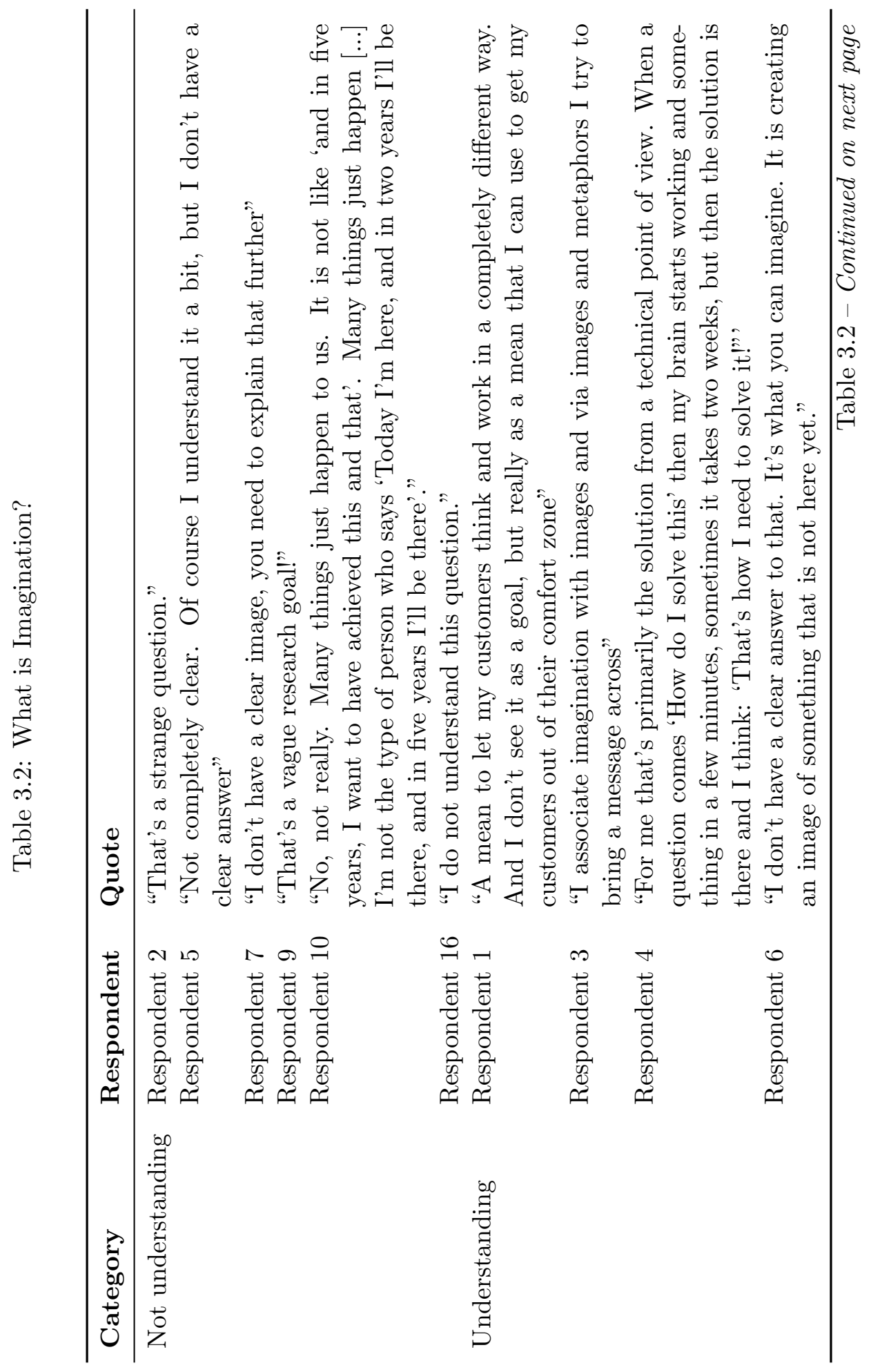




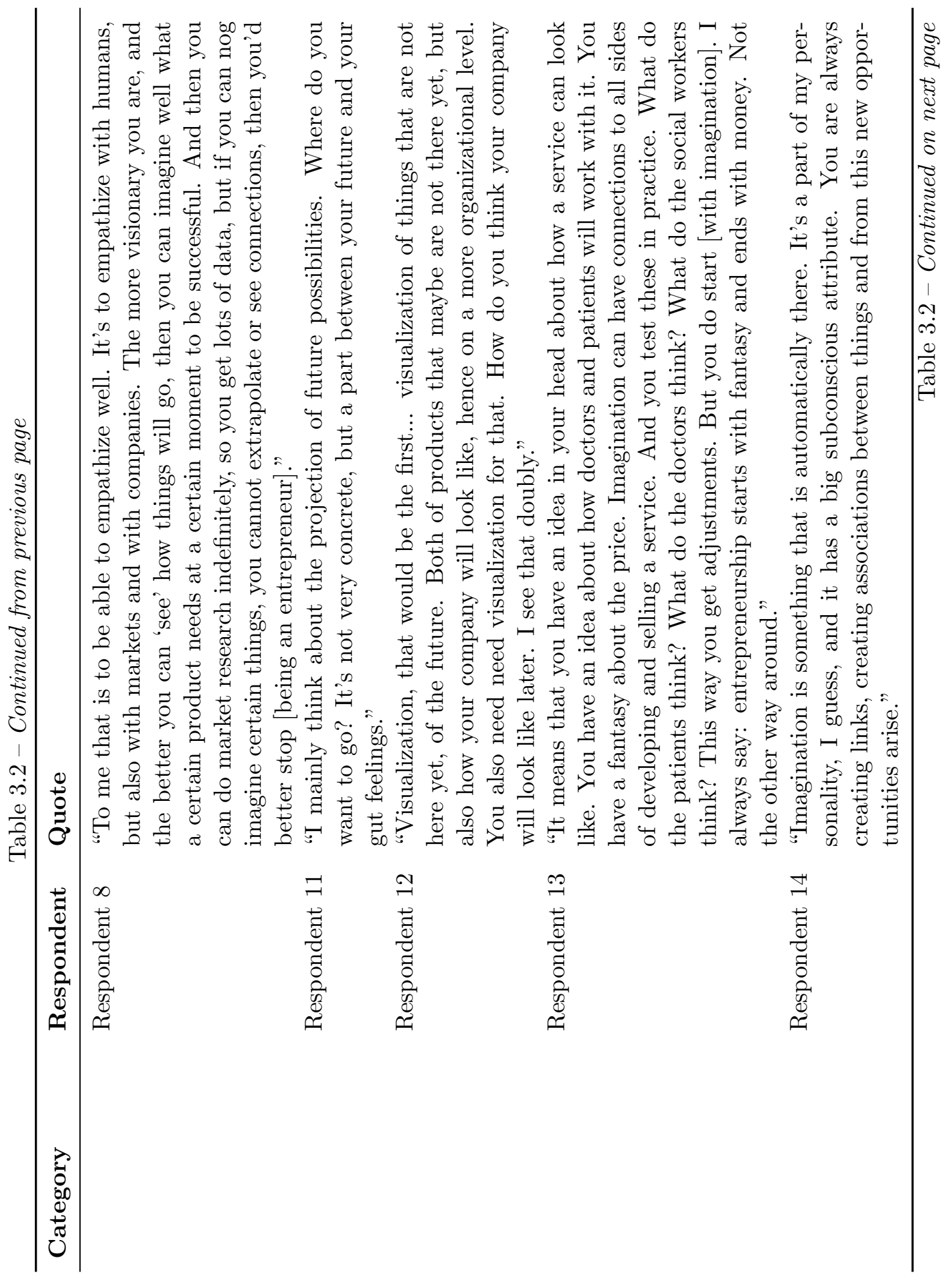




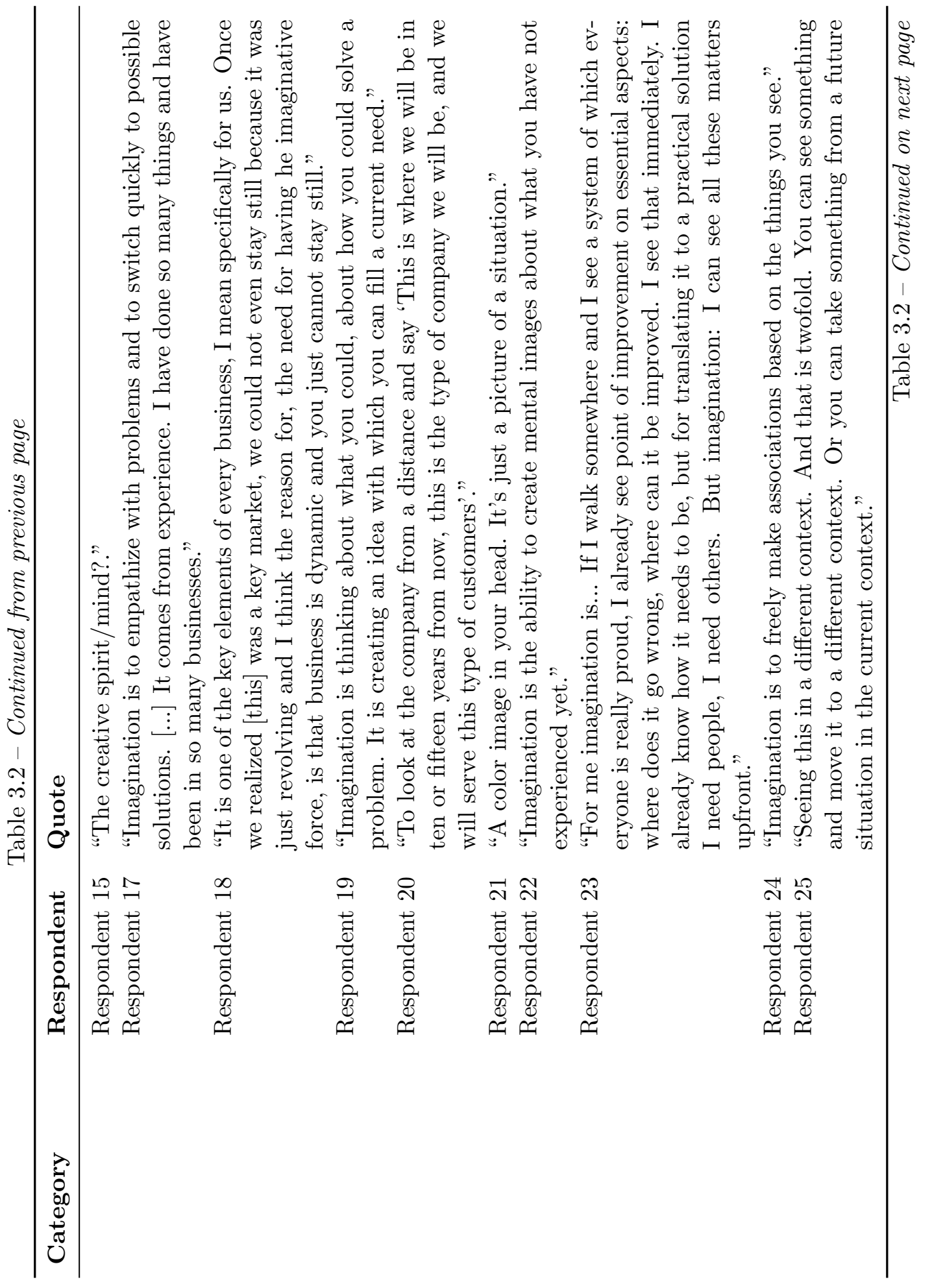




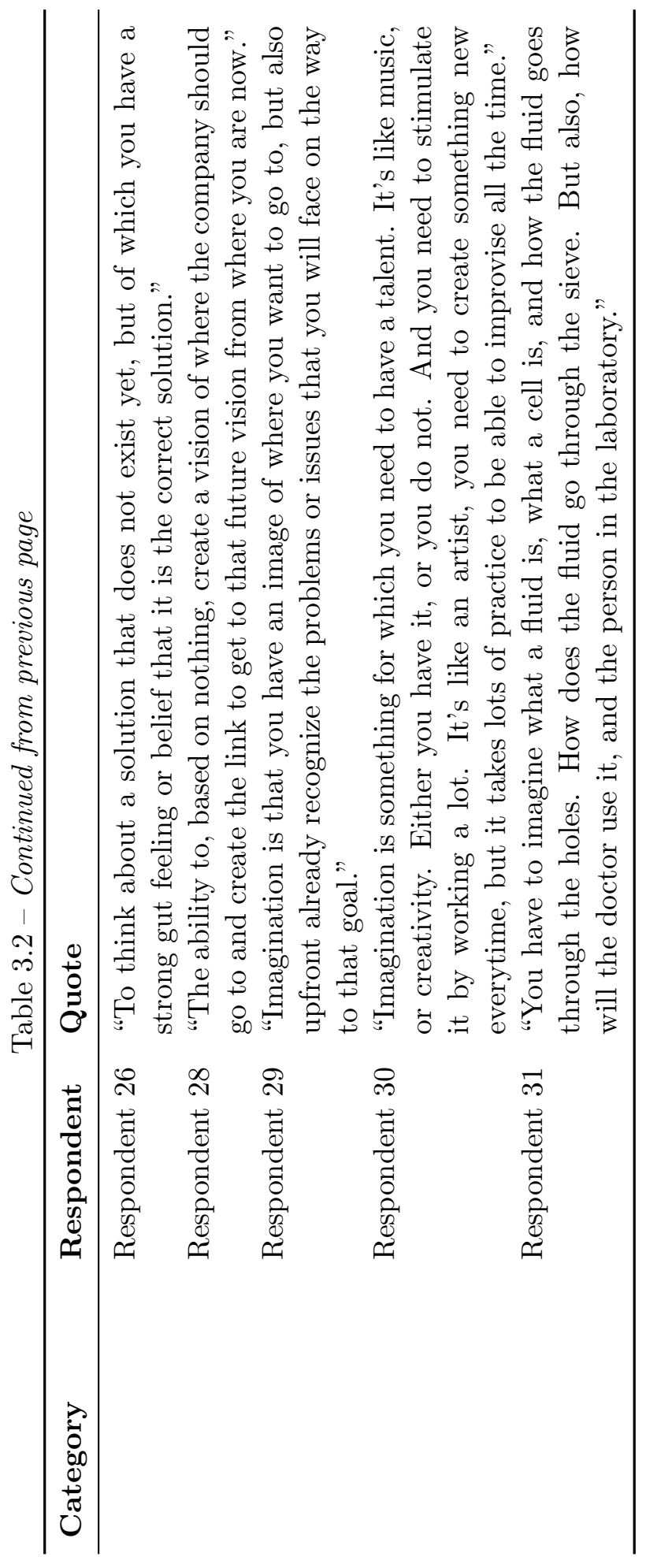


important when having a company. He often asked people close to him what they thought about that idea. Also in his personal life, he made sure that financially he had possibilities to start a company. His imaginative thoughts helped him from an early age on to prepare him for the company he has now. According to our respondents they are always using their imagination. "It is a bit of a subconscious process", according to respondent 14. "I [cognitively visualize] a lot while driving my car, especially on long rides: how do these [organizational] processes work? What do I need, what are the missing parts?" (Respondent 23). Respondent 11 adds that using his imagination happens automatically, but he has the idea that this is not the case for everyone and he wonders whether using the imagination can be learned and taught. However, almost every entrepreneur that we interviewed used their imagination. Hence imagination is a thought process that is often used by entrepreneurs and is activated automatically; they are often not aware that they started using it.

Our respondents said that their imagination helped them to prepare of the future because using their imagination helped them to close gaps in their knowledge. By imagining how the future might be, they learned about new future possibilities of which they had no knowledge before. Imagination was used when they needed knowledge beyond the boundaries of their experience. "The missing pieces in your knowledge are complemented by your imagination" (Respondent 31). Hence, imagination is used by entrepreneurs to prepare for the future.

Another important aspect of the definitions of imagination that the respondents gave, is that the imagination processes consist of creating links between abstract concepts. By using their imagination, the entrepreneurs created connections between before unrelated issues, which enabled them to analyze problems 
from a different point of view and to solve these problems. These problems are often technical problems, as respondent 31 illustrates: "You have to imagine what a fluid is, what a cell is, and how the fluid goes through these holes. And additionally, how can we make the sieve and holes in such a way that they fit?". Hence, imagination is used by entrepreneurs to solve organizational and technical problems.

From this, we learn that although entrepreneurs might not always be aware of the concept of imagination, they do report the use of imagination often in their activities, be it in different words. Specifically, respondents referred to the use of imagination to make assessments and estimations, to think about and prepare for their own future as entrepreneurs and about their company's future and to think about resources. They use their imagination to create new knowledge on the boundaries of their current experiences by linking together hitherto unrelated concepts.

\subsubsection{Prospective Thinking}

After explaining the three types of imagination, most entrepreneurs recognize that they use prospective thinking. When asked what they use it for, the respondents reply that they imagine their future products, technological issues, or organizational aspects. Respondents 11 and 12 imagine their future products. Respondent 11 imagines how it will be if she would have a commercial product ready, and respondent 12, a producer of lab-on-a-chip devices, imagines how clients will use his devices and how he can prevent misusage of the devices. Respondents 1 and 7 imagine their technology and its implications. They both argue that they mainly 
use their imagination to link technical solutions to the customer's problem. "I'm not here to sell the technique, I'm here to solve a customer's problem. And imagination is an important part in that" (Respondent 1). Respondent 7 adds that it is mainly in the starting phase of solving the problem that imagination plays an important role. Respondents 4 and 10 focus on organizational aspects. Respondent 4 imagines where the company will be in five years from now, and he is especially interested in "what the shortest way is [to that imagined future] and how do I get there with as little possible money." Hence, entrepreneurs use prospective thinking to think about the future of their company and their products. Especially to retrieve information on how the future can be.

The entrepreneurs create an "ideal image" (Respondent 4) and while they know reality will be different (Respondent 11), they strive to reach that goal (Respondent 4). Respondent 12 explains how this works: "We continuously think about: how will this be? How reliable is that? What kind of decisions will [potential customers] make? [...] That is what we fantasize about. And you could call it also a whole list of hypotheses that one will test in practice. So these fantasies are also used to create different imaginations that will be tested in practice. And then [later] one gets all kinds of adjustments [of that image]." Hence, the use of prospective thinking can be compared to the scientific process of hypothesis testing: by creating new links based on current information, expectations (or hypotheses) about the future are made. By taking action upon these expectations, these hypotheses are tested.

Mainly the young, high-tech entrepreneurs use prospective thinking to set their goals. They imagine an "ideal image" of the future of their company and products and use that image as their goal. The do not use their imagination to answer 
questions like "Where am I going?" (Respondent 1), but more to answer a question like "Where do I want to go to?" (Respondent 4). Our respondents do not see the future in a deterministic way: to them there is no fixed, unknown future and there is no best solution to get where they want to be. Many entrepreneurs see themselves as the "captain of their ship". Using their imagination, they determine where they want to go to. Strategy and resources are all secondary, because their imagination determines where they want to go and based on their resources they select the strategy to reach their goal. Hence, prospective thinking is used to set a goal to which the entrepreneur is determined and which the entrepreneur is not willing to change easily.

From this we learn that entrepreneurs use prospective thinking to generate hypotheses about their company or products to be tested in practice. Prospective thinking is particularly important at the first stage of business development: entrepreneurs use prospective thinking to visualize the product or technology before it is actually made and to foresee how it solves potential customers' problems. Finally, prospective thinking is also reported to be used as a way to generate the goal of the company. This goal is leading in all their actions. Their prospective thoughts guide them through uncertainty as it gives them stability and a fixed point on the horizon.

\subsubsection{Counterfactual Thinking}

The respondents are quite unanimous about counterfactual thinking. They state that it is not useful to look back at the past and think about what if past situations would have been different. One has to learn from the past (Respondent 4), but 
mainly focus on "where one is now and how can we do it different and better" (Respondent 1). Many entrepreneurs state that it is more important to focus on the future than to see how things could have been different.

On a different note, respondent 6 states that he is looking for alternatives for his current market. "What if there is no gasoline anymore? Our current market is based on fossil fuel. [...] Which market could we enter as well, which is not in conflict with our current market?" He therefore started looking for possible applications of the technology of his current products into other products in other markets.

When we did not ask about counterfactual thinking, but about how their strategies are created, the respondents used sentences in which they used counterfactual reasoning. Respondent 25: "And then we also do a 'what if. ..?' analysis with our company and ourselves. What if this happens, or what if this happens? What if this goes wrong, or what if that goes wrong?".

Multiple scenarios are created. These scenarios are not all written down as 'official' scenarios. Most of them are possibilities of which the entrepreneurs think. These thoughts stay in their head without being written down or being communicated to others. But all scenarios or possibilities should lead to the main goal they formulated using their prospective thoughts (see section "Prospective thinking"). Formulating multiple scenarios or possibilities based on their counterfactual thoughts prepared the entrepreneurs for the possible futures. "You're not being surprised, it does not come unexpected" according to respondent 29. Hence, counterfactual thinking is also used for 'pre-testing' strategies by analyzing assumed causality. "If I do A, do I really get to B, to my vision?". Additionally, counterfactual thinking helps entrepreneurs to prepare for possible futures. 
From this we learn that entrepreneurs state that they are not focused on the past and on imagining how situations could have had a different outcome. Although entrepreneurs state that they are focused on the present and future of their business, counterfactual thinking is important in multiple situations: a) learning from the past; b) 'pre-testing' whether strategies lead to the desired goal; and c) to prepare for possible futures.

\subsubsection{Perspective Taking}

Most entrepreneurs in our sample agree that taking the perspective of their customers is essential. They actively think about how the end users will use their products, in order to improve current products. Respondent 8, for instance, uses perspective taking to better understand how the end users of his products (patients with a specific disease) will use his product. He states that "if you do not know how it is to have this disease, then it's difficult to imagine how it should work in practice. Therefore, I have hired relatively many employees with this disease, because they can combine their professional knowledge with the practical knowledge of the disease."

Another aspect for which the entrepreneurs use their imagination, is to think of new products and solutions. Respondent 14, for example, said that when he finally thought he had made the perfect product, he realized that people who cannot move, cannot use his product. By putting himself into the position of people with a physical disability, he started to explore the possibilities for controlling devices by using thoughts. Using perspective taking opened up several possibilities for new products for him. 
Some respondents, mainly the older non-high-tech companies, state that they cannot rely on their imagination to create future goals for their company (e.g., Respondent 10). They call themselves very customer driven and do exactly what the customers wants them to do. Other respondents, mainly the young hightech companies, state that it is important to take your customer with you in the process, but you cannot have your customer steer your company. "You are the entrepreneur, you yourself determine the future" (Respondent 4). They express that there is a difference between on, the one hand, what you think your customers wants and, on the other hand, what you think you would need if you were in your customer's situation. According to these respondents it is not important to think about what the customer wants, but to listen to your potential customer and discover the "need behind the need" (Respondent 20) by putting yourself in the situation of the customer and analyze that situation.

From this we learn that perspective taking is particularly helpful for entrepreneurs to imagine the interaction between their customers with their products. In addition to this, our findings show that some entrepreneurs use this technique to think about different market segments which currently may not (be able to) use the product. This helps them to think of new market segments. Surprisingly, however, perspective taking is not used to imagine the needs of the customers. Most entrepreneurs emphasize that talking to potential entrepreneurs is key and that the use of perspective taking afterwards helps in recognizing the real need. 


\subsubsection{Relation with Information}

When asked about how the entrepreneurs use their imagination to generate their business ideas, the entrepreneurs focus on signals from the market and their gut feelings. First of all, they base their ideas on what they "saw" in the market. Respondent 3 explains: "We saw the internet hype, we saw investors with money burning in their pockets to invest it in internet technology. We thought, this cannot go wrong, we have to be part of this. We were convinced that the internet would change how we think, how we do business. In fact, it would change everything. So yes, we just saw that. We saw that it is a quick world where one can make lots of money. It's as simple as that! We saw imagines of fundamental developments and suddenly you realize that doing business is going to change."

By interacting with stakeholders, like customers (Respondent 9), employees (Respondent 1), and investors (Respondent 11), entrepreneurs also gain important input to adapt their imagination. For example, Respondent 11 explains that information from the investors, who are involved in many companies, she got additional information that made her imagine new scenarios for developing the business.

The market, however, does not give all the information. The missing parts need to be filled up by imagination, intuition (Respondent 3) or gut feelings (Respondent 10). These gut feelings were often not very specific, but in the end they turned out to be true. According to respondent 1, one starts with with a vague idea. Then she put herself in the shoes of the customer "What would I want [if I was the customer]? Well, I would like this, and I would like to have support with that. I would not like it, if I would not know whether the information I give [to the 
company], is treated confidential. I would like to be able to walk into the company and see how they do it. And all that [information] I used to design my company."

Respondent 3 imagined both his direct customer and the end user. According to him, using a different approach to the end user, will give products and services that better suit the wishes of the end user. Using a different financial structure would give his direct customer a better overview of how much the direct customer is paying per contract with the end user. By gathering this information via their imagination, the entrepreneurs were able to answer the customers' question better than their competitors do.

Respondent 11 explains why she uses imagination for thinking about her business opportunity. According to her it is because by imagining the future and possible scenarios, she can easier switch between scenarios. "If one approach does not work, then we have a plan B". If she would not have imagined these scenarios, you suddenly had to invent a new solution. Now she was prepared and could more easily change her plans.

However, instead of looking at what is possible, the entrepreneurs often have a goal in mind. "It's not like: I start a company, what should I do? No, I want to achieve this and what do I need?" (Respondent 1). It is this goal that they have in mind and want to achieve. The entrepreneurs state that because they have this image of how the company will look like, they are able to steer their company into the right direction, especially in times when it seems difficult to hold on to their vision.

From this we learn that information is an important precedent of imagination. On the one hand the entrepreneurs collect information about the market, on the other hand the entrepreneurs use their imagination to make sense out of the infor- 
mation of the environment. The entrepreneurs observe what is happening around them and imagine a) possible scenarios that might result in business opportunities and b) the needs of customers' and how they can solve their problems with their business ideas.

\subsubsection{Relation with Prior Knowledge and Experience}

For developing a business strategy, the entrepreneurs use their imagination in a similar way as for recognizing business opportunities. They start by gathering information, for instance at customers (Respondent 3). The respondents argue that facts and information are really important, but are not enough. The entrepreneurs first collect facts and then fill the gaps in their knowledge by imagination. Their knowledge and experience play a big role in this. Most of the entrepreneurs state that because they have extensive knowledge of the market, they can make realistic imaginings of how the future could be. This is partly due to the fact that because they have so much knowledge and experience, there are few gaps in their knowledge that have to be filled by the imagination.

However, some entrepreneurs also recognize the danger of being too experienced. Respondent 18 states that "experience can also have the opposite effect. Where that occurs is if you look at a 3-5 year plan. Experience counts, there is no doubt about that. But if you are really looking ahead at the future, a new generation, sometimes inexperience counts."

From this we learn that the relation between prior knowledge and experience on the one hand and imagination on the other is like a two sided sword: on the one had more prior knowledge and experience leads to a more realistic imagination. 
On the other hand, it can block the newness of the imaginations.

\subsection{Discussion}

Previous literature has stated that entrepreneurs use their imagination. However, how entrepreneurs use their imagination remained unclear. Our contribution is twofold. First, we show what entrepreneurs use their imagination for. Second, we show how entrepreneurs use the three different imagination processes - prospective thinking, counterfactual thinking, and perspective taking - in opportunity identification and strategic decision making processes.

We find that entrepreneurs use many different terms when they talk about imagination. Closely related terms entrepreneurs use are for example 'to make an estimate' or 'to visualize'. The term 'imagination' or 'to imagine' is not always part of the vocabulary of entrepreneurs. However, most entrepreneurs had an idea about what imagination is, which is related to the definition we used in this research, and agree that they use their imagination for business related activities.

Some entrepreneurs said that they do not use imagination. The work by Cornelissen and Clarke (2010) may explain why some entrepreneurs say this. Cornelissen and Clarke (2010) state that after imagining the idea, entrepreneurs need to sell the idea as a rational story to other stakeholders. Therefore, they think of rational arguments to explain the idea. These reasons, based on facts and logic are then used to sell the idea and the imagination process is forgotten.

Another finding is that both factual knowledge as well as imagination are not enough by themselves. They are both needed. Entrepreneurs first collect facts and then fill the gaps in their knowledge by the use of their imagination. They 
therefore use the combination of both prior knowledge and the learning from their imagination to create business ideas and develop strategies. To be able to use their imagination in an effective way, they need their knowledge and experience. Especially the entrepreneurs that are still at the phase of transforming research findings and prototypes into full products, state that imagination is very beneficial to them. The entrepreneurs say that they can hold on to a goal that they imagined. Using imagination therefore gives them a sense of security and stability. However, the goal the entrepreneurs have imagined is quite abstract and broad due to a lack of knowledge and experience. On the other hand, entrepreneurs, who already have a fully operating company for several years, state that their knowledge and experience, which they gained during the entrepreneurial process, improve the precision of the imagination. However, the further in the process, the less useful the imagination gets, as there are more boundary conditions that these entrepreneurs cannot change anymore due to path dependency. This suggests that the effectiveness of imagination over time shows an inverted U-shape. Therefore, we propose:

Proposition 1a. The amount of imagination used in the entrepreneurial process declines over time.

Proposition $1 \mathrm{~b}$. The relationship between the effective of the use of imagination and time in the entrepreneurial process has an inverted U-shape.

This study has practical implications, especially for high-tech entrepreneurs. Whereas these often high-educated entrepreneurs may be trained to use their analytical thinking to explore the available knowledge, high-tech entrepreneurship is surrounded by high levels of uncertainty and quickly changing environments. 
This study shows that the use of imagination may be a useful tool to deal with lacking information. By imagining how the future may be, these entrepreneurs may gather information which can guide them towards their goals. As the lack of information is greater in environments of high uncertainty and at the beginning of the entrepreneurial process, the effectiveness of the use of imagination will be great. Hence,

Proposition 1c. The inverted U-shape relationship between the effective of the use of imagination and time in the entrepreneurial process is positively skewed.

Proposition 2. The effectiveness of the use of imagination is greater in high uncertainty environments than in low uncertainty environments.

Another practical implication follows directly from our finding that the entrepreneurs stated that you should not try to take the perspective of the customer, but that you should talk to the customer. Perspective taking is used to determine the reasoning of the customer and to discover the 'need behind the need'. Discovering their actual needs is mainly useful when customers face high uncertainty and quickly changing environments, because then they are not always aware of what they want and what is possible.

We find that entrepreneurs use prospective thinking to form ideas about how the future could be, including opportunity beliefs (Shepherd et al., 2007). This process resembles the entrepreneurial theorizing process as described by Felin and Zenger (2009). Our contribution here is our notion that not only the opportunity belief is being created by the imagination, but, in a broader sense, the future setting surrounding the opportunity is imagined. Hence, we conclude that prospective thinking is used to create "third-person opportunities" (McMullen and Shepherd, 
2006). After that the opportunity belief, based on the possible future, can be created. To create opportunity beliefs entrepreneurs put themselves into the position of their future-selves, using perspective taking. Hence, we conclude that perspective taking is used to create "first-person opportunities" (McMullen and Shepherd, 2006).

Proposition 3a. To create third-person opportunity beliefs, entrepreneurs use their prospective thinking.

Proposition 3b. To create first-person opportunity beliefs, entrepreneurs use their perspective taking.

We also found that imaging the future gives a feeling of certainty on how the future will be; it gives a feeling of control. This may link the use of imagination to entrepreneurs that use a causation approach (Sarasvathy, 2001). By creating an image of how the company will look like, one can argue that the entrepreneurs predict the future, and then select the best means to reach that future. However, using imagination can also be argued to be a tool for entrepreneurs that work in an effectuation approach (Sarasvathy, 2001). By regularly imagining how the future could be, the entrepreneurs can steer their company towards to direction that they imagined. They then focus on the controllable aspects of an unpredictable future. This helps to create a future that they imagined instead of trying to adapt their company to fit the predicted future.

We found that not all entrepreneurs use the terms 'imagination' or 'to imagine'. They used other words to describe these processes. One implication for further research on the use of imagination is that a broader vocabulary should be taken into account. 
Further research could study to what extent the use of imagination can be learned and taught. If that is the case, business incubators can train entrepreneurs to better use their imagination on moments that information is scarce or quickly changing. Different training methods may be developed for the different types of imagination.

Another suggestion for further research is to study when the use of imagination by entrepreneurs is most effective. Our findings suggest there may be an inverted U-shape relation of the effectiveness of imagination over time, but further research needs to look into this.

\subsection{Conclusion}

This chapter is an attempt to open up the black box that surrounds the topic of imagination within entrepreneurship research. Where previous research has stated that entrepreneurs use their imagination, we show that imagination plays an important role in the generation of business ideas and business strategies. More specifically we show that entrepreneurs use three different imagination processes. Prospective thinking is important for imagining the future state of the company, which serves as a goal for the entrepreneur. Counterfactual thinking helps to test whether possible strategies may help the entrepreneur to reach that imagined future state by cognitively testing the causal relation between the strategy and the future state in which the opportunity is being exploited. Perspective taking helps in to better understand the customer. Not to find out what the customer wants, but to better understand the underlying reasoning of the customer. We hope that future research will study the use of imagination further. 


\section{Chapter 4}

\section{How Do Nascent Entrepreneurs}

\section{Use Imagination In The Venture}

\section{Creation Process? A Weekly}

\section{Diary Study}

A previous version of this chapter has been presented at the $33^{\text {rd }}$ Babson College Entrepreneurship Research Conference, June 5-8, 2013 in Lyon, France and is published as Frederiks, A.J., Ehrenhard, M.L., and Groen, A.J. (2013) How do nascent entrepreneurs use imagination in the venture creation process? A weekly diary study. Frontiers of Entrepreneurship Research 33, p. 112-125. 


\subsection{Summary}

In this chapter we build on the conclusions drawn in the previous chapters and focus on how nascent entrepreneurs use their imagination in the venture creation process. We study the use of imagination by differentiating between distinct imagination processes and business related uses of imagination. Additionally, we link the use of imagination to the pursuit of the business idea. We analyzed 5,803 weekly diaries that were kept by 164 entrepreneurs. We found that prospective thinking is important for opportunity recognition and counterfactual thinking for creating strategy. Our findings suggest that entrepreneurs indeed use their imagination and that by making better use of their imagination the chance of pursuing the business idea increases.

\subsection{Introduction}

The entrepreneurship literature abundantly states that imagination is used by entrepreneurs (e.g., Baron and Ensley, 2006; Cornelissen and Clarke, 2010; Gartner, 2007; Sarasvathy, 2001, 2008; Witt, 1998, 2007). Yet very little is known about how imagination is used by entrepreneurs. Imagination is the creation of mental images of external objects, events or situations not present to the senses (Frederiks, 2014). These mental images are created by three separate processes (Frederiks, 2014). The first imagination process is prospective thinking, which is imagining what the future might look like (Kahneman and Tversky, 1982). The second process is counterfactual thinking, which is imagining what the present would look like based on an alternative past (Byrne, 2005). The third process is perspective 
taking, which is imagining what someone else's thoughts and actions would look like (Markman et al., 2009).

In addition to the three imagination processes, seven different business related uses of imagination were found in the literature (Frederiks, 2014). Among these seven are imagining the future state of one's company and imagining strategic scenarios for the company. However, besides that imagination consists of three imagination processes and that there are seven business related uses of the imagination, it remains unknown which imagination processes entrepreneurs use to imagine these business related uses of imagination. We address this gap by empirically testing the relationships between imagination processes and their different entrepreneurial uses. Additionally, whether the use of imagination increases the chance of pushing a business idea is unknown as well. We address this gap by empirically testing the relationship between the use of imagination and the pursuit of the business idea.

We study the use of imagination by researching weekly diaries of nascent high-tech entrepreneurs. Therefore, our research question is: "How do nascent entrepreneurs use imagination in the venture creation process?" Answering this question gives us insight in whether entrepreneurs use their imagination and for which purposes. These results help entrepreneurs and practitioners in using imagination more effectively.

We start by discussing the theoretical relations between the three imagination processes and present seven imagination outcomes. In the methods section we explain how we coded and analyzed the diaries. After that we present the results of the analyses and in the last section we discuss the results and draw conclusions. 


\subsection{Theoretical framework}

The term "imagination" or "to imagine" is often used in everyday language but has no commonly accepted definition. Some scholars see imagination as a process (Mills, 1959), whereas others see imagination as the outcome of a process (Gendler, 2011). Hence, imagination is a multidimensional construct, consisting of three different processes that create fictional mental images that could become true (Frederiks, 2014). The three imagination processes will be discussed in more depth below. After that, seven business related outcomes of imagination processes are discussed.

\subsubsection{Imagination Processes}

Prospective thinking. Prospective thinking is "the ability to 'pre-experience' the future by simulating it in our minds" (Gilbert and Wilson, 2007, p. 1352). According to Kahneman and Tversky (1982), there are three categories of prospective thinking. The first category is prediction. One can predict situations or events by imagining them. For instance, one can imagine how two people that you know well, but have never met before - for example, your business partner and a potential customer - might get along. How can you 'know' whether these people will or will not like each other (Kahneman and Tversky, 1973, 1982)?

The second category of prospective thinking is assessing the probability of a specified event. Whereas prediction assumes a specified, currently existing situation and an imagined future situation, assessing the probability assumes a specified, currently existing situation, and a specified future situation. One can imagine the ease with which this future state can be reached, within the constraints of a realis- 
tic model of the economic situation and market conditions (Carroll, 1978; Tversky and Kahneman, 1973).

The third and last category of prospective thinking is assessing conditioned probabilities. Entrepreneurs may ask themselves: "If the economy goes into a double-dip, what are the likely consequences for my company?" This mental simulation assumes a specified, not currently existing starting situation and an imagined future situation. To run such a mental simulation, one needs to imagine how to get from the current situation to the specified starting situation. Only when one can mentally bridge that gap, one can run such a simulation (Kahneman and Tversky, 1982).

Counterfactual thinking. Counterfactual thinking is imagining "what might have been" in a given situation. According to (Kahneman and Tversky, 1982) distinguish between two categories of counterfactual thinking. The first cateoory is counterfactual assessment. One can use counterfactual simulations to 'modify' a past event and simulate what would have happened and how it might have affected the present (Byrne, 2005; Roese, 1997). If two events happen after each other event $A$ happens first, event $B$ happens afterwards - one can use counterfactual assessment to see how event $B$ looks like, if event $A$ would have been different.

The second category is assessment of causality. With assessment of causality, there is a pre-specified event $B$ and one mentally tests whether event $B$ would still be possible if event $A$ was changed (Kahneman and Tversky, 1982). An example of an assessment of causality would be: Would we still have made a loss (event $B$ ), if we had not merged with that company we bought three years ago (event $A$ ).

Perspective taking. The third imagination process is perspective taking. With perspective taking, one puts oneself in someone else's position. Perspective taking 
is a cognitive process that is highly related to, but distinct from, empathy, which is an intuitive emotional aspect (Lamm et al., 2007). Using perspective taking, one can imagine the actions and feelings of other people. Moreover, perspective taking can also be used to imagine oneself being in the situation of another. Perspective taking can be useful to entrepreneurs when they, for instance, imagine how potential customers would use a possible new product or service.

\subsubsection{Business Related Uses of the Imagination Processes}

Besides the aforementioned three processes of imagination, seven business uses of imagination can be distinguished (Frederiks, 2014). These business related uses of imagination are the outcomes of the imagination processes. The first business related use of imagination is "idea and opportunity creation". This states that entrepreneurs use their imagination to create new business and opportunities to start a business (e.g., Chiles et al., 2007; Felin and Zenger, 2009). The second one is "(inter)action of stakeholder", where entrepreneurs imagine how stakeholders act and react on the actions, products and services of the entrepreneur. Imagining how a future customer would react on your product is an example of this category (e.g., Hart and Sharma, 2004; Galinsky et al., 2008).

The third business related use of imagination is imaging the "likelihood of success of one's company or product". Entrepreneurs imagine how likely it is that the company or product will be successful or unsuccessful (e.g., Zhao et al., 2011, 2012). The fourth is "scenarios/plans for company/product", where entrepreneurs imagine plans or scenarios to reach an imagined future state of the company or product (e.g., Felin and Zenger, 2009; Szulanski and Amin, 2001). The fifth is 
"future state of the company or product" (e.g., Chiles et al., 2007; ogilvie, 1998). An example is when entrepreneurs imagine how many employees the company has, or how much profit they make, in five years from now. The sixth is imagining the "social impact of the company or product". A (social) entrepreneur imagining how his/her product would improve the lives of people or animals would be an example of this sixth category (e.g., Buchholz and Rosenthal, 2005; McVea, 2009).

The seventh use, "development of entrepreneur" is imagining how one can develop oneself or one's personal situation. For example, imagining how one should improve one's behavior in a feedback-receiving situation, would fit this category (e.g., Byrne, 2005).

These seven categories all discuss different business related outcomes of the three imagination processes. Whether some imagination processes lead to specific business related outcomes, or whether some of these seven outcomes are more the result of one imagination process than another imagination process is unknown. In this study we explore the existence of these suggested relationships.

\subsubsection{Main Hypothesis}

So far, next to three studies on the use of counterfactual thinking in entrepreneurship (Baron, 1998, 2000a; Gaglio and Katz, 2001; Gaglio, 2004) no (empirical) research was conducted on the use of imagination in entrepreneurship. It is therefore unknown whether entrepreneurs use these all three processes for each business related use of imagination, or that they use some imagination process more often than others for a specific business related use of imagination. Therefore, we propose the following null-hypothesis and alternative hypothesis: 
$\mathbf{H}_{0}$ :Imagination processes and business related uses of imagination are independent.

$\mathbf{H}_{\mathbf{a}}$ :Imagination processes and business related uses of imagination are dependent.

There are good reasons to expect that we will need to refute our null-hypothesis and accept the alternative hypothesis. We will present this reasons in the next section, where we build further hypotheses on the relation between imagination processes and business-related uses of imagination in case we need to refute our null-hypothesis.

\subsubsection{Hypothesis Building}

In case we will reject the null-hypothesis and accept the alternative hypothesis, we want to know which combinations of imagination processes and business related outcomes cause the dependence between imagination processes and business related uses of imagination. In other words, which combination of imagination processes and business related uses of imagination occur significantly more often or less often than one would expect based on the null-hypothesis?

For instance, to come up with business ideas or opportunities, one mainly focuses on the future (Haynie et al., 2009). More specifically, entrepreneurs think of business ideas or create opportunities through their expectations of an imagined future (Chiles et al., 2007). The use of prospective thinking is more effective than the use of counterfactual thinking or perspective taking to imagine business ideas or opportunities and, therefore, we hypothesize that: 
Hypothesis 4.1. Entrepreneurs use prospective thinking more often than expected to imagine business ideas or opportunities.

When entrepreneurs imagine the (inter)actions of stakeholders, they put themselves into the shoes of these stakeholders to try to find out what these stakeholders may think and might do. Perspective taking is the imagination process that enables people to imagine how others might think and act. Therefore, we expect that the use of perspective taking is more effective than the use of counterfactual thinking or perspective taking to imagine the (inter)action of stakeholders. Thus, we hypothesize that:

Hypothesis 4.2. Entrepreneurs use perspective taking more often than expected to imagine the (inter)action of stakeholders.

One of the judgmental activities that prospective thinking can be used for, is assessing probabilities (Kahneman and Tversky, 1982). Therefore, we expect that the use of prospective thinking is more effective than the use of counterfactual thinking or perspective taking to imagine the likelihood of success of a company and/or product. Hence, we hypothesize that:

Hypothesis 4.3. Entrepreneurs use prospective thinking more often than expected to imagine the likelihood of success of their company.

Imagining new scenarios for a company is a part of strategy making. Szulanski and Amin (2001) have two prescriptions for successful strategy making. The first prescription is discipline, which is "the consistent application of rules to evaluate the full set of given alternatives" (Szulanski and Amin, 2001, p. 541), and the second prescription is imagination, which generates this variety of alternatives. To 
come up with these alternatives, we argue that one needs to use counterfactual thinking. Many alternative plans can be generated by repeatedly mentally modifying a part of a plan and simulating what the end result of that plan would be. By both being imaginative in creating alternatives and by being disciplined in the evaluation of these alternatives, successful strategies can be created (Szulanski and Amin, 2001). Therefore, we expect that the use of counterfactual thinking is more effective than the use of prospective thinking or perspective taking to imagine new strategic plans and we hypothesize that:

Hypothesis 4.4. Entrepreneurs use counterfactual thinking more often than expected to imagine new scenarios for their company.

To imagine the future state of their company or their products, entrepreneurs need to predict the future. Predicting is one of the judgmental tasks that prospective thinking can be used for. Therefore, we expect that the use of prospective thinking is more effective than the use of counterfactual thinking or perspective taking to imagine the future state of the company and/or the product(s). Thus, we hypothesize that:

Hypothesis 4.5. Entrepreneurs use prospective thinking more often than expected to imagine the future state of their company.

Imagining the social impact of the company and its product is also a forwardlooking activity. One predicts the future, and specifically the effects that the company will have on society. As said above, prospective thinking is used to predict. Therefore, we expect that the use of prospective thinking is more effective than the use of counterfactual thinking or perspective taking to imagine the social impact of a company or product. Hence, we hypothesize that: 
Hypothesis 4.6. Entrepreneurs use prospective thinking more often than expected to imagine the social impact of their company.

Entrepreneurs also imagine their personal development, they imagine how they will get better at certain tasks at which they are currently not so good. Here the entrepreneurs predict their future behavior. And prospective thinking is needed for prediction. Therefore, we expect that the use of prospective thinking is more effective than the use of counterfactual thinking or perspective taking to imagine the one's personal development and we hypothesize that:

Hypothesis 4.7. Entrepreneurs use prospective thinking more often than expected to imagine their personal development.

\subsection{Methods}

\subsubsection{Measurements}

The 193 mainly nascent high-tech entrepreneurs that participated in a university related one-year incubation program in the Netherlands were requested to fill out an online weekly diary. Filling out the diaries was an official part of the incubation program for both research reasons and as a reflection moment for the entrepreneurs. To stimulate the participants to fill out the online diaries on the intranet of the incubation program, the entrepreneurs could not participate in weekly trainings if they did not fill out the diaries for more than two weeks in a row. Only in exceptional cases, like illness, this rule was not applied. This resulted in a dataset containing 6,271 diary entries. In the diary the entrepreneurs were asked to answer the following four questions: 
1. What were the most important things that you learned in the past week?

2. What results have you made in the past week?

3. What issues have you been most concerned with in the past week?

4. What are the next steps that you are going to take in the coming weeks?

To reduce skewed perception of the behavior, an interval-contingent recording with fixed schedule was chosen (Bolger et al., 2003; Laurenceau and Bolger, 2005): the entrepreneurs were asked to fill in independently their weekly diaries (e.g., Larsen and Kasimatis, 1990), near the end of their workweek. The information that the entrepreneurs entered into the diaries was not discussed with them. An anonymized diary entry can be found as an example in Appendix B.

\subsubsection{Sampling}

The entrepreneurs who participated in the university related incubation program are mainly nascent, high-tech (potential) entrepreneurs from the Netherlands. These entrepreneurs differed in their progress. Some did not have a business idea yet, but wanted to become an entrepreneur; others already had a business and want their business to grow. By participating in this program the entrepreneurs received trainings, office facilities, access to networking events, and a personal coach. The diaries were filled out by 193 entrepreneurs, of which 170 male and 23 female. This resulted into 6,271 diary entries. This means that the entrepreneurs filled out the diaries for 32.49 weeks in a year $\left(\sigma^{2}=16.55\right.$ weeks/year). We removed 29 entrepreneurs from the dataset, because these entrepreneurs filled out the diaries less than 10 times in a year. That means that our final sample consisted 
of 164 entrepreneurs (85.0\%), of which 143 male and 21 female, who in total filled out 5,803 diary entries $(92.5 \%)$. These entrepreneurs filled out the diaries for 37.20 weeks in a year $\left(\sigma^{2}=12.85\right.$ weeks/year). Not surprisingly, we found more occurrences of imagination in longer diary entries $(\tau=.36, p<.01$, one-tailed). However, we decided to leave the short diary entries in the dataset, so we could analyze the complete set of each entrepreneur.

\subsubsection{Research Design and Procedures}

Five final year business administration bachelor students and one master student independently coded the sample in multiple steps. Before the introduction meeting, the authors created a codebook and the coders read about imagination, its processes, and its business related outcomes. During the introduction meeting the first and second author presented and discussed the concepts with the coders. The goal of this introduction meeting was to minimize the risk of ambiguity for the coders, and give them the same understanding of the concepts.

After discussing the coding of a random subsample, the full set of 6,271 entries was divided in thirteen sets of approximately 500 entries. Based on the codebook, the coders coded one set of 500 entries per week. Every week the codes of the set of the week before were discussed to see whether the coders agreed unanimously to the three aforementioned issues. Differences were discussed until unanimity was reached. Additionally the codebook was further developed at each meeting by adding new phrases that signaled a specific imagination process or outcome. A final version of the codebook can be found in Appendix C. After a total of thirteen weeks the whole sample of 6,271 entries was coded and all the difficult codes were 
discussed.

In the next phase, the coders reached a unanimous decision about all the codes in the sample by discussing all the coded phrases. The coders often had coded the entries different from each other in the first weeks, but had more common decisions on the coding of the diary entries in later weeks. Therefore, discussing every diary entry together in this last step ensured that the entries that were coded in the first weeks were coded in the same way as the entries that were coded in the last weeks.

\subsection{Results}

\subsubsection{Co-occurrences}

We counted the co-occurrences of each imagination process with each business related use of imagination that we found in the dataset. Table 4.1 provides an overview of these co-occurrences. We find that the entrepreneurs used their imagination 1,442 times in the diaries we studied. They use prospective thinking 1,055 times $(73.2 \%)$, perspective taking 195 times (13.5\%), and counterfactual thinking 193 times $(13.4 \%)$.

Regarding the business related uses of imagination, we find that entrepreneurs use their imagination most often to imagine the (inter)action with stakeholders (445 times, $30.9 \%$ ). They also often imagine scenarios and plans for the company (397 times, $27.5 \%$ ), and imagine the future of the company and its products (316 times, $21.9 \%$ ). The other outcomes are much less prominent. Especially the social impact of the products and the company is a business related use of imagination 


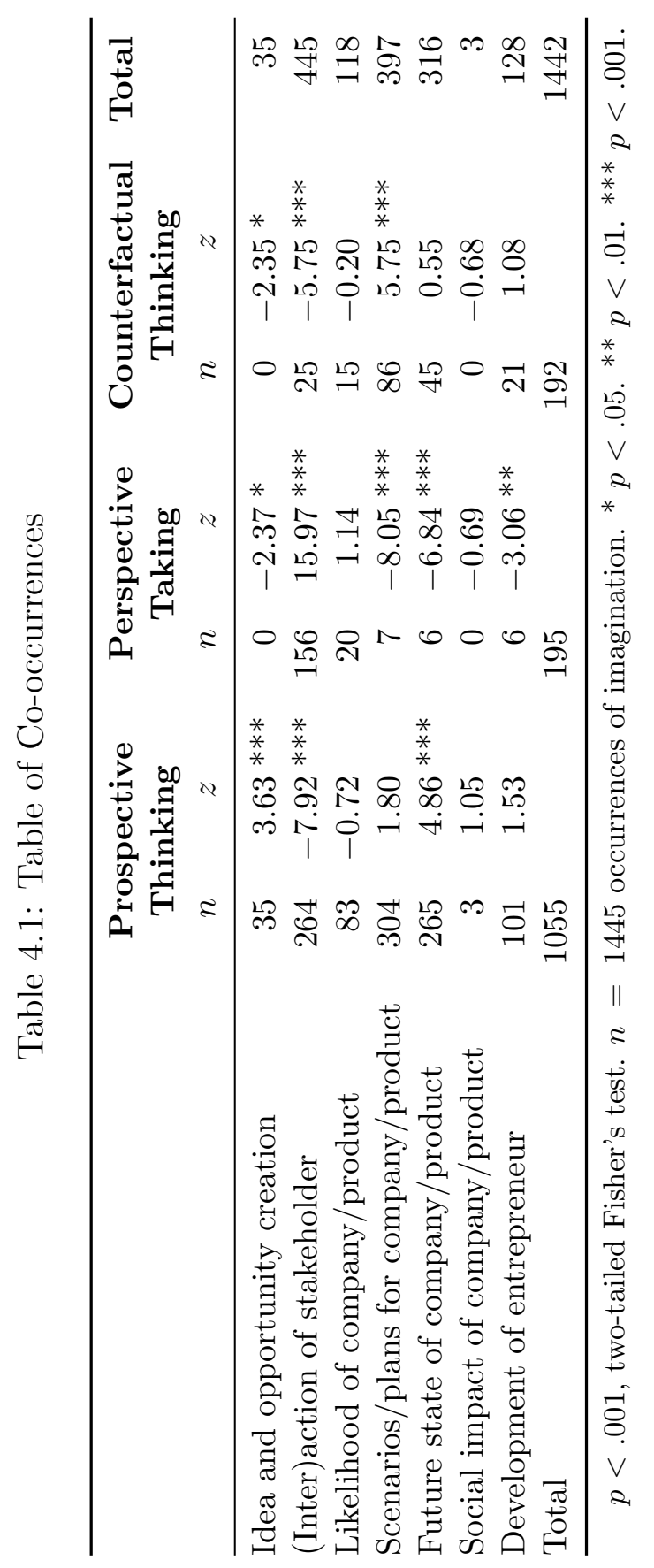


that the entrepreneurs in this sample hardly mention.

To test the main null-hypothesis, which implies that entrepreneurs use all three imagination processes equally for each business related use of imagination, we analyze the contingency table in Table 4.1 using $R$ ( $R$ Core Team, 2014). We analyze the contingency table with Fisher's exact test for $r \times c$ contingency tables with Monte Carlo simulations (Mehta and Patel, 1983, 1986), because more than $20 \%$ of the expected values are below 5 and some are even below 1 (Agresti, 2007). Fisher's exact test for $r \times c$ contingency tables with Monte Carlo simulations show that the imagination process and the business related uses of imagination are not independent ( $p<.001$, two-tailed Fisher's exact test). This means that the chance that the use of the imagination processes is not equally shared among the processes per outcome. In other words, some imagination processes are more likely to cooccur with a business related use of imagination than other imagination processes. This leads us to reject the null-hypothesis.

To gain a better understanding of which imagination processes are more likely than other imagination processes to co-occur with specific business related imagination outcomes and thus to test our other hypotheses, we calculate the standardized residuals, see also Table 4.1.

We find that the entrepreneurs use prospective thinking significantly more often than expected to imagine ideas and opportunities $(z=3.63, p<.001)$. This confirms Hypothesis 4.1. Subsequently, we find that the entrepreneurs imagine the (inter)action of stakeholders when using perspective taking significantly more often than expected $(z=15.97, p<.001)$, which confirms Hypothesis 4.2. The third hypothesis cannot be confirmed, as the use of prospective thinking does not co-occur more often with imagining the likelihood of success than expected 
$(z=-0.72$, n.s. $)$. Therefore, we reject Hypothesis 4.3. When using counterfactual thinking, the entrepreneurs imagine significantly more often than expected the scenarios and plans for the company or products $(z=5.75, p<.001)$. This confirms Hypothesis 4.4. Additionally, we find that entrepreneurs imagine significantly more often than expected the future state of the company or products when using prospective thinking $(z=4.86, p<.001)$. Therefore, we confirm Hypothesis 4.5. The sixth hypothesis cannot be confirmed, because the use of prospective thinking does not co-occur more often with imagining the social impact of the company than expected $(z=1.05$, n.s. $)$. Hence, we reject Hypothesis 4.6 . We also reject Hypothesis 4.7, because the use of prospective thinking does not co-occur more often with prospective thinking than expected $(z=1.53$, n.s. $)$.

Besides the hypothesized relationships, we find additional co-occurrences that occur less often than expected, and therefore indicate that the imagination processes and business related uses of imagination are dependent. First, prospective thinking co-occurs significantly less with the (inter)action of stakeholders than expected $(z=-7.92, p<.001)$. Second, perspective taking co-occurred significantly less than expected with ideas and opportunities $(z=-2.37, p<.05)$, scenarios and plans for the company or products $(z=-8.05, p<.001)$, the future state of the company or product $(z=-6.84, p<.001)$, and the development of the entrepreneur $(z=-3.06, p<.01)$. Last, counterfactual thinking co-occurred significantly less than expected with ideas and opportunities $(z=-2.35, p<.05)$ and the (inter)action of stakeholders $(z=-5.75, p<.001)$. 


\subsubsection{Imagination Over Time}

To test whether imagination changes over time, we introduce a variable $t_{i, j}$ which represents the day on which participant $j$ created diary entry $i$ since participant $j$ created his/her first diary entry $i=0$. Variable $t_{i, j}$ is therefore defined as:

$$
t_{i, j}= \begin{cases}1 & \text { if } i=0 \\ D_{i, j}-D_{i-1, j}+t_{i-1, j} & \text { if } i>0\end{cases}
$$

where $D_{i, j}$ is the date on which participant $j$ created diary entry $i$.

As a measurement for imagination, we determined for each diary entry $(n=$ 5803 ) the total amount of imagination that was counted. Using R-package 'pscl' (Jackman, 2002; Zeileis et al., 2008), we found that the data is over-dispersed $\left(\chi^{2}(1)=\right.$ 286.77, $p<0.01, r=0.22)$, but not significantly zero-inflated $(z=0.83, p=.20$, $r=0.01$ ). Therefore, we performed a negative binomial regression (Zeileis et al., 2008) using R-package 'MASS' (Venables and Ripley, 2002) with the total amount of imagination as the dependent variable, and time $\left(t_{i, j}\right)$ and gender as independent variables. The results of this analysis can be found in Table 4.2.

Table 4.2: Predicting Amount of Imagination

\begin{tabular}{llrrr}
\hline Predictor & \multicolumn{4}{c}{ Total Use of Imagination } \\
& \multicolumn{1}{c}{$\beta$} & $\mathrm{SE} \beta$ & \multicolumn{1}{c}{$Z$} & $e^{\beta \mathrm{a}}$ \\
\hline Gender (Male $\rightarrow$ Female) & $-0.4591^{* * *}$ & 0.1055 & -4.352 & 0.6319 \\
Day Number & $-0.0007^{*}$ & 0.0003 & -2.099 & 0.9993 \\
Constant & $-1.3012^{* * *}$ & 0.0618 & -21.029 & 0.2722 \\
\hline
\end{tabular}

Log likelihood $(4)=-3419.4, p<.001 . n=5803$ diary entries. ${ }^{*} p<.05$. ${ }^{* *} p<.01 .{ }^{* * *} p<.001$.

${ }^{\mathrm{a}} e^{\beta}=$ exponentiated $\beta$.

The negative binomial model (log likelihood ratio $=-3419.4, \mathrm{df}=4, p<.001)$ shows that the total amount of imagination decreases slightly, but significantly, 
over time $(\beta=-.0007, p<.05)$. Surprisingly, our results also show that the total amount of imagination in our sample is significantly less for women compared to men $(\beta=-.46, p<.001)$.

\subsubsection{Pursuit of the Business Idea Explained by Imagination}

To test whether the use of imagination can predict the success of a start-up, we need to study imagination on an entrepreneur/company level instead of a diaryentry level. We therefore aggregated the values of the three imagination process variables and the seven imagination outcomes variables, while correcting for the amount of diaries an entrepreneur filled out, in the following way:

$$
x_{\text {sum }, n, j}=\frac{\sum_{i_{j}=0}^{i_{\max , j}} x_{n, i, j}}{i_{\max , j}}
$$

with $x_{\text {sum }, n, j}$ as the aggregated value of variable $x_{n, i, j}$ over diary entry $i$, and with $n \in\{1,10\}$, representing the three imagination processes and seven imagination outcomes, for entrepreneur $j$. By dividing the summation by the total amount of diaries that was filled out by entrepreneur $j\left(i_{\max , j}\right)$, we correct for the fact that the more diaries were filled out, the more imagination occurrences were found.

To measure the success of the entrepreneur, we gathered data in July 2014 via LinkedIn to see whether the entrepreneurs $(n=125)$ had 1) Quit the company, but did not start a new company; 2) Quit the company, but started a different company; or 3) Continued with the company. Using R's 'nnet' package (Venables and Ripley, 2002), we performed a multinomial logistic regression on this categori- 
cal variable to test whether the imagination process (Table 4.3) or the imagination outcomes (Table 4.4) could predict the success of the start-up.

Based on the multinomial logistic regression model with imagination processes $\left(\chi^{2}(8)=21.779, p<.01\right)$, which can be found in Table 4.3, we find that the entrepreneurs who quit their initial company, but started working on a new company, used significantly more prospective thinking $(\beta=.07, p<.05)$ and significantly less perspective taking $(\beta=.22, p<.05)$ than the entrepreneurs who quit working on their initial company, but did not start a new venture afterwards. Surprisingly, there is no difference in use of imagination between the entrepreneurs that quit the company and did not start a new one, and the entrepreneurs who are still working on their initial venture.

Based on the multinomial logistic regression model with imagination outcomes $\left(\chi^{2}(14)=35.262, p<.001\right)$, which can be found in Table 4.4, we find that the entrepreneurs who quit their company and started a new venture used their imagination significantly more to think about the future of their company and products $(\beta=.44, p<.05)$, and significantly less about how stakeholders would (inter)act $(\beta=-.18, p<.05)$, compared to the entrepreneurs who quit their company but did not start a new venture. Also entrepreneurs who are still working on their company used their imagination significantly more to think of the future of their company $(\beta=.38, p<.05)$ and significantly less about how stakeholders would (inter)act $(\beta=-.11, p<.05)$ compared to the entrepreneurs who quit their company but did not start a new venture. Subsequently, the entrepreneurs that are still working on their company also thought significantly less about how they should develop themselves $(\beta=-.19, p<.05)$ compared to entrepreneurs that quit working on their company and did not start a new venture. 


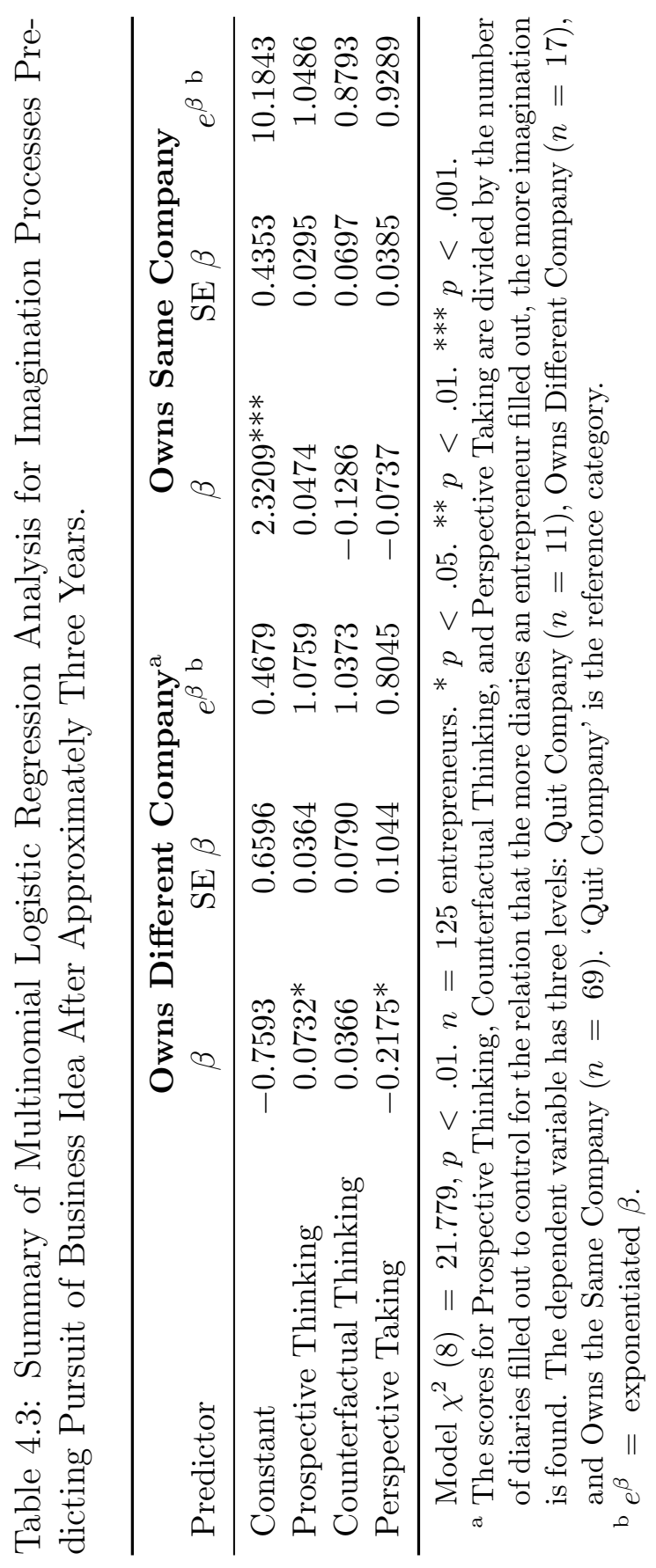




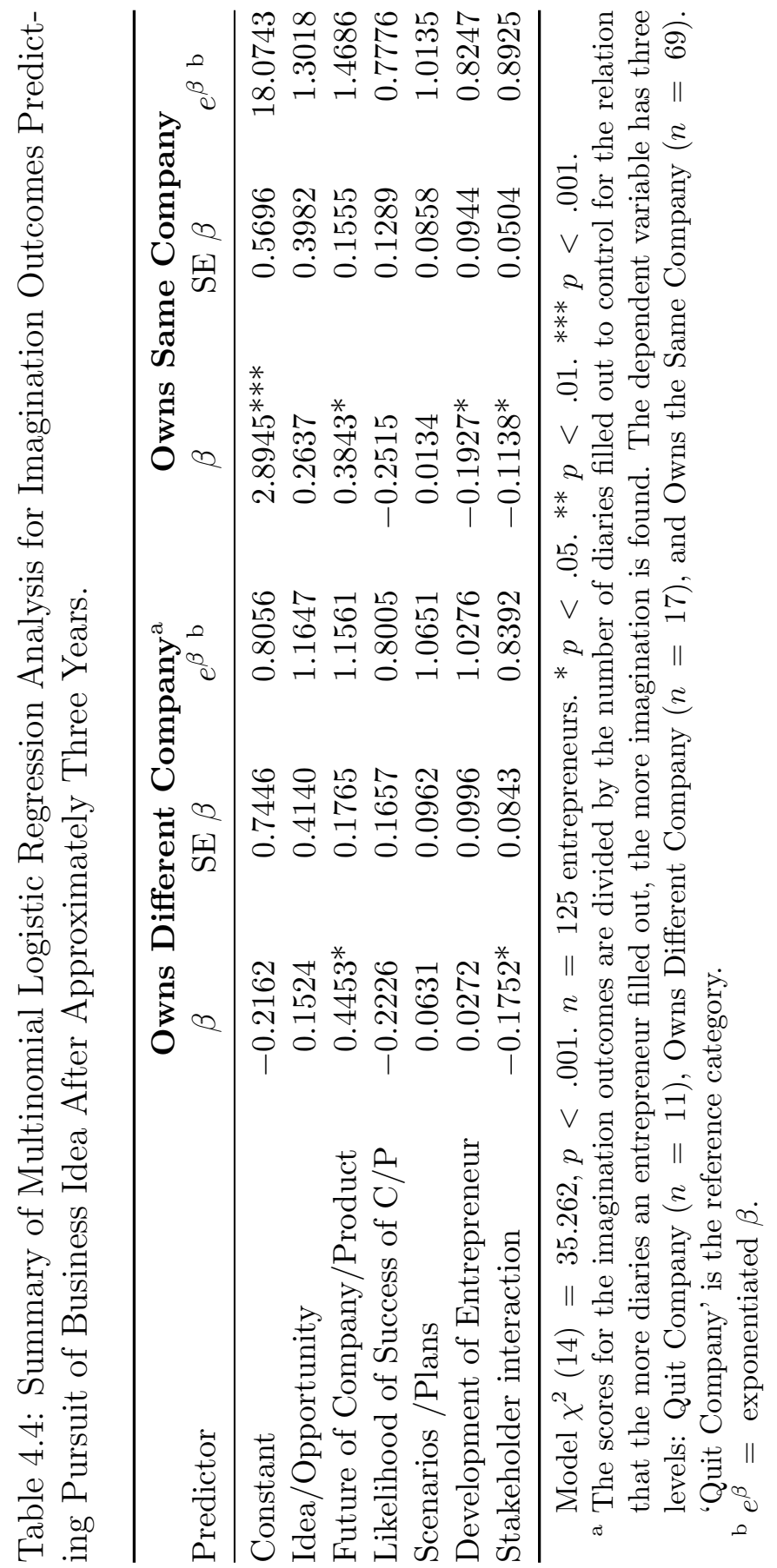


Additionally, we gathered data concerning whether the entrepreneurs $(n=61)$ had made a profit, neither a profit nor a loss, or a loss one year after exiting the incubation program, and therefore one year after filling out the last diary. We performed a multinomial logistic regression on this categorical variable to test whether the imagination process or the imagination outcomes could predict the financial success of the start-up. Unfortunately, this did not give any significant results, probably due to the small sample, which is due to the high amount of missing values on this performance variable.

\subsection{Discussion}

\subsubsection{Implications}

The results of this research have several implications. First, rejecting the general null-hypothesis on the independence of imagination processes and business related uses of imagination, means that certain business related uses of imagination depend on the use of certain imagination processes. With this implication we contribute to the research stream on the use of imagination by entrepreneurs. Because of this research we advice scholars, when researching the use of imagination by entrepreneurs, to be more explicit which imagination process they refer to. Using the term "imagination" or "to imagine" is not enough.

Second, some combinations of imagination processes and business related uses of the imagination occur more often, or less often, than when one would expect an independent relation between imagination processes and imagination uses. Therefore, entrepreneurs use certain imagination process more often for a business re- 
lated use of imagination than other processes. With this implication we contribute to the field of entrepreneurship research. The use of imagination is necessary in most steps in the entrepreneurial process. Our findings show which imagination processes co-occur more often with specific business related uses of imagination.

Third, showing that imagining the future of the company has a positive relation to the chance of pursuing the business idea, means that entrepreneurs who often thought about the future of their company were more often an entrepreneur after a few years than entrepreneurs who did not often think about the future of their company. With this finding we contribute to the literature stream on entrepreneurial success by suggesting that the use of imagination may play an important role.

Fourth, we show that the amount of imagination usage decreases slightly over time. This can be explained by the fact that in the beginning of the venture creation process much is unknown and the use of imagination can provide some information of the possible future. The further one continues in the venture creation process, the more information one gathers, which leads to a decreased need to use one's imagination.

Fifth, we contribute to the literature stream on entrepreneurship education. As our chapter shows that entrepreneurs use their imagination and that there is a positive link to pursuing the business idea, we suggest that entrepreneurship education programs should incorporate the use of imagination in their education programs and stimulate the use of imagination by entrepreneurs. More specifically, these programs should focus on the use of the different imagination processes.

These findings question the results of one of the few empirical findings on imagination in entrepreneurship. Baron (2000a) suggests that entrepreneurs use 
less counterfactual thinking than non-entrepreneurs. Although we did not compare our results to non-entrepreneurs, we do find that counterfactual thinking is the least used imagination process in our sample. However, this does not mean that the use of counterfactual thinking is unimportant. Especially to come up with scenarios for the company, the use of counterfactual thinking was found more often than a random link between imagination processes and outcomes would suspect.

These findings contradict the conceptual findings of Gaglio (2004), who suggests that people engaging in counterfactual thinking are more likely to find opportunities. However, in our sample we did not find an occurrence of counterfactual thinking with idea or opportunity creation.

\subsubsection{Limitations}

We address three limitations of our study. First, the participants in this research were part of an incubation program. They may therefore differ from other entrepreneurs. This limits the external validity. For example, 102 of 125 entrepreneurs $(81.6 \%)$ still run their initial company. Only 11 of 125 (8.8\%) quit their company after on average two and a half year. However, the participants in the incubation program differed in their experience - some did not even have a business idea, others already had a company - which improves the generalizability of our results.

Second, the internal validity of this research may be limited by the fact that not every entrepreneur took the diaries as serious as the other entrepreneurs. This is shown by the fact that not every entrepreneur filled out the diary every week, and by the fact that some entrepreneurs gave very short answers. Although the 
entrepreneurs were asked to fill in the diaries every week, on average the entrepreneurs filled out the diary seven times in ten weeks $(\mu=37.20$ weeks in one year, $\left.\sigma^{2}=12.85\right)$ and some of them filled in the diaries a few times, others almost every week. Our data therefore does not give a complete overview of the use of imagination, but a close proximate of the use of imagination by entrepreneurs. By taking out the entrepreneurs who filled out the diaries less than ten times in a year in our analyses and by not using the absolute number of imagination, but the amount of imagination divided by the amount of diary entries in the regression analyses, we limited the bias in our data. Moreover, some entrepreneurs answered the questions in one or two sentences, whereas wrote multiple paragraphs to each question. This may have biased our data, because the longer the text, the more occurrences of imagination were found. Also the fact that filling out the diaries was a requirement for the entrepreneurs to be allowed to go to classes on various business topics, and the fact that they were reminded of this requirement several times may have influenced the research.

Third, the construct validity of this research may be limited by the fact that the four questions the entrepreneurs had to answer in the diary were not specifically designed to capture the imagination of the entrepreneurs. Besides that, the questions may have steered the entrepreneurs to answer in a specific way that made them think more about prospective thinking and counterfactual thinking as the entrepreneurs were asked about the past week and the coming weeks. On the other hand, these broad questions can also be seen as a strength of this research, as the entrepreneurs were not pushed into using their imagination. Their answers can thus be seen as spontaneous utterances and every instance of imagination that we found to be a pure representation of their imaginative thoughts. Additionally, the 
use of imagination can be studied with other methods than diaries only. Studies that use think aloud protocols or experimental designs may give more information on how the imagination works. However, in this study we were interested in the use of imagination by entrepreneurs in their natural setting, for which diaries are better suited than think aloud or experimental studies. In these diaries the entrepreneurs filled out their main thoughts and ideas, which means they wrote down the most important ideas they could remember. Therefore, we argue, these diaries reflect the entrepreneurs' most important imaginative thoughts. For more limitations on the use of diaries, we refer to the work by Bolger et al. (2003).

\subsubsection{Further Research}

Our findings and implications open several areas for future research. First, we suggest, building on our implications presented before, that scholars should be more specific on what type of imagination is studied, instead of only using the abstract term "imagination". This reduces one of the burdens of studying the use of imagination by managers and entrepreneurs (Frederiks, 2014).

Second, we found that women use significantly less imagination than men. Our finding that there are gender differences in the use of imagination for entrepreneurship corresponds to fact that boys and girls use their imagination in different ways when they imagine themselves as entrepreneurs (Komulainen et al., 2009). Unfortunately, we do not have an explanation for the fact that women use less imagination than men. Additional research may explain these findings.

Third, as our findings show which imagination processes co-occur more often with specific business related uses of imagination, further research in these spe- 
cific areas is need. For example, we found that prospective thinking is related to thinking about opportunities. Therefore, research on opportunity identification may look into the role of prospective thinking. Additionally, we found that counterfactual thinking is related to the development of strategies. Strategy research should there incorporate the concept of counterfactual thinking.

Fourth, some entrepreneurs may use imagination for other imagination outcomes than other entrepreneurs. It would be interesting to see with a cluster analysis whether entrepreneurs can be divided in several groups of 'imaginers'. Some entrepreneurs may turn out to be more 'dreamers' that keep imagining different futures of a company, whereas others may imagine such a future once or twice and then continue to think about how to realize such a future.

Fifth, an advantage of using diaries is that the data is longitudinal. Our dataset captured the use of imagination by entrepreneurs over a one-year period. However, a one-year period may not be enough to capture the full entrepreneurial process for every venture. Therefore, a longitudinal study that captures the use of imagination over a longer period of time may give insight in the use of imagination in the full entrepreneurial process.

Sixth, an advantage of using diaries is that they contain much rich, in-depth data. Therefore, a more qualitative approach may be used to get more information from the dataset. It may give information on, for instance, the situation in which entrepreneurs start to imagine about their company.

Seventh, this study focused on mainly nascent, high-tech entrepreneurs. Further research on how and when experienced entrepreneurs and business managers use their imagination may contribute to a better understanding of imagination in business settings. 


\subsection{Conclusion}

In this chapter we coded the diaries of 193 entrepreneurs in a one-year university related incubation program in the Netherlands. We addressed the relationships between the three imagination processes and the seven business uses of imagination. We found that the imagination processes and business uses of imagination are dependent. This means that entrepreneurs use certain imagination processes more often for certain business uses and less for other business uses.

This research shows that these entrepreneurs mainly use their imagination to imagine a future state of there company, the scenarios and plans to reach that future state, and the (inter)action of the stakeholders that are needed to bring the company to that future state. In this chapter we also found that entrepreneurs mainly use prospective thinking and counterfactual thinking when they use their imagination. To be more specific: when entrepreneurs imagine the future state of the company they mainly use prospective thinking and some counterfactual thinking. When they imagine the scenarios and plans they also use mainly prospective thinking and counterfactual thinking, but already more counterfactual thinking and less prospective thinking then when they imagined the future state. When they then imagine the (inter)action of the stakeholders that they need to make the future state come reality by implementing the scenarios and plans, they also mainly use prospective thinking and some counterfactual thinking, but also perspective taking plays here quite an important role.

The use of imagination in this sample differed by gender: women in this sample were found to be less likely to use their imagination. Additionally, we found that the use of imagination declines over time. In the beginning of the venture creation 
process the use of imagination is more needed due to big uncertainties. Later in the venture creation process more information is available and the use of imagination is less pertinent.

The use of imagination is also a predictor of the pursuit of the business idea of a start-up company. Entrepreneurs that imagined the future of their company and products are more likely to be an entrepreneur after three years, either with the same or a new start-up, compared to entrepreneurs that did not often imagine the future of their company. Imagining how stakeholders will act is a negative predictor of pursuing the business idea. Entrepreneurs that more often imagined how others would act were more likely to quit their company without having started up a new venture after three years.

In closing, we suggest that further research on this topic is important, not only for building and testing theory on this particular topic, but also for focusing more attention on the creative aspects of business and management. For this reason, we hope that our study on the use of imagination by nascent entrepreneurs may contribute to a better understanding of this concept and that other scholars will help us to better understand entrepreneurs' use of the imagination. 


\section{Chapter 5}

\section{Using Imagination to Better}

\section{Identify Business Opportunities?}

\section{An Experimental Study}

A previous version of this chapter has been presented at the $35^{\text {th }}$ Babson College Entrepreneurship Research Conference, June 10-13, 2015 in Wellesley, MA, United States of America. 


\section{$5.1 \quad$ Summary}

Entrepreneurs use their imagination for identifying business opportunities. However, whether the use of imagination has an effect on the quality of the business opportunities that they identify is unknown. In this study, we test the effect of the use of three imagination processes (prospective thinking, counterfactual thinking, and perspective taking) on the quality of a business opportunity identified by the participants. We conducted two studies with an experimental design where we compared three experimental groups and a control group. In each experimental condition, we stimulated the use of one of the three imagination processes using a manipulation. We did not stimulate the use of imagination in the control group. The manipulations we used in the two studies differed, but we find the same result: participants of whom the use of prospective thinking was stimulated identified business opportunities of a higher quality than the participants of whom the use of counterfactual thinking, perspective taking was stimulated or of whom the use of imagination was not stimulated at all. This chapter provides empirical support that the use of imagination, more specifically the use of prospective thinking, is beneficial for identifying business opportunities. A practical implication of this study is that teaching the use of prospective thinking to (potential) entrepreneurs may be beneficial for the business opportunity identification stage.

\subsection{Introduction}

Although many scholars state that entrepreneurs use their imagination (e.g., Baron, 2006; Baron and Ensley, 2006; Chiles et al., 2010; Cornelissen and Clarke, 2010; 
Davidsson, 2015; Foss and Foss, 2008; Foss et al., 2008; Gartner, 2007; Sarasvathy, 2001, 2008; Witt, 1998, 2007), little is known about this concept, nor about its use by entrepreneurs. From previous work we know that imagination consists of three distinct, but related processes (Markman et al., 2009). One imagination process, prospective thinking, is "'pre-experiencing' the future by simulating it in our minds" (Gilbert and Wilson, 2007, p. 1352); another imagination process, counterfactual thinking, is thinking about what might have been (Byrne, 2005); a last imagination, perspective taking, is mentally putting yourself into some else's shoes (Markman et al., 2009).

Some scholars argue that entrepreneurs imagine new business opportunities (Chiles et al., 2010; Cornelissen and Clarke, 2010; Foss and Foss, 2008; Klein, 2008; Olson Jr, 1996), but unfortunately hardly any scholar has studied how entrepreneurs imagine new business opportunities and whether the use of imagination is beneficial at all. One exception is the work by Gaglio (Gaglio and Katz, 2001; Gaglio, 2004), who proposed that entrepreneurs use counterfactual thinking for identifying opportunities. Another exception is the conceptual and empirical work by Baron (Baron, 1998, 2000a,b), who finds mixed results regarding the benefits of counterfactual thinking for opportunity recognition. Therefore, the effect of the use of imagination on the identification of opportunities remains unclear. Hence, our research question in this chapter is: "Does the use of imagination affect the quality of the identified business opportunities"

The aim of this chapter is twofold. First, we aim to understand how the use of imagination, operationalized by its three sub-processes, affects the quality of the business opportunity. Second, using an experimental design, we aim to provide empirical support for the use of imagination by entrepreneurs in general, and the 
benefits of its use for opportunity identification more specifically. We start by building a theoretical framework and generating hypotheses on the effect of the use of imagination on the quality of the business opportunity. As there is no well validated way to stimulate the use of a specific imagination processes in an experimental setting, we test these hypotheses in two studies with two different ways of stimulating the use of imagination processes. At the end of this chapter we will discuss our findings and present our conclusions.

\subsection{Theoretical Framework}

In this section we will present our theoretical framework. Many scholars have written on the topic of business opportunities, as this is a key concept in entrepreneurship literature. Our aim is not to provide a full overview of this literature, but to provide a condensed overview of the key aspects of business opportunities related to the use of imagination. We start by presenting such an overview and then present the literature on the use of imagination by entrepreneurs. We close this section by generating hypotheses based on the use of imagination for identifying business opportunities.

\subsubsection{Business Opportunities}

Business opportunities are at the core of entrepreneurship research (e.g., McMullen et al., 2007; Shane and Venkataraman, 2000) and many definitions of business opportunities have been proposed in the literature (e.g., Herron and Sapienza, 1992; Bhave, 1994; Shane and Venkataraman, 2000; Eckhardt and Shane, 2003). For example, Baron (2006) argues that a business opportunity is "a perceived 
means of generating economic value (i.e., profit) that previously has not been exploited and is not currently being exploited by others" (Baron, 2006, p. 107). Based on that definition, Baron (2006) argues that a business opportunity a) generates economic value; b) is new; and c) is perceived as desirable by potential customers (Baron, 2006). In this chapter we want to distinguish between business opportunities based on the premise that some business opportunities are better than others. Due to this premise, Baron's definition is suitable for this study, because some business opportunities a) can generate more economic value than others; b) can be newer than others; and c) can be perceived more desirable than others (Baron, 2006). Following Baron's (2006) reasoning, a high quality business opportunity is therefore a business opportunity of which the combination of economic value generation, newness, and perceived desirability is higher than other business opportunities.

Many articles have been written discussing whether opportunities are created (Alvarez and Barney, 2007; Alvarez, 2008) or recognized (Baron and Ensley, 2006). Engaging in such a debate is not the aim of this chapter. In fact, regarding the use of imagination for identifying business opportunities, both the recognition approach and the creation approach can be feasible (e.g., Zahra, 2008). One can argue, on the one hand, that entrepreneurs recognize objective opportunities and then use your imagination to imagine how potential customers would react. On the other hand, one can argue that entrepreneurs imagine a business opportunity and then create the circumstances for the opportunity to be profitable. In this chapter we aim to explore the effect of the imagination processes on the quality of a business opportunity, regardless of the process through which the opportunities are identified. Based on DeTienne and Chandler (2004), who argue that oppor- 
tunity identification is the overall term for identifying opportunities, regardless whether identification takes place through active search, passive search, fortuitous discovery, or creation, we refer to neither opportunity recognition nor creation, but to opportunity identification.

How entrepreneurs identify opportunities has been explained with entrepreneurial alertness (Busenitz, 1996) or pattern recognition (Baron and Ensley, 2006). Following Cornelissen and Clarke (2010), we argue that some of these explanations overemphasize the individual and his or her cognitive abilities (e.g., Kirzner, 1999; Kaish and Gilad, 1991; Baron and Ensley, 2006), whereas other explanations overemphasize the context or environment such an entrepreneur is in (e.g., Aldrich and Fiol, 1994). (Cornelissen and Clarke, 2010) argue, from a sensemaking approach, that the interaction between the individual and his/her context leads to the identification of opportunities. Entrepreneurs then "operate at the edge of what they do not know" (Hill and Levenhagen, 1995, p. 1057). They therefore need to make sense out of their current situation. By then imagining possible futures (Gilbert and Wilson, 2007) and hence opportunities (Cornelissen and Clarke, 2010), entrepreneurs act based on these mental images (McMullen and Shepherd, 2006; Mitchell and Shepherd, 2010). The use of imagination is therefore one way to explain how entrepreneurs identify opportunities. In the following section we will elaborate on what imagination is and how it can be used to identify high quality business opportunities. 


\subsubsection{Imagination}

The verb 'to imagine' and the nouns 'imagination' and 'mental simulation' have no commonly accepted definition. In previous research, imagination has been defined as a faculty in the brain, a cognitive process, or as an outcome of cognitive processes (e.g., Loasby, 2001; Schau, 2000; Beach and Mitchell, 1987; Mills, 1959). In this study we will use the process description of imagination, because only the process approach allows us to study the use of imagination by entrepreneurs. Mills, for example, defines imagination as 'putting together hitherto isolated items, by finding unsuspected connections' (Mills, 1959, p. 201). Imagination generates a simulation of a series of actions and events in concrete and specific form (Taylor et al., 1998). These events seem real due to the fact that imagination tends to be bounded by what is plausible (Kahneman and Miller, 1986; Taylor et al., 1998). Therefore, the outcomes of imagination can function as a plan and are plausible and relevant to real-world problem solving activities (Taylor et al., 1998). Previous research has shown that imagination processes only start to develop in human beings from the age of three or four years old on (Atance and O'Neill, 2005), are based on memory (Schacter et al., 2007), and are performed when the mind is not perceiving the present (i.e. the stimulus is not present) (Buckner and Carroll, 2007; Chiu, 1989). Imagination is used to construct and reconstruct the past and the future in the present (Johnson and Sherman, 1990). Construction refers to "creating a past and future in the present" and reconstruction refers to "altering (distorting) our memory for or anticipation of what has been created" (Johnson and Sherman, 1990, p. 483).

Following Markman et al. (2009), we argue that imagination consists of three 
sub-processes: prospective thinking, counterfactual thinking, and perspective taking.

\subsubsection{Prospective Thinking}

First, prospective thinking, is the "ability to 'pre-experience' the future by simulating it in our minds" (Gilbert and Wilson, 2007, p. 1352). Kahneman and Tversky (1982) distinguish between three categories of prospective thinking. The first category of prospective thinking is prediction. Prediction starts with the current, specified situation and generates the most likely future situation. An example is imagining whether two people, whom you know well, but whom do not know each other, may get along well (Kahneman and Tversky, 1982).

The second category of prospective thinking is assessing the probability of a specified event. This category differs from prediction, because prediction assumes a specified, currently existing situation, and a non-specified, imagined future situation, whereas assessing the probability of a specified event assumes a specified, currently existing situation, and a specified, non-existing future situation. Prediction therefore focuses on imagining the future situation, whereas with assessing the specified event one imagines the ease with which the specified future event can be reached, within the constraints of a realistic model of the economic situation and market conditions (Carroll, 1978; Tversky and Kahneman, 1973).

The third and last category of prospective thinking is assessing conditioned probabilities. Entrepreneurs may ask themselves: "If the economy goes into a double-dip, what are the likely consequences for my company?" This mental simulation assumes a specified, not currently existing starting situation and an imagined future situation. To run such a mental simulation, one needs to imagine how 
to get from the current situation to the specified starting situation. Only when one can mentally bridge that gap, one can run such a simulation (Kahneman and Tversky, 1982).

\subsubsection{Counterfactual Thinking}

Counterfactual thinking is imagining "what might have been" in a given situation. Kahneman and Tversky (1982) distinguish between two categories of counterfactual thinking. The first category is counterfactual assessment. One can use counterfactual simulations to 'modify' a past event and simulate what would have happened and how it might have affected the present (Roese, 1997). If two events happen after each other - event $A$ happens first, event $B$ happens afterwards one can use counterfactual assessment to see how event $B$ looks like, if event $A$ would have been different.

The second category is assessment of causality. With assessment of causality, there is a pre-specified event $B$ and one mentally tests whether event $B$ would still be possible if event $A$ was changed (Kahneman and Tversky, 1982). An example of an assessment of causality would be: "would we still have made a loss (event $B$ ), if we had not merged with that company we bought three years ago (event A)?"

\subsubsection{Perspective Taking}

The third imagination process is perspective taking. With perspective taking, one puts oneself in someone else's position. Perspective taking is a cognitive process that is highly related to, but distinct from, empathy, which is an intuitive emotional aspect (Lamm et al., 2007). Using perspective taking, one can imagine the actions 
and feelings of other people. Moreover, perspective taking can also be used to imagine oneself being in the situation of another. Perspective taking can be useful to entrepreneurs when they, for instance, imagine how potential customers would use a possible new product or service.

\subsubsection{The Use of Imagination and the Quality of the Business Opportunity}

In this section we further we explore the relationship between the use of imagination and the quality of the business opportunities. As mentioned before, prospective thinking is used to imagine possible futures (Gilbert and Wilson, 2007). By using prospective thinking, entrepreneurs can imagine possible futures based on developing and exploiting a business opportunity (Felin and Zenger, 2009). They can, for instance, test whether pursuing a specific business opportunity is beneficial or not. By actively thinking upfront about these issues, potential entrepreneurs mentally 'test' multiple possible business opportunities and disregard the unfeasible opportunities. Potential entrepreneurs select the opportunity they regard to be the best and test in practice if the potential entrepreneur decides to pursue this opportunity. Therefore, we hypothesize that:

Hypothesis 5.1. Individuals who use prospective thinking while thinking of a business opportunity, think of a business opportunity of higher quality than individuals who do not actively use their imagination at all.

The use of counterfactual thinking may also have a beneficial effect on the quality of the business opportunity. Gaglio (2004) argues that opportunity finders engage sooner in counterfactual thoughts and generate more counterfactuals than 
non-finders. Additionally, she argues that opportunity finders generate counterfactuals that are based on unusual or unexpected events. The counterfactuals that are based on unusual or unexpected events may lead to business opportunities that one has not thought of before and which could be better a business opportunity than the opportunities one has thought of before. Therefore, we hypothesize that:

Hypothesis 5.2. Individuals who use counterfactual thinking while thinking of a business opportunity, think of a business opportunity of higher quality than individuals who do not actively use their imagination at all.

By taking the perspective of different stakeholders, potential entrepreneurs can mentally test whether important stakeholders like potential customers, investors, and suppliers, are interested in this business opportunity (McMullen, 2010). By taking the perspective of the potential customers, an entrepreneur may argue why and why not a customer may be interested in buying the product or service. This gives valuable information to the potential entrepreneurs, who can adjust their ideas based on the information they got from the perspective taking activity. Therefore, we hypothesize that:

Hypothesis 5.3. Individuals who use perspective taking while thinking of a business opportunity, think of a business opportunity of higher quality than individuals who do not actively use their imagination at all.

An overview of the proposed hypotheses can be found in Figure 5.1. 


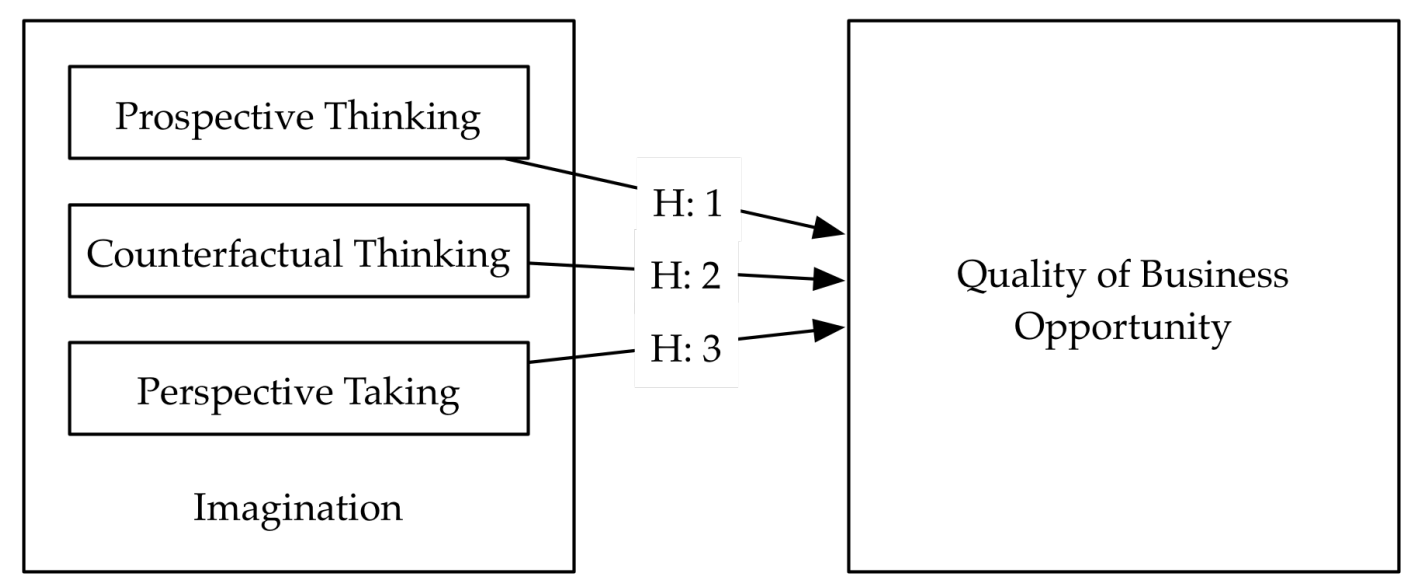

Figure 5.1: Conceptual Model

\subsection{Methods}

As there is no validated approach to stimulate the use of imagination in an experimental setting, we chose to use two different manipulations in our experimental design to stimulate the use of imagination. By using two different manipulations to stimulate the use of imagination, we aim to increase the construct validity of our research. In the two studies we focus on studying business opportunity identification with potential entrepreneurs. Potential entrepreneurs are individuals who might engage in entrepreneurial activities, but currently do not have experience in entrepreneurial activities, such as opportunity identification. Following this reasoning, we chose to assess the use of imagination of university students who are interested in entrepreneurship. According to the literature, university students have a high entrepreneurial intention (Bae et al., 2014) and are therefore likely to become entrepreneurs, but have less entrepreneurial experience than entrepreneurs. To increase the chance that these students will become entrepreneurs, and therefore are currently potential entrepreneurs, we asked students who joined 
an entrepreneurship elective, to participate in these studies.

In both studies we conducted a survey-based experiment in which we used a basic randomized between-groups design comparing three conditions (prospective thinking, counterfactual thinking, and perspective taking) and a control group. The participants were randomly assigned to a condition. Because technological innovation is a source for business opportunities (Shane, 2001) we use the description of a technological innovation as a starting point for identifying business opportunities in both studies.

We performed the statistical analyses in R (R Core Team, 2014) ${ }^{1}$.

\subsection{Study 1}

We start by giving an overview of the methods we used in study 1 . We then continue by presenting the results of this study. Afterwards we will present the methods and results of study 2. Subsequently we will discuss our findings of both studies and draw our conclusions.

\subsubsection{Methods}

\subsubsection{Participants}

The sample in study 1 consists of a total of 162 students $(73.5 \%$ male; age $\mu=$ 22.97 years, $\sigma^{2}=2.90$ ) from two universities in the Netherlands, see Table 5.1. We did not find differences between the two samples, regarding nationality and entrepreneurial experience. We did find differences regarding gender, age and study

\footnotetext{
${ }^{1}$ For the analyses we made use of the following R-packages: multilevel (Bliese, 2013), and psych (Revelle, 2015)
} 
level. The difference in age and study level may be explained by the fact that, at one of the universities, the entrepreneurship elective was open for bachelor students only, whereas at the other university the elective was open for both bachelor and master students. The fact that master students in general are older than bachelor students, can explain these differences. As both age and gender neither have an effect on, nor are significantly related to the dependent variables of this study, the analyses of this study are based on the full sample of both universities.

Baseline homogeneity tests showed no significant differences between the conditions, see Table 5.2. More background information of our sample can be found in Table 5.1 and Table 5.2.

\subsubsection{Manipulation Task}

We gave the participants separate, but related, manipulation tasks for each condition (prospective thinking condition, counterfactual thinking condition, perspective taking condition, and control group). The aim of these tasks was to trigger the use of one of the three imagination processes (for the experimental groups) or no imagination trigger at all (control group). In the following sections we present a description of the manipulation task for each condition.

Prospective Thinking Condition In the prospective thinking condition participants were asked to write down three possible implant technologies that, to the best of their knowledge, do not yet exist, but which they think could be invented in the coming ten years. This way, the participants were triggered to imagine future applications of implant technologies. By prescribing the same industry to every participant, only the use of prospective thinking varies. 


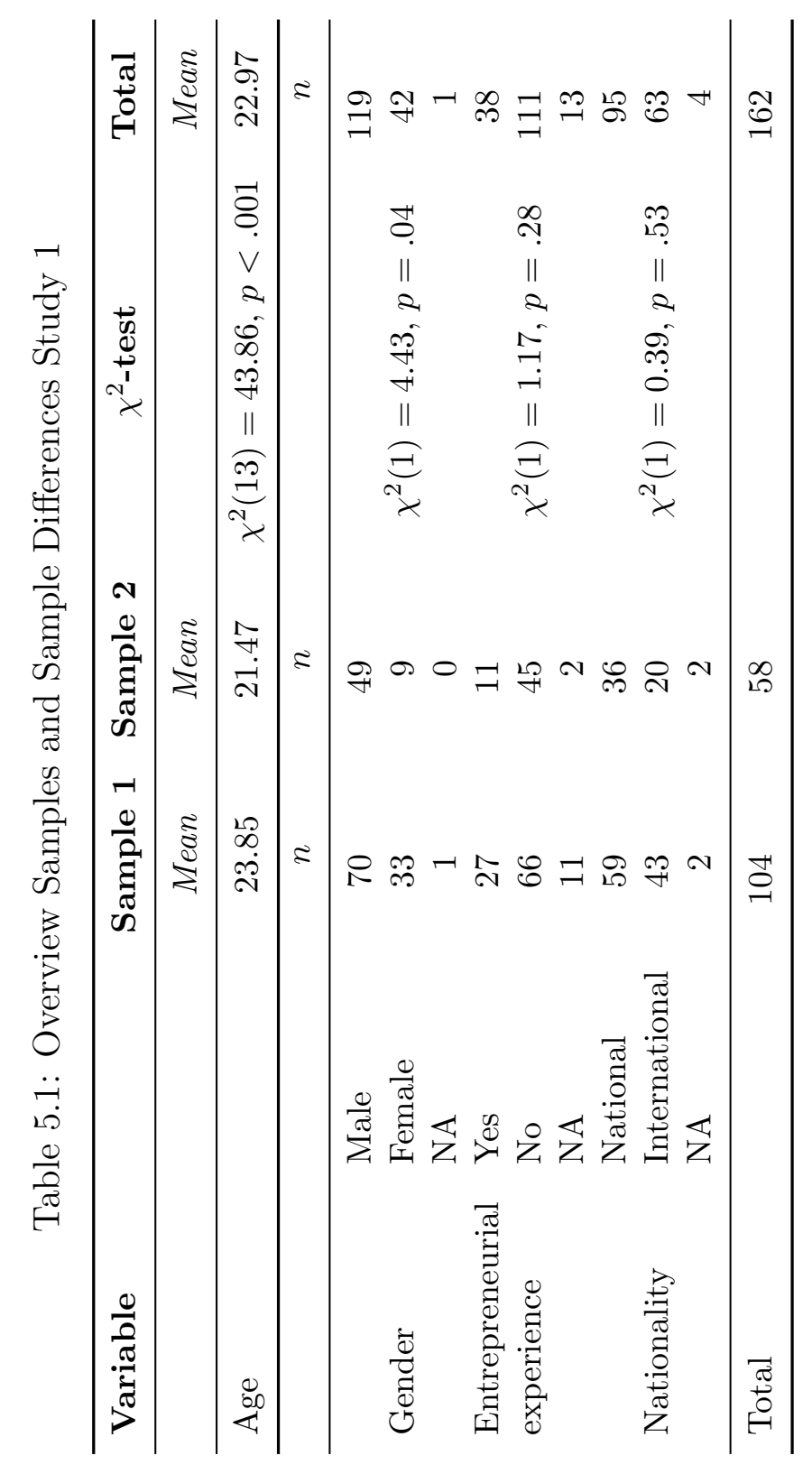




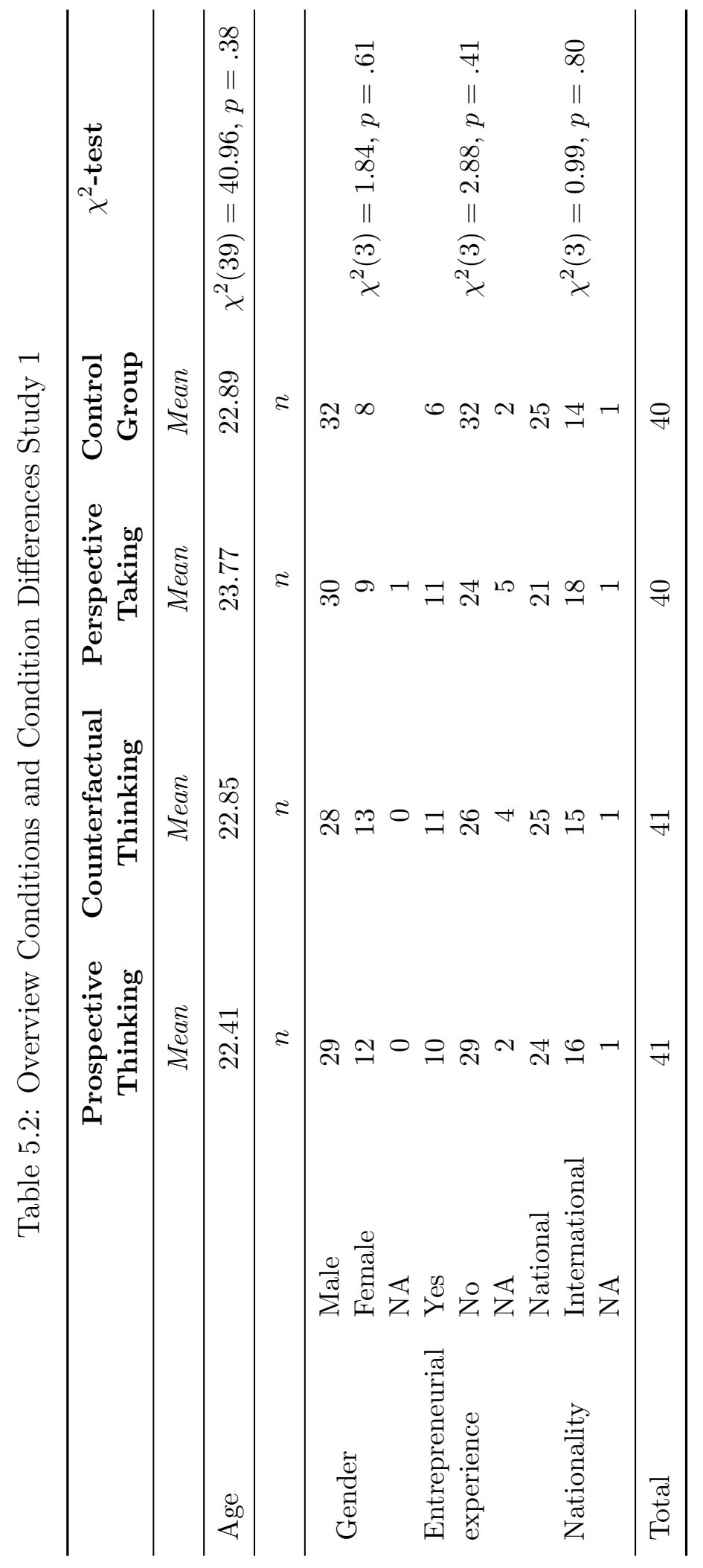


Counterfactual Thinking Condition In the counterfactual thinking condition the participants were asked 1) to suppose that artificial lungs would be a normal and widely used and accepted technology in our current society, and 2) write down the consequences this would have for our current way of living. With this question we ask the participants to assume a non-existing alternative situation (i.e. artificial lungs are a widely used and accepted technology), and from that alternative situation the participants are triggered to imagine the consequences. By making the alternative situation a predetermined situation, only the use of counterfactual thinking to imagine the consequences of this counterfactual situation varies.

Perspective Taking Condition In the perspective taking condition the participants were asked to 1) to think of a, to the best of their knowledge, not existing implant technology for deaf-mute people, 2) put themselves into the position of a deaf-mute person, 3) to argue from that point of view how that technology works and how it would improve "their" life. An additional remark was given in which they were told that the technology is not able to remove the causes, nor the physical symptoms of neither the hearing-impaired, nor mute people, to prevent the answer that the technology would help the deaf-mute people to be able to hear and speak. With this question we ask the participants to put themselves into the position of a person of a very specific group (deaf-mute people) and argue how their life can be improved by using implant technologies. Hereby we trigger the participants to mentally put themselves into the shoes of a predetermined group 
of people. Very few participants have experience with deaf-mute people, but many people can imagine to some extent how it is to not be able to talk and speak.

Control Group Condition In the control group the participants were asked to write down three different implant technologies that are currently available. By answering this question, participants rely on their memory instead of their imagination. This question is suitable for the control group condition, because no use of imagination is triggered.

One could argue that the manipulation of the conditions was not equal, in the sense that participants in the prospective thinking had more freedom the use their imagination, than the participants in the other conditions. However, we chose to limit the freedom in the counterfactual thinking and perspective taking conditions to make sure that possible differences between the conditions are caused by the use of the specific process of imagination, and not by other factors. For example, by not limiting the use of perspective taking to a specific sub-group (i.e. deaf-mute people), one can argue that participants could put themselves into the shoes of a person they know very well. Then they would not have used their imagination, but their knowledge and memory. By predetermining the type of person the participants should imagine themselves to be, the participants should use their perspective taking, instead of their knowledge.

\subsubsection{Experimental Task}

The experimental task consisted of describing, in one's own words, a high-quality business opportunity. The high-quality business opportunity should be based on the invention of "flexible glass that can be bent, folded, and rolled up and will not 
break". We gave participants the same description of a newly invented technology so comparison between the business opportunities they identified based on that new technology was possible. The participants were informed that a high-quality business opportunity is a business opportunity, which 1) has potential economic value, 2) is new, and 3) is perceived as desirable by potential customers. After describing the business opportunity participants were asked to argue based on these three criteria why their business opportunity is a high quality business opportunity according to them.

The participants identified, based on the invention of bendable, foldable, rollable, and unbreakable glass, many different business opportunities. Some opportunities were mentioned often: fifty participants $(30.9 \%)$ thought of a foldable, unbreakable smartphone or tablet, and ten participants $(6.2 \%)$ thought of unbreakable spectacles. Fifty-one participants (31.5 \%) came up with business opportunities that were unique in this sample. Examples of such business opportunities are glass windows for earthquake sensitive areas, lab equipment for scientific experiments, and a foldable glass cover that keeps one dry in the rain, but does not block one's view.

\subsubsection{Measures}

Manipulation Check To check whether our manipulations of the imagination process conditions were successful, we asked participants at the end of the experimental task to what extend they considered they engaged in any of the three imagination processes. We developed an imagination scale consisting of six items (Cronbach's $\alpha=.70$ ). For prospective thinking a two-item scale was used (Cronbach's $\alpha=.65)$. An example of an item is "During [the manipulation task] I 
tried to think of the future of the implant technology industry." For counterfactual thinking a three-item scale (Cronbach's $\alpha=.68$ ) was used. "During [the manipulation task] I tried to think of several possible scenarios" is an example of such an item. For perspective taking a one-item scale was used: "During [the manipulation task] I tried to put myself in the shoes of the end customer." The participants answered these items on a 5-point scale ranging from 1 (not at all) to 5 (completely). The participants were asked to fill out these items after both the manipulation and the experiment tasks were completed to avoid priming.

We conducted three one-way analysis of variance tests on the use of the three imagination processes for the three experimental condition and the control group condition. Each test was followed by a post-hoc analysis using Tukey's HSD test. The results can be found in Table 5.3. First, the use of prospective thinking was significantly different in the four conditions $(F(3,152)=14.59, p<.001$, $\eta^{2}=.22$ ). The use of prospective thinking in the prospective thinking condition is significantly higher $(p=.02)$ than in the counterfactual thinking condition, significantly higher $(p<.001)$ than in the perspective taking condition, and significantly higher $(p<.001)$ than in the control group. We conclude that our manipulation of prospective thinking was successful.

Table 5.3: Overview Manipulation Check Study 1

\begin{tabular}{lccccccccc}
\hline $\begin{array}{l}\text { Use of } \\
\text { Imagination }\end{array}$ & \multicolumn{2}{c}{$\begin{array}{c}\text { Prospective } \\
\text { Thinking }\end{array}$} & \multicolumn{2}{c}{$\begin{array}{c}\text { Counterfactual } \\
\text { Thinking }\end{array}$} & $\begin{array}{c}\text { Perspective } \\
\text { Taking }\end{array}$ & \multicolumn{2}{c}{$\begin{array}{c}\text { Control } \\
\text { Group }\end{array}$} & F-test \\
\hline & Mean & S.D. & Mean & S.D. & Mean & S.D. & Mean & S.D. \\
\hline Prospective thinking & 4.18 & 0.53 & 3.54 & 1.02 & 3.24 & 1.09 & 2.78 & 1.07 & $14.59^{* * *}$ \\
Counterfactual thinking & 3.44 & 0.88 & 3.59 & 0.81 & 3.23 & 0.85 & 2.97 & 1.07 & $3.43^{*}$ \\
Perspective taking & 3.86 & 1.07 & 4.03 & 1.09 & 4.49 & 0.60 & 2.88 & 1.22 & $17.41^{* * *}$ \\
\hline
\end{tabular}

$* p<.05 .{ }^{* *} p<.01 .{ }^{* * *} p<.001$. 
Second, the use of counterfactual thinking was significantly different in the four conditions $\left(F(3,153)=3.43, p=.02, \eta^{2}=.06\right)$. The use of counterfactual thinking was significantly higher $(p=.02)$ in the counterfactual thinking condition than in the control group. The use of counterfactual thinking was not significantly higher $(p=.89)$ in the counterfactual thinking condition than in the prospective thinking condition, and not significantly higher $(p=.30)$ than in the perspective taking condition. These results provide evidence for partial manipulation success of counterfactual thinking.

Last, the use of perspective taking was significantly different in the four conditions $\left(F(3,152)=17.41, p<.001, \eta^{2}=.26\right)$. The use of perspective taking was significantly higher $(p=.04)$ in the perspective taking condition than in the prospective thinking condition, and significantly higher $(p<.001)$ than in the control group. The use of perspective taking was not significantly higher $(p=.20)$ in the perspective taking condition than in the counterfactual thinking condition. These results provide evidence for partial manipulation success of perspective taking.

High-Quality Business Opportunity To assess the potential economic value of the business opportunity, we asked two independent coders, experienced in evaluating business opportunities, to rate each business opportunity. One coder is an investor, the other coder is experienced in judging business plans. The coders were asked to indicate to what extent they agree with the statement "The business opportunity has potential economic value". They answered using a 7-point scale ranging from 1 (strongly disagree) to 7 (strongly agree).

To assess the newness of the business opportunity, the same coders were asked 
to rate to what extent they agree with the statement "The business opportunity is new" on the same 7-point scale, also ranging from 1 (strongly disagree) to 7 (strongly agree). These coders assessed the perceived desirability of the business opportunity by rating to what extent they agree with the statement "The business opportunity is perceived as desirable by potential customers", also on a 7-point scale ranging from 1 (strongly disagree) to 7 (strongly agree).

In line with prior work, we defined a high-quality business opportunity as a business opportunity that has joint potential economic value, newness, and is perceived as desirable by potential customers (Baron, 2006). This means that when a business opportunity scores low on at least one of these criteria, the business opportunity is not considered to be of high quality. Therefore we multiplied the scores on potential economic value, newness, and perceived desirability to obtain an overall measure of the quality of the business opportunity (see Hoever et al., 2012, for a similar procedure).

To determine the inter-rater reliability and inter-rater agreement we calculated the intraclass correlation coefficients $(I C C)$ and $r_{w g}$ values (Bliese, 2000; James et al., 1984). The results show good inter-rater reliability and inter-rater agreement (LeBreton and Senter, 2007; Woehr et al., 2015): potential economic value $I C C(1)=.32, I C C(2)=.99$, mean $r_{w g}=.56$; newness $I C C(1)=.16, I C C(2)=$ .97 , mean $r_{w g}=.63$; perceived desirability $\operatorname{ICC}(1)=.11, I C C(2)=.95$, mean $r_{w g}=.71$.

\subsubsection{Procedures}

Prior to the class, the students were informed that during this class they would be asked to participate in a research on entrepreneurship. During the class, the study 
was briefly introduced and the students were informed that their participation was not compulsory or in any way related to the evaluation of the course. After this introduction the surveys for data collection were handed out at the beginning of the class. We divided the four different surveys randomly among the students. Additionally, we instructed the students to fill out these surveys individually. The survey took about 15 minutes to be filled out. After collecting all the surveys the first author debriefed the students by telling them what the goal of this research was and he gave a short lecture on the use of imagination by entrepreneurs.

\subsubsection{Results}

Table 5.4 shows the descriptive statistics and the correlations for the variables in this study. We dummy-coded the variables gender $(0=$ male $)$, nationality $(0=$ national students), and entrepreneurial experience $(0=$ yes $)$.

To test whether the use of imagination has an influence on the quality of the business opportunity, we performed a one-way analysis of variance test, see Table 5.5. We found that there were significant differences in the quality of the business opportunities between the four conditions $(F(3,120)=2.91, p=.04$, $\left.\eta^{2}=.06\right)$. To verify between which groups there were differences on the quality of the business opportunity, we performed post-hoc comparisons using Tukey's HSD test. First, we found that the quality of the business opportunities in the prospective thinking condition is significantly higher than in the control group $(p=.03)$. These results support Hypothesis 5.1.

Second, we found that the quality of the business opportunities in the counterfactual thinking condition is not significantly higher $(p=.41)$ than in the control 


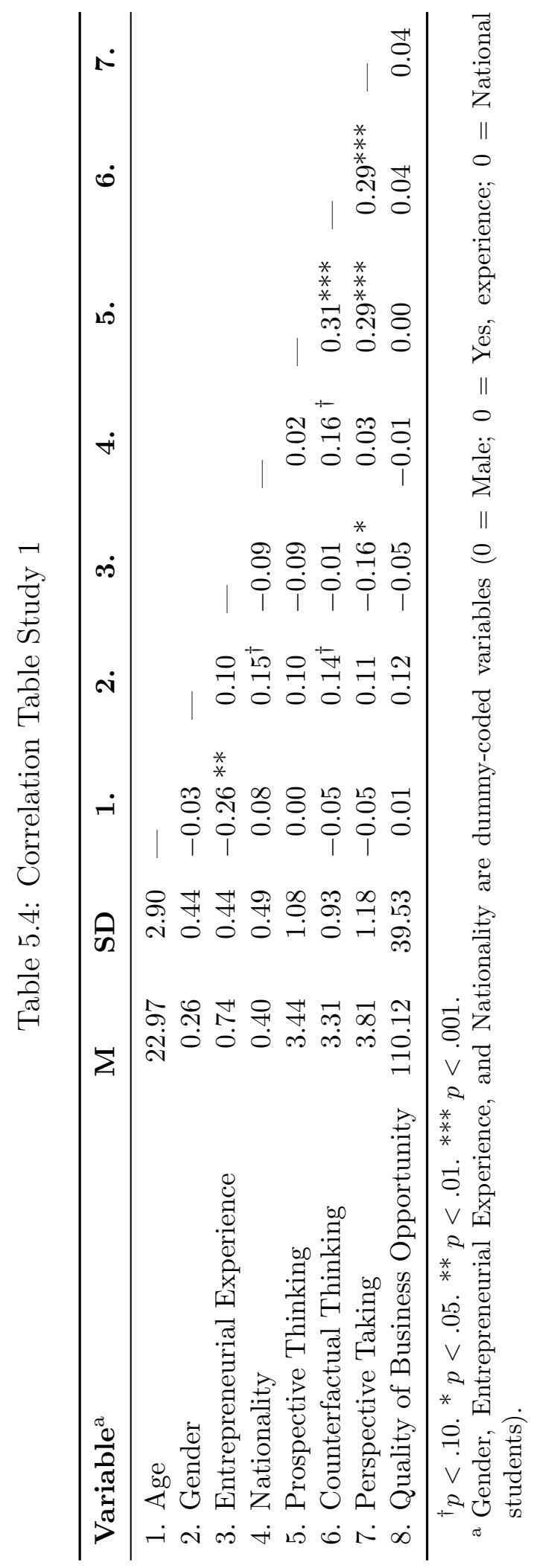




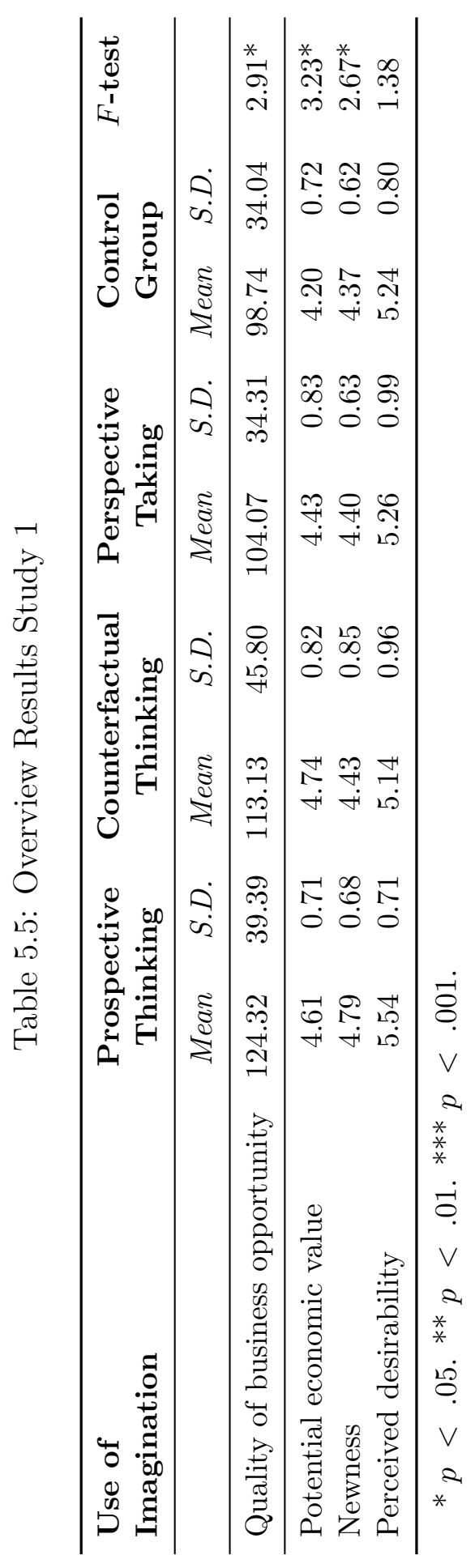


group. These results do not support Hypothesis 5.2. Third, we found that the quality of the business opportunity in the perspective taking condition is not significantly higher $(p=.94)$ than in the control group. These results do not support Hypothesis 5.3. The differences between the other conditions were not significant.

Additionally, we tested the effect of the imagination processes on each single criteria of the quality of the business opportunities by performing three one-way analysis of variance tests. We found that the condition had a significant effect on the potential economic value of the business opportunity $(F(3,138)=3.23$, $\left.p=.02, \eta^{2}=.07\right)$. Post-hoc analyses with Tukey's HSD test showed that counterfactual thinking had a significant effect $(p=.02)$ on the potential economic value of a business opportunity compared to the control group. Additionally, we found that the condition had a significant effect on the newness of a business opportunity $\left(F(3,137)=2.67, p=.05, \eta^{2}=.06\right)$. Post-hoc analyses with Tukey's HSD test showed that prospective thinking had a significant effect $(p=.07)$ on the newness of a business opportunity compared to the control group. Both the differences between the other conditions for the potential economic value and newness were not significant, as well as the differences between the conditions for the perceived desirability of a business opportunity.

\section{$5.6 \quad$ Study 2}

We will now present the methods and the results of the second study. As noted before, afterwards we will discuss the findings of both studies. 


\subsubsection{Methods}

\subsubsection{Participants}

The sample in study 2 consists of a total of 137 students $(67.9 \%$ male; age $\mu=$ 21.22 years, $\sigma^{2}=1.88$ ) from both a technical study program and an international business study program in a university in the Netherlands, see Table 5.6. Baseline homogeneity tests showed no significant differences between the conditions, see Table 5.7. More background information of our sample can be found in Table 5.6 and Table 5.7.

\subsubsection{Manipulation Task}

Analogous to study 1, the participants in this study received separate manipulation tasks for each condition. We describe the manipulation task in more depth in the follow sections.

Anagram Task Following Sanna $(1996,1998)$, the participants in the counterfactual condition had to perform an anagram task. However, to keep the conditions comparable in length and cognitive effort, we decided to include this anagram task for all conditions. We randomly selected twenty anagrams from Gilhooly and Johnson (1978) and asked the participants to solve these anagrams within nine minutes (Sanna, 1996). The participants answered on average 10.26 anagrams correctly $\left(\sigma^{2}=4.17\right)$; three participants answered all anagrams correctly. No significant differences were found in the number of correct answers to the anagram task between the conditions $(F(3,133)=0.89, p=.45)$. 


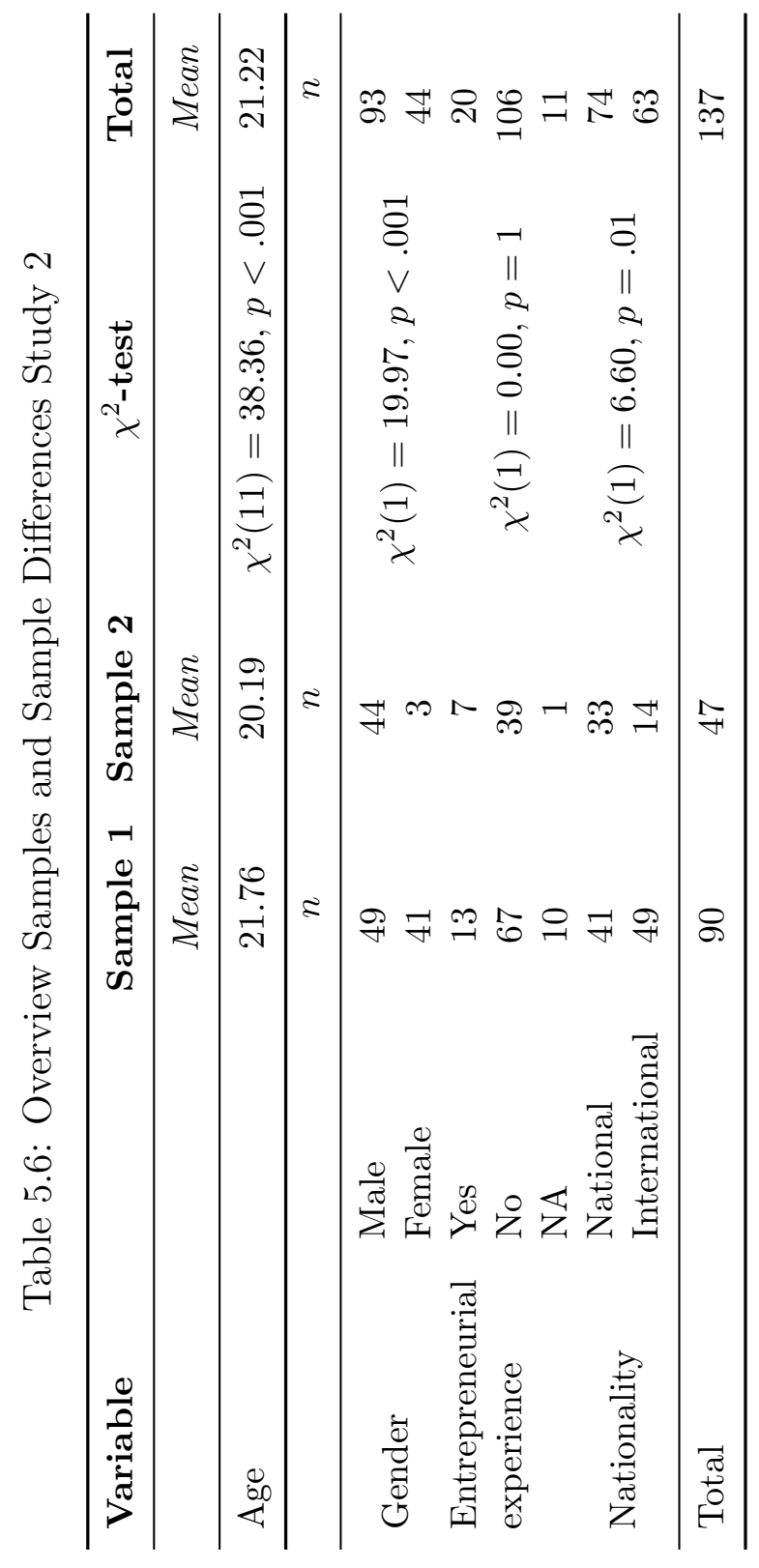




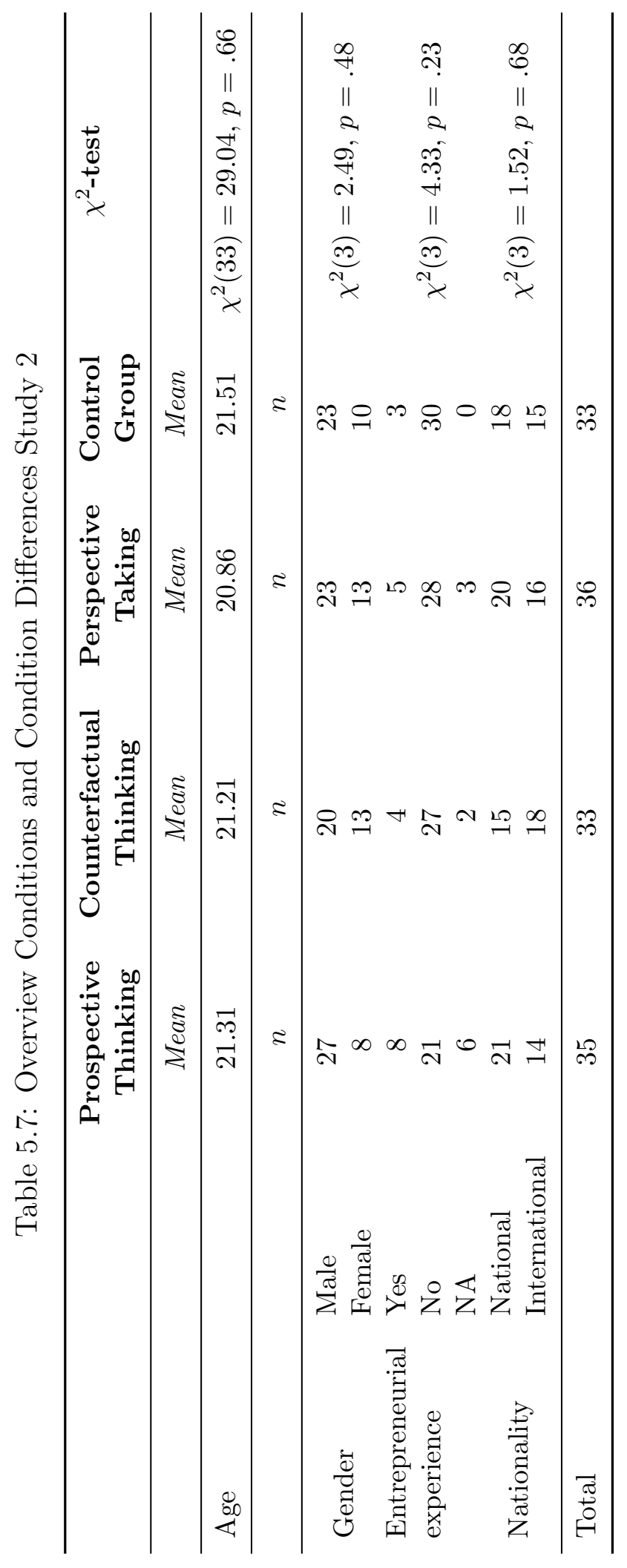


Prospective Thinking Condition In the prospective thinking condition participants filled out the Subjective Probability Task (MacLeod et al., 1996). In this task, participants are asked to judge how probable it is that certain future events will happen to them. This task stimulates participants to think about how their future may be and therefore stimulates prospective thinking. By having the participants explicitly focus on their own future, perspective taking thoughts are being reduced.

Counterfactual Thinking Condition For the manipulation task in the counterfactual thinking condition we followed the procedure described by Sanna (1996). We asked the participants to generate and write down "what if...?" and "if only..." thoughts about their performance on the aforementioned anagram task. We explained that these thoughts can either be about how their performance could have been better or could have been worse (Sanna, 1996).

Perspective Taking Condition For the manipulation task in the perspective taking condition we followed the procedure described by Galinsky and Ku (2004). We showed a color picture of a young woman sitting on a couch and asked the participants to take the perspective of the individual on the picture, to imagine how a typical day for this individual would look like, and to write down a typical day for this person in as much detail as possible.

Control Group Condition In the control group condition we did not want to stimulate imaginative thoughts at all. We therefore asked the participants to fill out a personality test. Due to the international background of our sample, we chose the International English Big Five Mini-Markers by Thompson (2008). 


\subsubsection{Experimental Task}

Comparable to study 1, the participants were asked to describe, in their own words, a high-quality business opportunity based on a technology we described. We followed Grégoire et al. (2010) by presenting the invention of SMART ${ }^{\circledR}$ (SelfMastery and Regulation Training) by NASA, which "could revolutionize the way all sorts of people could improve their attention and concentration skills." (Grégoire et al., 2010, p. 428). We gave all participants the same technology, so we could compare the business opportunities. After the participants described their business opportunity, we asked them several clarification questions, inspired by the lean canvas (Maurya, 2012), to get a more complete understanding of the business opportunity of which they thought:

1. What is the product or service?

2. What problem(s) will it solve? Please explain.

3. Who are the target customers? Please explain.

4. What value does this deliver to the customer? Please explain.

5. How does it solve this/these problem(s)? Please explain.

6. Via which channel(s) will this product or service be sold? Please explain.

7. How will it generate revenues? Please explain.

8. What are the most important costs? Please explain.

9. What are the key activities that will be involved in setting up this business? Please explain. 
10. What is the competitive advantage of the product? Please explain.

\subsubsection{Measures}

Manipulation Check To check our manipulations, we developed an 11-item scale (Cronbach's $\alpha=.81$ ). For the prospective thinking condition we selected and adapted four items from the Impact of Future Events Scale by Deeprose and Holmes (2010) (Cronbach's $\alpha=.85$ ). An example of an item is "During [the manipulation task] I believed my thoughts about the future would definitely happen." For the counterfactual thinking condition we selected and adapted three items from the Counterfactual Thinking for Negative Events Scale by Rye et al. (2008) (Cronbach's $\alpha=.87$ ). An example of an item is "During [the manipulation task] I thought about how much better I could have performed if I had acted differently." We selected and adapted four items from a perspective taking manipulation check scale by Hoever et al. (2012) (Cronbach's $\alpha=.82$ ). An example of an item is "During [the manipulation task] I tried to take the perspective of someone else." The participating answered these items on a five-point scale which ranged from 1 (Never) to 5 (Very often). The participants were asked to fill out these items after both the manipulation and the experiment tasks were completed to avoid priming.

We conducted a one-way between-subjects analysis of variance to compare the effect of the condition on the use of prospective thinking in the prospective thinking, counterfactual thinking, perspective taking, and control group conditions, see Table 5.8. We found a significant effect of the condition on the use of prospective thinking for the four conditions: $F(3,125)=4.15, p=.008, \eta^{2}=.09$. Post-hoc comparisons using Tukey's HSD test indicated that significant differences in the 
use of prospective thinking could be determined between the prospective thinking and perspective taking conditions $(p=.005)$, between the prospective thinking and counterfactual thinking conditions $(p=.09)$, and between the prospective thinking and control condition $(p=.07)$. Hence, the manipulation of prospective thinking was successful at a $p<.10$ level.

Table 5.8: Overview Manipulation Check Study 2

\begin{tabular}{lrrrrrrrrr}
\hline $\begin{array}{l}\text { Use of } \\
\text { Imagination }\end{array}$ & \multicolumn{2}{c}{$\begin{array}{c}\text { Prospective } \\
\text { Thinking }\end{array}$} & \multicolumn{2}{c}{$\begin{array}{c}\text { Counterfactual } \\
\text { Thinking }\end{array}$} & $\begin{array}{c}\text { Perspective } \\
\text { Taking }\end{array}$ & \multicolumn{2}{c}{$\begin{array}{c}\text { Control } \\
\text { Group }\end{array}$} & F-test \\
\hline & Mean & S.D. & Mean & S.D. & Mean & S.D. & Mean & S.D. \\
\hline Prospective thinking & 3.12 & 0.79 & 2.48 & 1.09 & 2.21 & 1.14 & 2.46 & 1.23 & $4.15^{* *}$ \\
Counterfactual thinking & 2.24 & 0.80 & 2.83 & 1.13 & 1.80 & 1.07 & 2.12 & 0.96 & $5.88^{* * *}$ \\
Perspective taking & 2.85 & 0.90 & 2.41 & 1.02 & 3.58 & 0.84 & 2.77 & 0.89 & $9.53^{* * *}$ \\
\hline
\end{tabular}

${ }^{*} p<.05 .{ }^{* *} p<.01 .{ }^{* * *} p<.001$.

We found a significant effect of the condition on the use of prospective thinking for the four conditions: $F(3,126)=5.88, p<.001, \eta^{2}=.12$. Post-hoc comparisons using Tukey's HSD test indicated that significant differences in the use of counterfactual thinking could be determined between the counterfactual thinking and prospective thinking conditions $(p=.096)$, between the counterfactual thinking and perspective taking conditions $(p<.001)$, and between the counterfactual thinking and control condition $(p=.03)$. Hence, the manipulation of counterfactual thinking was successful at a $p<.10$ level.

We found a significant effect of the condition on the use of perspective taking at the $p<.001$ level for the four conditions: $F(3,125)=9.53, p<.001, \eta^{2}=.19$. Post-hoc comparisons using Tukey's HSD test indicated that significant differences in the use of perspective taking could be determined between the perspective taking and counterfactual thinking conditions $(p<.001)$, between the perspective taking 
and prospective thinking conditions $(p=.008)$, and between the perspective taking and the control condition $(p=.002)$. Hence, the manipulation of perspective taking was successful at a $p<.01$ level.

High-Quality Business Opportunity We defined and calculated a high-quality business opportunity in the same way as we did in study 1 . The results show weak inter-rater reliability and moderate to strong inter-rater agreement for $r_{w g}$ values based on slightly skewed distributions (Woehr et al., 2015): potential economic value $I C C(1)=-.00, I C C(2)=-.47$, mean $r_{w g}=.69$; newness $I C C(1)=-.00$, $I C C(2)=-.84$, mean $r_{w g}=.72$; perceived desirability $I C C(1)=.12, I C C(2)=$ .95 , mean $r_{w g}=.75$.

\subsubsection{Procedures}

Prior to the class, the students were informed that during this class they would be asked to participate in a research on entrepreneurship. During the class, the study was briefly introduced and the students were informed that their participation was not compulsory or in any way related to the evaluation of the course. After this introduction the surveys for data collection were handed out at the beginning of the class. We divided the four different surveys randomly among the students. Additionally, we instructed the students to fill out these surveys individually. The participants were instructed to first fill out the demographic variables only. Then they were instructed to fill out the anagram and that they had nine minutes to come up with as many correct answers as possible. After nine minutes the participants were instructed to fill out the rest of the survey, which took them about 25 minutes. After collecting all the surveys the first author debriefed the 
students by telling them what the goal of this research was and the first author gave a short lecture on the use of imagination by entrepreneurs.

\subsubsection{Results}

Table 5.9 shows the descriptive statistics and the correlations for the variables in this study. We dummy-coded the variables gender $(0=$ male $)$, nationality $(0=$ national students), and entrepreneurial experience $(0=$ yes $)$.

To test whether the use of imagination has an influence on the quality of the business opportunity, we performed a one-way analysis of variance test, see Table 5.10. We found that there were significant differences in the quality of the business opportunities between the four conditions $(F(3,113)=3.77, p=.01$, $\left.\eta^{2}=.09\right)$. To verify between which groups there were differences on the quality of the business opportunity, we performed post-hoc comparisons using Tukey's HSD test. We found that the quality of the business opportunities in the prospective thinking condition is significantly higher than in the control group $(p=.02)$. These results support Hypothesis 5.1.

Second, we found that the quality of the business opportunities in the counterfactual thinking condition is not significantly higher than in the control group $(p=.34)$. These results do not support Hypothesis 5.2.

Third, we found that the quality of the business opportunity in the perspective taking condition is not significantly higher than in the control group $(p=.95)$. These results do not support Hypothesis 5.3. The differences between the other conditions were not significant.

Additionally, we tested the effect of the imagination processes on each single 
150

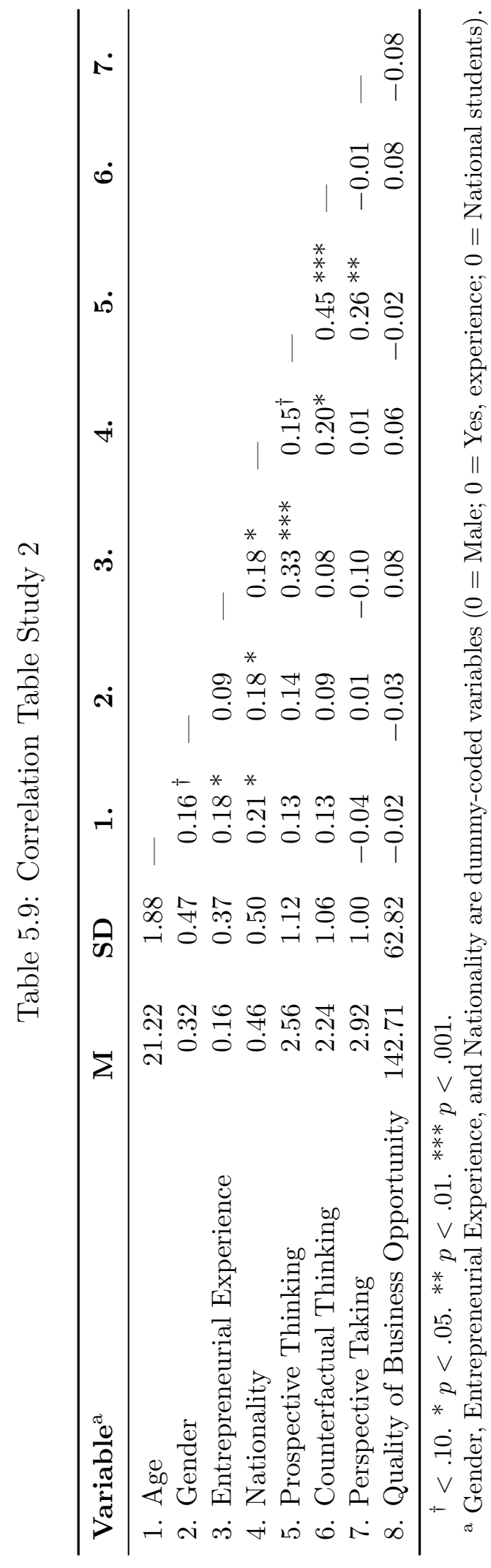

CHAPTER 5. AN EXPERIMENTAL STUDY 


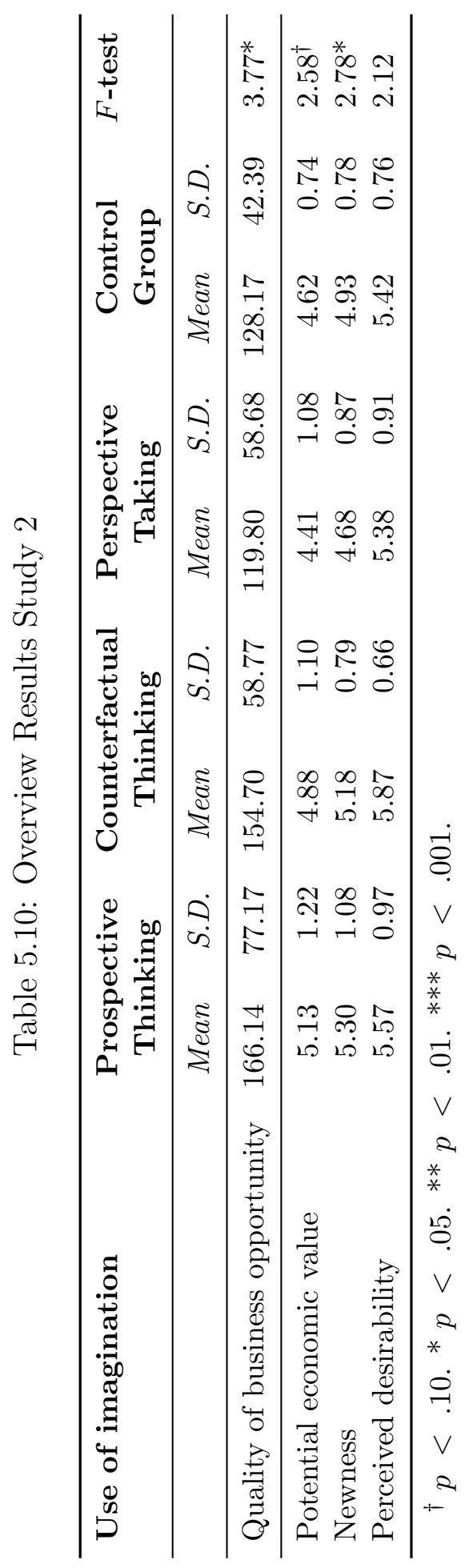


criteria of the quality of the business opportunities by performing three one-way analysis of variance tests. We found that the condition had a significant effect on the potential economic value of the business opportunity $(F(3,113)=2.58$, $\left.p=.06, \eta^{2}=.06\right)$. Post-hoc analyses with Tukey's HSD test showed that prospective thinking had a significant effect $(p=.05)$ on the potential economic value of a business opportunity compared to the perspective taking condition. Additionally, we found that the condition had a significant effect on the newness of the business opportunity $\left(F(3,114)=2.78, p=.04, \eta^{2}=.07\right)$. Post-hoc analyses with Tukey's HSD test showed that prospective thinking had a significant effect $(p=.04)$ on the newness of a business opportunity compared to the perspective taking condition. Both the differences between the other conditions for the potential economic value and newness of a business opportunity were not significant, as well as the differences between the conditions for the perceived desirability of a business opportunity.

\subsection{Discussion}

This chapter aimed to explore the effect of imagination processes on the quality of business opportunities. We did so by developing two experimental settings where we could compare the use of three different imagination processes (experimental groups) with no specific imagination process (control group) on the quality of a business opportunity identified by participants.

We find that participants that used prospective thinking in the manipulation task, are able to describe business opportunities of higher quality than the participants in the control group. We find no significant differences between these other 
three conditions. Hence, the use prospective thinking results into better quality business opportunities, but the use of counterfactual thinking or perspective taking does not lead to significantly better business opportunities compared to the control group.

Our findings have several contributions to the entrepreneurial cognition literature. Our first contribution is that imagination, and more specifically prospective thinking, is an important concept in identifying opportunities. To our knowledge, existing literature had not empirically studied the use of imagination for the identification of business opportunities. This opens up possibilities for further research as we will show further on in this section.

Secondly, existing literature found mixed results when studying the use of counterfactual thinking (e.g., Baron, 1998, 2000a,b). Our study cannot find support for the effects of counterfactual thinking and adds therefore support that counterfactual thinking may not be beneficial to entrepreneurs.

Third, we contribute to the entrepreneurial cognition literature by showing a way to study the use of imagination by entrepreneurs. The manipulations in our experiment worked well and offer possibilities for other researchers to study the use of imagination in an experimental setting.

\subsubsection{Implications}

These findings have multiple implications. First, these findings are a first attempt to empirically testing the claim of many scholars that imagination is important for identifying business opportunities. More specifically, we found that prospective thinking is important for identifying business opportunities that have a potential 
economic value and that are perceived as desirable.

Second, the results of this study have implications for entrepreneurial education. We showed that if potential entrepreneurs use their imagination, and more specifically, their prospective thinking, they are able to identify better business opportunities. Following this reasoning, entrepreneurship training programs aiming to raise entrepreneurial awareness or to enhance opportunity identification ability, can take these findings into consideration.

Last, we showed that we are able to trigger the participants to use the three different imagination processes. This enables other management scholars to conduct research on the use of imagination in different settings, such as organizations and experienced entrepreneurs.

\subsubsection{Limitations and Further Research}

The manipulations of the different experimental conditions worked well. In all conditions we are able to distinguish the use of the intended imagination process from the control group. In the prospective thinking condition, we were able to distinguish the use of prospective thinking from all other imagination processes. However, the manipulation of the counterfactual thinking and perspective thinking conditions could be improved. We were able to distinguish the use of these imagination processes between their conditions and the control group, but not from the other imagination processes. Further research may explore ways to better manipulate the imagination processes.

In this study the use of imagination was verified using self-reported measures by the participants. Preferably more items to measure the three imagination 
processes would be used. However, validated instruments measuring the use of imagination do not exist. Further research may develop a more reliable scale for the use of imagination by entrepreneurs.

\subsection{Conclusion}

These results provide preliminary evidence that the use of some imagination processes can lead to the identification of high quality business opportunities. The participants who were triggered to use prospective thinking identified business opportunities of better quality than participants who were triggered to use perspective thinking, or no specific imagination process at all (control group). The participants who were triggered to use counterfactual thinking created business opportunities of which the quality was not significantly different from the quality of the business opportunities in the other conditions. 



\section{Chapter 6}

\section{Discussion and Conclusion}

We started this dissertation with the objective to increase our understanding of the use of imagination by entrepreneurs. In the first chapter, we have introduced our main research question "How do entrepreneurs effectively use their imagination in the entrepreneurial process?" Additionally we derived four research questions that enable us to address this main research question. In the four chapters that followed, we studied each of these four research questions. In this last chapter of this dissertation, we will address our main research question, based on the findings and conclusions of the four research questions. To do so, we will start by presenting the key findings of the four research questions. Subsequently we discuss the limitations of this dissertation, the practical implications of our findings, and we will present an agenda for future research. 


\subsection{Summary of Key Findings}

In the first chapter we derived the four research questions for the studies in this dissertation. In the following chapters we have presented the studies we have conducted. In this section we will answer the four research questions that we derived in the first chapter by presenting the key findings for each research question.

\subsubsection{Research Question 1}

Numerous scholars state that entrepreneurs use their imagination, but what imagination is and how entrepreneurs use it remains unclear from their articles. To answer our first research question "What is imagination and how can entrepreneurs use their imagination effectively?", we used a two-step approach. First, we conceptualized what is imagination is, building on mainly psychology and management literature. Second, we theorized about when entrepreneurs use their imagination most effectively and presented propositions that guided us throughout the rest of the dissertation.

Scholars from multiple fields have studied the human imagination, for example, in fields like biology, neurology and psychology (Markman et al., 2009). However, we focused on the psychological literature only, because this field approaches imagination as a cognitive process. As such mental processes can be trained (Baron, 2006), entrepreneurs can be trained to use their imagination in the most effective way. Therefore, the field of psychology gives the most complete insight into how entrepreneurs can use their imagination more effectively.

We found three main streams of research on imagination. The first stream of research, based on the works by Aristotle (1907) and Kant (2010), focuses on 
imagination as a faculty. Such a faculty is a special place in the brain responsible for imaginative thoughts. For the conceptualization of imagination we did not focus on this stream of research, because phrenology did not find the existence of a faculty of imagination, nor of any faculty at all (Knight, 2007).

Based on a second stream of research, which regards imagination as the outcomes of imagination processes (e.g., Gordon, 1985), we found that these imagination processes create images of principles, goals, action and behavior, and anticipated events and states (Beach and Mitchell, 1987). This means that the images can be grouped in these four different categories.

We did focus on a third stream of research on imagination. This stream of research adopts a process-based view and regards imagination as mental processes (e.g., Markman et al., 2009). Based on their work, we conceptualized imagination as the combination of three mental processes: prospective thinking, counterfactual thinking, and perspective taking. Prospective thinking is the "ability to 'pre-experience' the future by simulating it in our minds" (Gilbert and Wilson, 2007, p. 1352); counterfactual thinking is the ability to "think about what might have been" (Byrne, 2005, p. 1); and perspective taking is "the cognitive capacity to consider the world from another individual's viewpoint" (Galinsky et al., 2008, p. 378).

Subsequently, we found that these processes require a narrow attentional breadth and a low present moment orientation (Dane, 2011), and are bounded by what is plausible and by an individual's prior knowledge and experience (Kahneman and Miller, 1986; Taylor et al., 1998). Therefore, imagination is different from related concepts, such as fantasizing (Oettingen et al., 2001; Oettingen and Mayer, 2002), mind wandering, absorption or flow (Dane, 2011). 
To answer the first research question, we first conceptualized imagination. In doing so, we built our conceptualization on the the key findings we summarized above. We define imagination as follows:

Imagination is a combination of three mental simulation processes - prospective thinking, counterfactual thinking, and perspective taking - that (1) require a narrow attentional breadth and a low present moment orientation; and that (2) create mental images - of principles, goals, action and behavior, and anticipated events and states - that are not currently present to the senses, and that are bounded by an individual's prior knowledge and experience, and by what is plausible.

Subsequently, to answer our first research question, we discussed factors that influence how entrepreneurs use their imagination most effectively. We derived five factors from our literature review. We found two situational factors, that is the imagination task and the dynamism of the environment, and three individual factors, namely domain-relevant knowledge, affect, and self-esteem.

The effectiveness of the use of imagination depends on the task the entrepreneur needs to execute. For well-structured problems, for example dealing with accounts receivable, a task is readily available to be applied (Shapiro and Spence, 1997). For ill-structured problems, however, no standard task is available. The need for the use of imagination is more apparent, because the entrepreneurs needs to think of a specific task to solve the problem. Therefore, we find that the use of imagination is more effective for solving ill-structured problems than for wellstructured problems (Chiles et al., 2007; Loasby, 2001; Sarasvathy, 2001, 2008). 
Based on our literature review, we found seven entrepreneurial tasks for which entrepreneurs use their imagination. The two entrepreneurial tasks for which entrepreneurs use their imagination that were mentioned most often by entrepreneurship scholars were identifying business opportunities (e.g., Witt, 2007) and developing new strategies (e.g., Szulanski and Amin, 2001). Based on these two tasks, we theorize on how entrepreneurs use their imagination for these two tasks and propose that the use of prospective thinking is more effective for imagining business opportunities than the other two imagination processes, whereas counterfactual thinking is more effective for creating business opportunities than the other two imagination processes. This first proposition served as the starting point for our fourth research question in chapter 5 .

We theorize on the effect of the dynamism of the environment and propose that the use of imagination is more effective in a dynamic environment than in a stable environment. Based on our proposition we focused in both our second and third research question on high-technology entrepreneurs. The high-technology industry is an example of an industry in which the environment is very dynamic. New technology rapidly overtakes older technology which causes a great deal of uncertainty for high-technology entrepreneurs.

Next to these two situational factors, we also found three individual factors that influence the effectiveness of the use of imagination by entrepreneurs. For domain-relevant knowledge we propose that its relation with the effective use of imagination has a inverted U-shape. We argue that the use of imagination by entrepreneurs with little domain-knowledge will lead to very novel, but nonrealistic ideas, whereas the use of imagination by entrepreneurs with much domainknowledge may lead to less novel, but very applicable ideas. The use of imagina- 
tion is therefore most effective with moderate domain-relevant knowledge. Based on this proposition we distinguished in research questions two and three between novel entrepreneurs, who do not have entrepreneurial experience, and experienced entrepreneurs.

A second individual factor that influences the effectiveness of the use of imagination by entrepreneurs, is the affect of the entrepreneur. We propose that an entrepreneur's positive affect strengthens the relation between the imagination task and the effective use of both prospective thinking and counterfactual thinking, but weakens the relationship between the imagination task and the effective use of perspective taking. The third and last individual factor we found was selfesteem. We propose that an individual's high self-esteem strengthens the relation between the imagination task and the effective use of imagination.

Based on these key findings we have derived an answer to the first research question. In this section we both answered the question what imagination is, and we found a set of factors that influence the effectiveness of the use of imagination. The answers have led us to both conceptualize imagination and form propositions on the effective use of imagination by entrepreneurs. Accordingly, these key findings were also the starting point of the other three studies in this dissertation, of which we will discuss the key findings below.

\subsubsection{Research Question 2}

By answering the first research question, we have conceptualized and demarcated imagination, and we have theorized on how entrepreneurs can use their imagination effectively. More specifically, we learned that imagination consist of three 
mental process (i.e., prospective thinking, counterfactual thinking, and perspective taking) and is used for seven entrepreneurial tasks in the venture creation process. In chapter 2 we proposed that experience is an important antecedent of the use of imagination. Therefore, we studied the use of imagination by experienced entrepreneurs in chapter 3. For this chapter we interviewed thirty-one entrepreneurs. Our research question was "How do experienced high-technology entrepreneurs use their imagination in opportunity identification and strategic decision-making processes?" In our interviews we mainly focused on their use of imagination for identifying the business opportunity and for developing their strategies.

We started our interviews by asking what imagination is according to the interviewees. As there is no commonly accepted definition for imagination, we wanted to know how our interviewees understood this concept. Our first finding is that most interviewees had a good understanding of this concept that fitted relatively well with our definition of imagination. Many entrepreneurs said that imagination is not the term they use regularly and that they prefer terms like 'to visualize' or 'to make an estimate'.

Second, we found that imagination is important in the early phases of the entrepreneurial process when information is not available yet. Due to the lack of information, entrepreneurs start to use their imagination see how the future could become, how their future products should look like, who their potential customers could be, and why these potential customers would buy their products (e.g., Maurya, 2012). By using imagination, the entrepreneur generates new information about how the future could be. This information about the future is then used to identify a business opportunity or to develop a strategy.

Third, we found that the reason entrepreneurs use their imagination is that 
imagining the future gives a feeling of certainty on how the future will be and hence it gives a feeling of control over the future and the company. By imagining the future of their company, entrepreneurs create a goal towards which they can work. By regularly imagining the future and working towards this imagined future, the future starts to shape as they imagined it (e.g., Sarasvathy, 2001).

Based on these findings we have derived an answer to our second research question. We conclude that the use of imagination is important to entrepreneurs, especially in dynamic environments where little information is available and the future is very uncertain. High-technology entrepreneurs often work in dynamic environments and they actively use their imagination to create an idea of the future. This idea takes the shape of a goal towards which the entrepreneurs work. The use of imagination is helpful as it gives the entrepreneur a feeling of control in a very uncertain environment.

\subsubsection{Research Question 3}

In chapter 4 we asked our third research question: "How do nascent entrepreneurs use their imagination in the venture creation process?" Based on the diaries of 164 nascent entrepreneurs, we derived to the following key findings.

The first key finding is that the chance that the use of the imagination processes is not equally shared among the processes per entrepreneurial task. In other words, some imagination processes are more likely to co-occur with a specific entrepreneurial task, than other imagination processes. We find that nascent entrepreneurs use prospective thinking significantly more often than we would expect based on a random distribution to imagine business ideas and opportunities, 
and the future of their company. Additionally, we find that these entrepreneurs use counterfactual thinking significantly more often to imagine scenarios and plans for their company, and perspective taking to imagine the actions of stakeholders. Although co-occurrence does not imply causality, these findings are a first indication that some imagination processes are used more often for some entrepreneurial tasks than for others. Therefore, we have preliminary findings which support Propositions 1a and 1b, from our first study in chapter 2 .

One of the advantages of using a diary-based method, is that processes can be studied over time. We find that the amount of imagination entrepreneurs use slightly, but significantly, decreases over time. This means that entrepreneurs use their imagination more often in the beginning of the venture creation process. This finding is in accordance with our findings in the first study, where we argued that the use of imagination is more effective in dynamic environments, which the beginning of the venture creation process most certainly is.

Surprisingly, we find that in our sample women use imagination significantly less often than men. We do not conclude that gender is a causal antecedent to the use of imagination. However, we cannot ignore this finding and therefore we will elaborate on this in section 6.5 on the future research agenda.

In the last step of this research we tested whether the use of imagination can be linked to the pursuit of the business idea. We defined three categories: first, the entrepreneur quit the company, and did not start a new company; second, the entrepreneur quit the company, and started a different company; or third, the entrepreneur continued with the company. We find that entrepreneurs who quit their company and then started a new company used significantly more prospective thinking and significantly less perspective taking than the entrepreneurs who quit 
their company and did not start a new venture.

Additionally, we find that entrepreneurs who quit their company and started a new venture used their imagination significantly more to think about the future of their company and products and less about how stakeholders would (inter)act than entrepreneurs who quit their company and did not start a new venture. Further on, we find that entrepreneurs who are still working on their initial company used their imagination significantly more to think of the future of their company and significantly less about how stakeholders would (inter)act.

We conclude that nascent entrepreneurs who use more prospective thinking and less perspective taking tend to have a bigger chance of pursuing the business idea than other entrepreneurs. Apparently, thinking about what the future might bring is more important for the pursuit of the business idea than thinking about what your current customers might need.

Based on these findings we have derived an answer to our third research question. We studied how nascent entrepreneurs use their imagination in the venture creation process. The answers we presented above have led us to conclude that entrepreneurs use the three imagination processes throughout the venture creation process for seven main entrepreneurial tasks. The amount of imagination that these entrepreneurs use decreases over time. Subsequently we conclude that the use of prospective thinking is positively related to the pursuit of the business idea, whereas perspective taking is negatively related to the pursuit of the business idea. 


\subsubsection{Research Question 4}

In the last study of this dissertation we wanted to experimentally test whether the use of imagination is beneficial to the entrepreneur. To be more precise we focused on one of the entrepreneurial tasks for which the imagination is used: identifying business opportunities. In this study we asked the question "Does the use of imagination affect the quality of the identified business opportunities?" Based on two experiments with 162 and 137 participants from diverse study backgrounds who participated voluntarily in an entrepreneurial elective, we derived the following key findings.

Based on the limited available theory and the previous chapters of this dissertation, we developed three hypotheses on the effect of the use of the three imagination processes on the quality of the business opportunity. In the two experiments we used two different ways to manipulate the three imagination processes and looked at the effect on the quality of the business opportunity that the participants had to develop. We found that participants who were triggered to use their prospective thinking thought of business opportunities that were of a higher quality, than the participants in the other conditions. The quality of the business opportunities of these participants was higher than the quality of the business opportunities of the participants in the counterfactual, perspective taking, and the control conditions. For the other conditions, we could not find a difference in the quality of the business opportunity, compared to the control group.

As both study designs lead to this same results, we conclude that the use of prospective thinking is beneficial to entrepreneurs when thinking about their business opportunity. We therefore answer the fourth research question by stating 
that not the use of imagination in general leads to the identification of better business opportunities, but more specifically, the use of prospective thinking does.

\subsection{Main Theoretical Contributions}

In the previous section we have summarized the key findings of the four studies in this dissertation. Based on these key findings, in this section we will provide the main theoretical contribution of our research in this dissertation.

Our first main contribution in this dissertation is the conceptualization and demarcation of imagination from a cognitive process perspective. While we know from previous research that the use of imagination is crucial for entrepreneurs (e.g., Baron, 2006; Cornelissen and Clarke, 2010; Foss and Foss, 2008; Foss et al., 2008; Gartner, 2007; Kaish and Gilad, 1991; Lumpkin and Dess, 1996; Mathews, 2010; Sarasvathy, 2001, 2008; Witt, 1998, 2007), both what imagination is, and how entrepreneurs use their imagination effectively, remain unclear from previous studies. We address the first concern by conceptualizing imagination. By taking a cognitive process perspective for our conceptualization, we offer a definition that could form the basis for future research on the use of imagination by entrepreneurs. By demarcating imagination, we provide scholars with a definition of imagination that clearly distinguishes imagination from closely related concept such as creativity and ideation.

Our second main contribution is our theorizing and proposition development on the effective use of imagination. We address the second concern by theorizing on the effective use of imagination. Based on our theorizing, we both developed several propositions on the effective use of imagination, and we provided a theo- 
retical model that addresses both situational and individual factors that affect the effective use of imagination. Our theorizing, propositions, and conceptual model may provide opportunities for future research to further our understanding on the use of imagination by entrepreneurs (see also section 6.5).

Our third main contribution is based on our finding that entrepreneurs use their imagination for different entrepreneurial tasks. Current literature mainly uses the term 'imagination' in relation to the identification of opportunities (e.g., Witt, 2007), and the development of strategies (Szulanski and Amin, 2001). However, our finding that entrepreneurs also use their imagination to think about the interactions they may have with important stakeholders of their venture (e.g., Hart and Sharma, 2004; Galinsky et al., 2008), and the social impact of their venture (e.g., Buchholz and Rosenthal, 2005; McVea, 2009), among other entrepreneurial tasks, adds to theory that entrepreneurs use their imagination for a wider variety of tasks than currently is implied by the literature.

Our fourth main contribution is based on the our finding that the effectiveness of the use of imagination depends upon the fit between the imagination process and the entrepreneurial task. Current literature uses the term 'imagination' without being specific about the imagination process (e.g., Gartner, 2007; Sarasvathy, 2002). Our findings that the use of prospective thinking is more effective for the identification of opportunities than the use of counterfactual thinking and perspective taking, and that entrepreneurs use more counterfactual thinking than prospective thinking or perspective taking, when developing strategies, add to theory that the effectiveness of the use of imagination depends on using the imagination process that is more effective for the entrepreneurial task that needs to be performed. Therefore, entrepreneurial scholars should be more specific when they 
use the term "imagination" in their studies.

\subsection{Implications for Practice}

The results from the studies in this dissertation not only form the basis of our contributions to theory, but also have several implications for practice. These implications are derived from both the literature we studied for this dissertation, and the empirical findings of our studies.

First, we found that entrepreneurs use their imagination to deal with uncertainty. Entrepreneurs who deal with an uncertain environment may benefit more the use of imagination. By imagining possible futures for their company, information is generated about how the future could unfold. By preparing for some of these possible futures, entrepreneurs gain a sense of control over their companies and their future. Entrepreneurs can actively make use of their imagination when their environment or future are deemed uncertain. Entrepreneurship support programs, like business incubators, and entrepreneurship educators can support entrepreneurs by actively training and coaching entrepreneurs to make use of imagination.

Second, entrepreneurs use their imagination for several aspects of the entrepreneurial process. From the review of the literature, the interviews we conducted and the diaries that we analyzed, we found that entrepreneurs mainly use their imagination to think of business opportunities and to develop strategies. The findings in this dissertation point to an effect of prospective thinking on identifying business opportunities, and an effect of counterfactual thinking on developing strategies. The use of imagination appears to be a quite successful approach for identifying business opportunities and may help entrepreneurs to de- 
velop strategies. These findings also have implications for strategy consultants. Due to the limited availability of information, and inherent uncertainty, when developing strategies, strategy consultants should allow for human imagination in their strategic models (cf., Kraaijenbrink et al., 2009).

Third, based on the set of entrepreneurs from the incubator that we studied, we found that the entrepreneurs who used more prospective thinking, and less perspective taking were more likely to continue pursuing their business idea. Based on these findings, using more prospective thinking appears to be a successful approach for entrepreneurs, to increase chances of pursuing the business idea.

Fourth, we found several factors that are of influence on the effective use of imagination by entrepreneurs. One of these factors is domain-relevant knowledge. We found that experts tend to use their imagination less frequent than novices. Experts have gathered more domain-relevant knowledge, and therefore have less knowledge gaps that may need to be filled by imagination. However, when experts use their imagination, what they imagine is more realistic, but less novel. Novices have gathered less domain-relevant knowledge, and therefore have more knowledge gaps that may need to be filled by imagination. When novices use their imagination, they come up with more novel ideas, but these ideas are less realistic. The inverted U-shape between domain-relevant knowledge and effective use of imagination implies that entrepreneurs with moderate domain-relevant knowledge use their imagination more effective. Entrepreneurs who posses much domain-relevant knowledge should be aware that when they use their imagination, their ideas may not be very novel and could try to increase the level of novelty of their ideas by making use of creative thinking. Entrepreneurs who posses little domain-relevant knowledge should be aware that their ideas may not be very realistic when they use 
their imagination. They could try to find individuals with high levels of domainrelevant knowledge to test their ideas in an early stage, for example by following a lean start-up approach (cf., Maurya, 2012).

Fifth, we found that the stage within the entrepreneurial process is an important antecedent of the effective use of imagination by entrepreneurs. In the beginning of the entrepreneurial process entrepreneurs have not gathered much information yet about their opportunity and venture. To fill these information gaps imagination may be used. Therefore, entrepreneurs may find the use of their imagination more effective in the early phases of the entrepreneurial process than in later phases. Entrepreneurship support programs such as business incubators and business plan competitions often focus on these early phases of the entrepreneurial process. Therefore, such entrepreneurship support programs may extend their services by taking the use of imagination into account. By actively stimulating the use of the imagination as a tool for gathering information about possible futures.

\subsection{Research Limitations}

In this dissertation we have made several design choices. These choices inherently lead to the limitations of this dissertation. First, we formulated propositions on the effect of both self-esteem and affect on the effective use of imagination in the second chapter of this dissertation, but these factors were not taken into account in the other three studies due to design choices. This opens up possibilities for future research, which we will describe later on in this chapter.

Second, in chapter 3 we chose to use interviews as a method for data gathering. Although most studies on entrepreneurial cognition use quantitative methods (Hin- 
dle, 2004), we wanted to use multiple methods in this dissertation to describe, study, and analyze the use of imagination. A pluralistic methodological approach fits with the engaged scholarship approach that we took in this dissertation (van de Ven and Johnson, 2006) and enables us to capture this phenomenon as complete as possible. Qualitative methods are very well suited to study entrepreneurial cognition (Hindle, 2004) but the use of interviews bring the disadvantage of introspection and retrospective bias. However, as we have used multiple methods throughout this dissertation we believe we provide a good overview of this concept.

Third, in chapter 4 we look at the co-occurrences between imagination processes and entrepreneurial tasks. However, co-occurrence is not causation. We cannot argue that imagination processes lead to entrepreneurial tasks, nor to successful execution of these tasks. However, our findings do open up possibilities for future research that studies causal effects, like we did in the chapter afterwards.

Fourth, the participants of that study were part of an venture incubation program. Therefore, these entrepreneurs may differ from other entrepreneurs, which limits the external validity of this study.

Fifth, when filling out the diaries, not all entrepreneurs filled out the diaries very serious. Not every entrepreneur filled out the diary every week, and some entrepreneurs gave very short answers. This may limit the internal validity of this study.

Sixth, in chapter 5 we used two experimental design to study the causal effect of the use of imagination on the quality of the business opportunities that the participants identified. Although the quality of a business opportunity can only be determined in hindsight, we used two independent coders to assess the quality of the business opportunities as a proxy. 


\subsection{Future Research Agenda}

This dissertation opens up multiple possibilities for future research on the use of imagination within business studies. First, future research should look into the effects of self-esteem and affect on the effective use of imagination by entrepreneurs. Based on the propositions we formulated in chapter 2, we expect that these factors have an influence into which entrepreneurship scholars could look. Additionally, entrepreneurship scholars may also look into the effect of the use imagination on affect (e.g., Shepherd, 2015).

Second, in one of our studies we found that the women in our sample used less imagination than the men in our sample. We do not have an explanation for this finding. Research on female entrepreneurship has studied the differences between male and female entrepreneurs (Eddleston and Powell, 2012), and differences among female entrepreneurs (e.g., Lewis, 2006). Research on gender differences in entrepreneurship has found, for example, that men and women evaluate opportunities differently (Gupta et al., 2012). However, whether male and female entrepreneurs use their imagination differently is a topic into which future research should look.

Third, a scale to measure the use of imagination may be developed in the future. Reliable and validated scales are key for sound research. If we want to continue researching imagination and its use by entrepreneurs to further our understanding of these processes, a scale that measure the use of imagination is important. Multiple types of scales may be developed. One scale could focus on measuring the amount of imagination used by entrepreneurs, whereas another scale could on measuring whether the use of imagination has been effective. The 
development of such scales opens up possibilities for researchers to further study the use of imagination and find other antecedents to the effective use of imagination by entrepreneurs.

Fourth, so far we only studied the use of imagination by one individual. Many entrepreneurs, however, work in teams (de Mol et al., 2015), and in networks (Groen, 2005) and the success of a company cannot be linked to only one individual (Dimov, 2007). Therefore, studying how entrepreneurs use their imagination in shared cognition settings, how entrepreneurs communicate the results of their imagination to other stakeholders (e.g., Cornelissen, 2005; Cornelissen and Clarke, 2010), and how the results of their imagination develops due to the communication with other stakeholders (e.g., Felin and Zenger, 2009) is important.

Fifth, although we have used multiple methods to study the use of imagination by entrepreneurs, other methods may reveil other aspects that may not have appeared in this dissertation. A possibility to use other methods would be a ethnographic study in a business incubator, possibly combined with think-aloud protocols. By following a group of entrepreneurs who are actively developing their business ideas may give more insights in how entrepreneurs use their imagination. 



\section{Appendix A}

\section{Interview Questions}

\section{Introduction}

1. What is imagination according to you?

2. Do you sometimes imagine business situations? If yes, could you give an example?

3. Do these imaginations have an effect on the business ideas and strategies of your company?

Explain how we see imagination; the three different processes of imagination: prospective thinking, counterfactual thinking, perspective taking

\section{Idea Generation}

4. How do you use your imagination to develop your business idea? 
5. Did you put yourself into the situation of potential customers/suppliers? If yes, how did this help you?

6. How are these imagination process influenced by interaction with others?

\section{Decision Making}

For the following questions, choose one recent, important strategic decision.

7. How did you identify the problem that preceded this decision?

8. Did you develop multiple scenarios after this problem identification? If yes, how did this help you?

9. How did you use your imagination for evaluating these scenarios?

10. How are these imagination processes influenced by interaction with others?

\section{Closing}

11. We talked about the influence of imagination on the development of business ideas and strategies. Are there other business aspects in which you use your imagination? If yes, could you elaborate on that? 


\section{Appendix B}

\section{Example of a Diary Entry}

Take: [NameParticipant]

Nr: \#15

Start: [Date] [Time]

End: [Date] [Time]

\section{Learnings}

I have reviewed many of the lessons I had learned last year in [BusinessDevelopmentProgram] and studied and re-read chapters in the following books:

- "Technology Ventures - from Idea to Enterprise" by Dorf \& Byers

- "Business Model Generation" by Osterwalder \& Pigneur

- "Value Merchants" from Jim Anderson

- "Earth Inc. - using nature's rules to build sustainable profits" by Gregory Unruh. 
- "From Green to Gold" by Daniel Etsy and Andrew Winston.

Results

With my business partner [NameBusinessPartner] we have further developed our business plan. We also had serious discussions on the potential value of a partnership with the interim management firm [NameInterimManagementFirm]. The partners of [InterimManagementFirm] want us to join them in developing solutions for implementing sustainability in organisations. Our conclusion so far is that besides a short term assignment there are more threats and risks than benefits involved. Next [F]riday October 15 we will discuss with them face to face again. My impression so far is that this issue is distracting us from the important thing we need to pay attention to. On Monday October 4, we had an excellent review meeting with [Director] from [BusinessSchool] and he is fully [] on board with our concept. The interest of [BusinessSchool] is in the following areas:

1. Co-facilitating a Learning Network;

2. Support in initial analysis phase of sustainability assignments;

3. Executive and organizational development programs for the organisations we will be transforming;

4. Coaching and sparring partner Additional internal or external research;

5. Proces[s] development in areas such as leadership development, change management.

The meeting with [Professor] from [University] has been scheduled on November 18, For this meeting [Professor] has also invited [Researcher] (sustainability, change 
and leadership processes) and [BusinessDirectorResearchInstitute1]. Meeting with [BusinessDirectorResearchInstitute2] is still pending.

\section{Issues}

We have not made any progress on our company name. Next week I have my final Business Panel presen[t]ation on [BusinessDevelopmentProgram] with an interview for the book; having a good name would be quite use full...! Next Monday, October 11, I have a second and final interview for a long interim management assignment with [Company]. It seems I am the only remaining candidate for this assignment. However I have mixed feelings about this: I do need [t]he income, so far this has been a very quiet year, but right now we are making great progress on our new venture, and this assignment brings money but it is actually the "wrong" assignment and diverts focus from our new venture. I will see how this develops and if I can bring a sustainability aspect into the equation and free time to further build on our new venture. Having a substantial income for a longer period could also provide a more stable base to develop and market our venture.

\section{Next steps}

- Prepare Business Panel presentation for next Thursday October 14

- Get appointment with [DirectorDevelopmentAgency] to explain new venture and identify potential areas of cooperation. a good relation with [DevelopmentAgency] could provide for interesting commercial leads.

- Discuss current rapid developments with my [PersonalCoach]. 



\title{
Appendix $\mathrm{C}$
}

Codebook "Imagination in

\author{
Diaries"
}


Table C.1: Codebook for imagination processes

\begin{tabular}{|c|c|c|c|}
\hline Category & Definition & Example $^{a}$ & $\begin{array}{l}\text { Doubt / Diffi- } \\
\text { cult / Different }\end{array}$ \\
\hline $\begin{array}{l}\text { Prospective } \\
\text { thinking }\end{array}$ & $\begin{array}{l}\text { Prospection is the "abil- } \\
\text { ity to "pre-experience' } \\
\text { the future by simulat- } \\
\text { ing it in our minds" } \\
\text { (Gilbert and Wilson, } \\
\text { 2007). }\end{array}$ & $\begin{array}{l}\text { "seems", "ex- } \\
\text { pect" }\end{array}$ & $\begin{array}{l}\text { "will" is often fac- } \\
\text { tual, "hopefully", } \\
\text { to hope is not to } \\
\text { imagine }\end{array}$ \\
\hline $\begin{array}{l}\text { Counterfactual } \\
\text { thinking }\end{array}$ & $\begin{array}{l}\text { Imagining "what might } \\
\text { have been or might hap- } \\
\text { pen" if non-factual as- } \\
\text { sumptions are made. }\end{array}$ & $\begin{array}{l}\text { "What if ...", } \\
\text { "Because oth- } \\
\text { erwise ...", "(I } \\
\text { wonder) if I } \\
\text { should have ...", } \\
\text { "If I ...". }\end{array}$ & \\
\hline $\begin{array}{l}\text { Perspective tak- } \\
\text { ing }\end{array}$ & $\begin{array}{l}\text { The third stream of re- } \\
\text { search focuses on the } \\
\text { possibility to imagine } \\
\text { people, by perspective } \\
\text { taking, i.e., putting one- } \\
\text { self in someone else's } \\
\text { position. }\end{array}$ & & \\
\hline
\end{tabular}

a The "Examples" or "Doubts" are hints that may help you to recognize the right application of imagination. However, finding these hints in the text does not mean automatically that this application is found. Always use your critical thinking to see whether that category really fits the text. 
Table C.2: Codebook for imagination outcomes

\begin{tabular}{|c|c|c|}
\hline Category & Definition & $\begin{array}{l}\text { Doubt / Diffi- } \\
\text { cult / Different }\end{array}$ \\
\hline $\begin{array}{l}\text { Ideas \& Opportu- } \\
\text { nities }\end{array}$ & $\begin{array}{l}\text {... new business ideas } \\
\text { and opportunities to } \\
\text { start a business. }\end{array}$ & $\begin{array}{l}\text { New idea for a } \\
\text { company. }\end{array}$ \\
\hline $\begin{array}{l}\text { Development of } \\
\text { entrepreneur }\end{array}$ & $\begin{array}{l}\text {...how the en- } \\
\text { trepreneur can improve } \\
\text { him/herself. }\end{array}$ & \\
\hline Future & $\begin{array}{l}\text {... a future state of the } \\
\text { company or product. }\end{array}$ & $\begin{array}{l}\text { New idea for an } \\
\text { existing company. }\end{array}$ \\
\hline Likelihood & $\begin{array}{l}\text {...the likelihood / fea- } \\
\text { sibility of company or } \\
\text { product. }\end{array}$ & \\
\hline Scenarios / Plans & $\begin{array}{l}\text {... a plan or steps to- } \\
\text { wards a future state of } \\
\text { company or product. }\end{array}$ & \\
\hline $\begin{array}{l}\text { Acting with } \\
\text { stakeholder }\end{array}$ & $\begin{array}{l}\text {...acting with stake- } \\
\text { holders. }\end{array}$ & \\
\hline Societal impact & $\begin{array}{l}\text {... impact on society of } \\
\text { company / social conse- } \\
\text { quences of company. }\end{array}$ & \\
\hline
\end{tabular}

a The "Examples" or "Doubts" are hints that may help you to recognize the right application of imagination. However, finding these hints in the text does not mean automatically that this application is found. Always use your critical thinking to see whether that category really fits the text. 



\section{Appendix D}

\section{Coding Sample}

Table D.1: Coding sample

\begin{tabular}{|c|c|c|}
\hline Process & Business related use & Sample quote \\
\hline Prospective Thinking & Ideas \& Opportunities & $\begin{array}{l}\text { "maybe as a quick win we can } \\
\text { dust off some of these apps } \\
\text { and make them work on mod- } \\
\text { ern Nokia smartphones or An- } \\
\text { droid phones in a short time" }\end{array}$ \\
\hline Prospective Thinking & Development of entrepreneur & $\begin{array}{l}\text { "It will be neces[s]ary for } \\
\text { me in the future to take a } \\
\text { good vacation at a warm place } \\
\text { when the winter is in its peak" }\end{array}$ \\
\hline Prospective Thinking & Future state of the company & $\begin{array}{l}\text { "Maybe with offering of new } \\
\text { detector technology and USP } \\
\text { optics I can combine all ac- } \\
\text { tivities and also reduce the } \\
\text { amount of investment money" }\end{array}$ \\
\hline Prospective Thinking & Likelihood & $\begin{array}{l}\text { "We think this will become an } \\
\text { order very soon" }\end{array}$ \\
\hline Prospective Thinking & Scenarios / Plans & $\begin{array}{l}\text { "A new approach might be to } \\
\text { attack the management with } \\
\text { a solution orientated presen- } \\
\text { tation." }\end{array}$ \\
\hline Prospective Thinking & (Inter)acting with Stakeholders & $\begin{array}{l}\text { "He maybe can help me with } \\
\text { ideas from the [university]." }\end{array}$ \\
\hline
\end{tabular}


Table D.1 - Continued from previous page

\begin{tabular}{|c|c|c|}
\hline Process & Business related use & Sample quote \\
\hline Prospective Thinking & Societal Impact & $\begin{array}{l}\text { "This will create a point of } \\
\text { difference to all big players" }\end{array}$ \\
\hline Counterfactual Thinking & Ideas \& Opportunities & - \\
\hline Counterfactual Thinking & Development of entrepreneur & $\begin{array}{l}\text { "I ma }[\mathrm{y}] \mathrm{b}[\mathrm{e}] \text { started to high in } \\
\text { the negotiations" }\end{array}$ \\
\hline Counterfactual Thinking & Future state of the company & $\begin{array}{l}\text { "If this is a success[s] [we] } \\
\text { can get orders [every week] for } \\
\text { printing models for the con- } \\
\text { sumer market." }\end{array}$ \\
\hline Counterfactual Thinking & Likelihood & $\begin{array}{l}\text { "I even think it might not } \\
\text { have been a good idea to join } \\
\text { the [incubator]" }\end{array}$ \\
\hline Counterfactual Thinking & Scenarios / Plans & $\begin{array}{l}\text { "If I could make a new start } \\
\text { I would have done it with a } \\
\text { partner and not alone." }\end{array}$ \\
\hline Counterfactual Thinking & (Inter)acting with Stakeholders & $\begin{array}{l}\text { "I could have made more of } \\
\text { the encounter with the panel } \\
\text { members" }\end{array}$ \\
\hline Counterfactual Thinking & Societal Impact & - \\
\hline Perspective Taking & Ideas \& Opportunities & - \\
\hline Perspective Taking & Development of entrepreneur & $\begin{array}{l}\text { "But when you ask } 100 \text { peo- } \\
\text { ple if I am a perfectionist, } 100 \\
\text { people will say: "no, not [au- } \\
\text { thor's own name]", }\end{array}$ \\
\hline Perspective Taking & Future state of the company & $\begin{array}{l}\text { "My first customer I think } \\
\text { who could buy a system is } \\
\text { OCE therefore I tried to map } \\
\text { the complete printer[ ] market } \\
\text { in 2-3 days which will take } \\
\text { more time." }\end{array}$ \\
\hline Perspective Taking & Likelihood & $\begin{array}{l}\text { "Customers will probably buy } \\
\text { between } 300 \text { and } 500 \text { gram - } \\
\text { They will come back for spe- } \\
\text { cialties - They will visit the } \\
\text { store twice a month?" }\end{array}$ \\
\hline Perspective Taking & Scenarios / Plans & $\begin{array}{l}\text { "Still I think they might think } \\
\text { of it some day, but it will be } \\
\text { (partially) too late for them } \\
\text { to be dangerous, juridically } \\
\text { speaking." }\end{array}$ \\
\hline
\end{tabular}


Table D.1 - Continued from previous page

\begin{tabular}{lll}
\hline Process & Business related use & Sample quote \\
\hline Perspective Taking & (Inter)acting with Stakeholders & "And in my opinion my target \\
& & area isn't going to search the \\
& internet to find me, they rely \\
& on referrals. And to become \\
& a referral, they have to know \\
& who you are, and they have to \\
Perspective Taking & Societal Impact & know you're reputation." \\
\hline
\end{tabular}





\section{Bibliography}

Agresti, A. (2007). An introduction to categorical data analysis. Wiley Series in Probability and Statistics. Wiley, Hoboken, NJ, $2^{\text {nd }}$ edition.

Ajzen, I. (1991). The theory of planned behavior. Organizational Behavior and Human Decision Processes, 50(2):179-211.

Aldrich, H. E. and Fiol, C. M. (1994). Fools rush in? The institutional context of industry creation. Academy of Management Review, 19(4):645-670.

Alvarez, S. A. (2008). Introduction to creativity, imagination, and opportunities. Strategic Entrepreneurship Journal, 2(1):53-55.

Alvarez, S. A. and Barney, J. B. (2007). Discovery and creation: Alternative theories of entrepreneurial action. Strategic Entrepreneurship Journal, 1(1-2):11-26.

Alvarez, S. A. and Barney, J. B. (2010). Entrepreneurship and epistemology: The philosophical underpinnings of the study of entrepreneurial opportunities. Academy of Management Annals, 4(1):557-583.

Alvarez, S. A., Barney, J. B., McBride, R., and Wuebker, R. (2014). Realism in the study of entrepreneurship. Academy of Management Review, 39(2):227-233. 
Anderson, C. A. (1983). Imagination and expectation: The effect of imagining behavioral scripts on personal intentions. Journal of Personality and Social Psychology, 45(2):293-305.

Aristotle (1907). De anima. Cambridge University Press, Cambridge, United Kingdom.

Arora, P., Laurence, G. A., and Haynie, J. M. (2013). Counterfactual thinking and entrepreneurial self-efficacy: The moderating role of self-esteem and dispositional affect. Entrepreneurship Theory and Practice, 37(2):359-385.

Atance, C. M. and O'Neill, D. K. (2005). The emergence of episodic future thinking in humans. Learning and Motivation, 36(2):126-144.

Bae, T. J., Qian, S., Miao, C., and Fiet, J. O. (2014). The relationship between entrepreneurship education and entrepreneurial intentions: A meta-analytic review. Entrepreneurship Theory and Practice, 38(2):217-254.

Bandura, A. (1977). Self-efficacy: Toward a unifying theory of behavioral change. Psychological Review, 84(2):191-215.

Bandura, A. (1982). Self-efficacy mechanism in human agency. American Psychologist, $37(2): 122-147$.

Bandura, A. (2001). Social cognitive theory: An agentic perspective. Annual Review of Psychology, 52:1-26.

Baron, R. A. (1998). Cognitive mechanisms in entrepreneurship: Why and when entrepreneurs think differently than other people. Journal of Business Venturing, $13(4): 275-294$. 
Baron, R. A. (2000a). Counterfactual thinking and venture formation: The potential effects of thinking about "what might have been". Journal of Business Venturing, $15(1): 79-91$.

Baron, R. A. (2000b). Psychological perspectives on entrepreneurship: Cognitive and social factors in entrepreneurs' success. Current Directions in Psychological Science, $9(1): 15-18$.

Baron, R. A. (2004). The cognitive perspective: A valuable tool for answering entrepreneurship's basic "why" questions. Journal of Business Venturing, 19(2):221239.

Baron, R. A. (2006). Opportunity recognition as pattern recognition. Academy of Management Perspective, 20(1):104-119.

Baron, R. A. and Ensley, M. D. (2006). Opportunity recognition as the detection of meaningful patterns: Evidence from comparisons of novice and experienced entrepreneurs. Management Science, 52(9):1331-1344.

Baron, R. A. and Ward, T. B. (2004). Expanding entrepreneurial cognition's toolbox: Potential contributions from the field of cognitive science. Entrepreneurship Theory and Practice, 28(6):553-573.

Batson, C. D. (2009). Two forms of perspective taking: Imagining how another feels and imagining how you would feel. In Markman, K. D., Klein, W. M. P., and Suhr, J. A., editors, Handbook of imagination and mental simulation, pages 267-279. Psychology Press, New York, NY.

Batson, C. D., Lishner, D. A., Carpenter, A., Dulin, L., Harjusola-Webb, S., Stocks, E. L., Gale, S., Hassan, O., and Sampat, B. (2003). “... As you would have them 
do unto you": Does imagining yourself in the other's place stimulate moral action? Personality and Social Psychology Bulletin, 29(9):1190-1201.

Baumeister, R. F., Masicampo, E. J., and Vohs, K. D. (2011). Do conscious thoughts cause behavior? Annual Review of Psychology, 62:331-361.

Beach, L. R. and Mitchell, T. R. (1987). Image theory: Principles, goals, and plans in decision making. Acta Psychologica, 66(3):201-220.

Beike, D. R., Markman, K. D., and Karadogan, F. (2008). What we regret most are lost opportunities: A theory of regret intensity. Personality and Social Psychology Bulletin, 35(3):385-397.

Bhave, M. (1994). A process model of entrepreneurial venture creation. Journal of Business Venturing, 9(3):223-242.

Bliese, P. D. (2000). Within-group agreement, non-independence, and reliability: Implications for data aggregation and analysis. In Klein, K. J. and Kozlowski, S. W. J., editors, Multilevel theory, research, and methods in organizations: Foundations, extensions, and new directions, pages 349-381. Jossey-Bass, San Francisco, CA.

Bliese, P. D. (2013). multilevel: Multilevel functions. R package version 2.5.

Bolger, N., Davis, A., and Rafaeli, E. (2003). Diary methods: Capturing life as it is lived. Annual Review of Psychology, 54:579-616.

Boudreaux, D. J. and Holcombe, R. G. (1989). The Coasian and Knightian theories of the firm. Managerial and Decision Economics, 10(2):147-154.

Braun, K. A., Ellis, R., and Loftus, E. F. (2002). Make my memory: How advertising can change our memories of the past. Psychology $\&$ Marketing, 19(1):1-23. 
Buchholz, R. A. and Rosenthal, S. B. (2005). The spirit of entrepreneurship and the qualities of moral decision making: Toward a unifying framework. Journal of Business Ethics, 60(3):307-315.

Buckner, R. L. and Carroll, D. C. (2007). Self-projection and the brain. Trends in Cognitive Sciences, 11(2):49-57.

Busenitz, L. W. (1996). Research on entrepreneurial alertness: Sampling, measurement, and theoretical issues. Journal of Small Business Management, 34(4):35-44.

Byrne, R. M. J. (2005). The rational imagination: How people create alternatives to reality. MIT Press, Cambridge, MA.

Carroll, J. S. (1978). The effect of imagining an event on expectations for the event: An interpretation in terms of the availability heuristic. Journal of Experimental Social Psychology, 14(1):88-96.

Chia, R. (1996). Teaching paradigm shifting in management education: University business schools and the entrepreneurial imagination. Journal of Management Studies, 33(4):409-428.

Chiles, T. H., Bluedorn, A. C., and Gupta, V. K. (2007). Beyond creative destruction and entrepreneurial discovery: A radical Austrian approach to entrepreneurship. Organization Studies, 28(4):467-493.

Chiles, T. H., Tuggle, C. S., McMullen, J. S., Bierman, L., and Greening, D. W. (2010). Dynamic creation: Extending the radical Austrian approach to entrepreneurship. Organization Studies, 31(1):7-46.

Chiu, F.-C. (2012). Fit between future thinking and future orientation on creative imagination. Thinking Skills and Creativity, 7(3):234-244. 
Chiu, L. P. W. (1989). Differential diagnosis and management of hallucinations. Journal of the Hong Kong Medical Association, 41(3):292-297.

Converse, B. A., Lin, S., Keysar, B., and Epley, N. (2008). In the mood to get over yourself: Mood affects theory-of-mind use. Emotion, 8(5):725-730.

Cornelissen, J. P. (2005). Beyond compare: Metaphor in organization theory. Academy of Management Review, 30(4):751-764.

Cornelissen, J. P. and Clarke, J. S. (2010). Imagining and rationalizing opportunities: Inductive reasoning and the creation and justification of new ventures. Academy of Management Review, 35(4):539-557.

Costa, S. F., Ehrenhard, M. L., Caetano, A., and Santos, S. C. (2016). The role of different opportunities in the activation and use of the business opportunity prototype. Creativity and Innovation Management doi:10.1111/caim.12160.

Costa, S. F., Santos, S. C., and Caetano, A. (2013). Prototypical dimensions of business opportunity in early stages of the entrepreneurial process. Revista Psicologia: Organizações e Trabalho, 13(3):265-278.

Curşeu, P. L. (2008). The role of cognitive complexity in entrepreneurial strategic decision-making. In Vermeulen, P. A. M. and Curşeu, P. L., editors, Entrepreneurial strategic decision-making: A cognitive perspective, pages 68-88. Edward Elgar, Cheltenham, United Kingdom.

Dane, E. (2010). Reconsidering the trade-off between expertise and flexibility: A cognitive entrenchment perspective. Academy of Management Review, 35(4):579-603.

Dane, E. (2011). Paying attention to mindfulness and its effects on task performance in the workplace. Journal of Management, 37(4):997-1018. 
Dane, E. and Pratt, M. G. (2007). Exploring intuition and its role in managerial decision making. Academy of Management Review, 32(1):33-54.

Davidsson, P. (2015). Entrepreneurial opportunities and the entrepreneurship nexus: A re-conceptualization. Journal of Business Venturing, 30(5):674-695.

Davis, M. H. (1983). Measuring individual differences in empathy: Evidence for a multidimensional approach. Journal of Personality and Social Psychology, 44(1):113126.

de Mol, E., Khapova, S. N., and Elfring, T. (2015). Entrepreneurial team cognition: A review. International Journal of Management Reviews, 17(2):232-255.

Deeprose, C. and Holmes, E. A. (2010). An exploration of prospective imagery: The impact of future events scale. Behavioural and Cognitive Psychotherapy, 38(2):201209.

DeTienne, D. R. and Chandler, G. N. (2004). Opportunity identification and its role in the entrepreneurial classroom: A pedagogical approach and empirical test. Academy of Management Learning and Education, 3(3):242-257.

Dimov, D. (2007). Beyond the single-person, single-insight attribution in understanding entrepreneurial opportunities. Entrepreneurship Theory and Practice, 31(5):713-731.

Eckhardt, J. E. and Shane, S. A. (2003). Opportunities and entrepreneurship. Journal of Management, 29(3):333-349.

Eddleston, K. A. and Powell, G. N. (2012). Nurturing entrepreneurs' work-family balance: A gendered perspective. Entrepreneurship Theory and Practice, 36(3):513-541. 
Edelman, L. and Yli-Renko, H. (2010). The impact of environment and entrepreneurial perceptions on venture-creation efforts: Bridging the discovery and creation views of entrepreneurship. Entrepreneurship Theory and Practice, 34(5):833-856.

Eggers, J. P. and Kaplan, S. (2013). Cognition and capabilities: A multi-level perspective. Academy of Management Annals, 7(1):295-340.

Eisenhardt, K. M. (1989). Making fast strategic decisions in high-velocity environments. Academy of Management Journal, 32(3):543-576.

Escalas, J. E. (2004). Imagine yourself in the product. Journal of Advertising, 33(2):3748.

Faucette, J. (2012). The power of business imagination. In: http://www . entrepreneur . com/article/223429 Retrieved on August 31, 2015.

Felin, T. and Zenger, T. R. (2009). Entrepreneurs as theorists: On the origins of collective beliefs and novel strategies. Strategic Entrepreneurship Journal, 3(2):127-146.

Foss, K. and Foss, N. J. (2008). Understanding opportunity discovery and sustainable advantage: The role of transaction costs and property rights. Strategic Entrepreneurship Journal, 2(3):191-207.

Foss, N. J., Klein, P. G., Kor, Y. Y., and Mahoney, J. T. (2008). Entrepreneurship, subjectivism, and the resource-based view: Toward a new synthesis. Strategic Entrepreneurship Journal, 2(1):73-94.

Frederiks, A. J. (2014). Conceptualizing imagination and its effective use in business. Academy of Management Proceedings, 2014(1):16145. 
Gaglio, C. M. (2004). The role of mental simulations and counterfactual thinking in the opportunity identification process. Entrepreneurship Theory and Practice, 28(6):533552.

Gaglio, C. M. and Katz, J. A. (2001). The psychological basis of opportunity identification: Entrepreneurial alertness. Small Business Economics, 16(2):95-111.

Galinsky, A. D. and Ku, G. (2004). The effects of perspective-taking on prejudice: The moderating role of self-evaluation. Personality and Social Psychology Bulletin, 30(5):594-604

Galinsky, A. D., Maddux, W. W., Gilin, D., and White, J. B. (2008). Why it pays to get inside the head of your opponent: The differential effects of perspective taking and empathy in negotiations. Psychological Science, 19(4):378-384.

Gans, J. S. and Stern, S. (2003). The product market and the market for "ideas": Commercialization strategies for technology entrepreneurs. Research Policy, 32(2):333-350.

Gartner, W. B. (2007). Entrepreneurial narrative and a science of the imagination. Journal of Business Venturing, 22(5):613-627.

Gendler, T. S. (2011). Imagination. In Zalta, E. N., editor, The Stanford encyclopedia of philosophy. Stanford University, Stanford, CA.

Gilbert, D. T. and Wilson, T. D. (2007). Prospection: Experiencing the future. Science, 317(5843):1351-1354.

Gilhooly, K. J. and Johnson, C. E. (1978). Effects of solution word attributes on anagram difficulty: A regression analysis. Quarterly Journal of Experimental Psychology, 30(1):57-70. 
Gilovich, T. and Medvec, V. H. (1994). The temporal pattern to the experience of regret. Journal of Personality and Social Psychology, 67(3):357-365.

Gioia, D. A., Corley, K. G., and Hamilton, A. L. (2013). Seeking qualitative rigor in inductive research: Notes on the Gioia Methodology. Organizational Research Methods, 16(1):15-31.

Giraudeau, M. (2008). The drafts of strategy: Opening up plans and their uses. Long Range Planning, 41(3):291-308.

Glaser, B. G. and Strauss, A. L. (1967). The discovery of grounded theory: Strategies for qualitative research. Aldine, Chicago, IL.

Gordon, R. (1985). Imagination as mediator between inner and outer reality. Arts in Psychotherapy, 12(1):11-15.

Graham, D. and Bachman, T. T. (2004). Ideation: The birth and death of ideas. Wiley, Hoboken, NJ.

Granovetter, M. S. (1985). Economic action and social structure: The problem of embeddedness. American Journal of Sociology, 91(3):481-510.

Grant, A. M. and Berry, J. W. (2011). The necessity of others is the mother of invention: Intrinsic and prosocial motivations, perspective taking, and creativity. Academy of Management Journal, 54(1):73-96.

Grégoire, D. A., Barr, P. S., and Shepherd, D. A. (2010). Cognitive processes of opportunity recognition: The role of structural alignment. Organization Science, 21(2):413431. 
Grégoire, D. A., Corbett, A. C., and McMullen, J. S. (2011). The cognitive perspective in entrepreneurship: An agenda for future research. Journal of Management Studies, 48(6):1443-1477.

Gregory, W. L., Cialdini, R. B., and Carpenter, K. M. (1982). Self-relevant scenarios as mediators of likelihood estimates and compliance: Does imagining make it so? Journal of Personality and Social Psychology, 43(1):89-99.

Groen, A. J. (2005). Knowledge intensive entrepreneurship in networks: towards a multilevel/multi dimensional approach. Journal of Enterprising Culture, 13(1):69-88.

Gupta, V. K., Turban, D. B., and Pareek, A. (2012). Differences between men and women in opportunity evaluation as a function of gender stereotypes and stereotype activation. Entrepreneurship Theory and Practice, 37(4):771-788.

Hamel, G. (1999). Bringing Silicon Valley inside. Harvard Business Review, 77(5):70.

Harrison, E. F. and Pelletier, M. A. (2001). Revisiting strategic decision success. Management Decision, 39(3):169-180.

Hart, S. L. and Sharma, S. (2004). Engaging fringe stakeholders for competitive imagination. Academy of Management Executive, 18(1):7-18.

Hassabis, D., Kumaran, D., and Maguire, E. A. (2007). Using imagination to understand the neural basis of episodic memory. Journal of Neuroscience, 27(52):14365-14374.

Haynie, J. M., Shepherd, D. A., and McMullen, J. S. (2009). An opportunity for me? The role of resources in opportunity evaluation decisions. Journal of Management Studies, 46(3):337-361.

Hennessey, B. A. and Amabile, T. M. (2010). Creativity. Annual Review of Psychology, 61:569-598. 
Herron, L. and Sapienza, H. J. (1992). The entrepreneur and the initiation of new venture launch activities. Entrepreneurship Theory and Practice, 17(1):49-55.

Hill, R. C. and Levenhagen, M. (1995). Metaphors and mental models: Sensemaking and sensegiving in innovative and entrepreneurial activities. Journal of Management, 21(6):1057-1074.

Hindle, K. (2004). Choosing qualitative methods for entrepreneurial cognition research: A canonical development approach. Entrepreneurship Theory and Practice, 28(6):575607.

Hjorth, D. (2011). On provocation, education and entrepreneurship. Entrepreneurship E Regional Development, 23(1-2):49-63.

Hodgkinson, G. P. and Healey, M. P. (2008). Cognition in organizations. Annual Review of Psychology, 59(1):387-417.

Hodgkinson, G. P., Maule, A. J., and Bown, N. J. (2004). Causal cognitive mapping in the organizational strategy field: A comparison of alternative elicitation procedures. Organizational Research Methods, 7(1):3-26.

Hoeffler, S. (2003). Measuring preferences for really new products. Journal of Marketing Research, 40(4):406-420.

Hoever, I. J., van Knippenberg, D., van Ginkel, W. P., and Barkema, H. G. (2012). Fostering team creativity: Perspective taking as key to unlocking diversity's potential. Journal of Applied Psychology, 97(5):982-996.

Hofmann, F. (2010). Intuitions, concepts, and imagination. Philosophical Psychology, 23(4):529-546. 
Hsieh, C., Nickerson, J. A., and Zenger, T. R. (2007). Opportunity discovery, problem solving and a theory of the entrepreneurial firm. Journal of Management Studies, 44(7):1255-1277.

Ireland, R. D. and Webb, J. W. (2007). A cross-disciplinary exploration of entrepreneurship research. Journal of Management, 33(6):891-927.

Jackman, S. (2002). pscl: Classes and methods for $R$ developed in the Political Science Computational Laboratory, Stanford University. Stanford, CA. R package version 1.04.4.

James, L. R., Demaree, R. G., and Wolf, G. (1984). Estimating within-group interrater reliability with and without response bias. Journal of Applied Psychology, 69(1):85-98.

Johnson, M. K. and Sherman, S. J. (1990). Constructing and reconstructing the past and the future in the present. In Higgins, E. T. and Sorrentino, R. M., editors, Handbook of motivation and cognition: Foundations of social behavior, pages 482-526. Guilford Press, New York, NY.

Johnson, P. and Duberley, J. (2000). Understanding management research: An introduction to epistemology. SAGE, London, United Kingdom.

Jonson, B. (2005). Design ideation: The conceptual sketch in the digital age. Design Studies, 26(6):613-624.

Kahneman, D. (2003). A perspective on judgment and choice: Mapping bounded rationality. American Psychologist, 58(9):697-720.

Kahneman, D. and Miller, D. T. (1986). Norm theory: Comparing reality to its alternatives. Psychological Review, 93(2):136-153. 
Kahneman, D. and Tversky, A. (1973). On the psychology of prediction. Psychological Review, 80(4):237-251.

Kahneman, D. and Tversky, A. (1982). The simulation heuristic. In Kahneman, D., Slovic, P., and Tversky, A., editors, Judgment under uncertainty: Heuristics and biases, pages 201-208. Cambridge University Press, Cambridge, United Kingdom.

Kaish, S. and Gilad, B. (1991). Characteristics of opportunities search of entrepreneurs versus executives: Sources, interests, general alertness. Journal of Business Venturing, $6(1): 45-61$.

Kant, I. (2010). The critique of pure reason. Pennsylvania State University, University Park, PA.

Keating, A. and McLoughlin, D. (2010). The entrepreneurial imagination and the impact of context on the development of a new venture. Industrial Marketing Management, 39(6):996-1009.

Kirzner, I. M. (1973). Competition and entrepreneurship. University of Chicago Press, Chicago, IL.

Kirzner, I. M. (1979). Perception, opportunity, and profit: Studies in the theory of entrepreneurship. University of Chicago Press, Chicago, IL.

Kirzner, I. M. (1999). Creativity and/or alertness: A reconsideration of the Schumpeterian entrepreneur. Review of Austrian Economics, 11(1):5-17.

Klein, P. G. (2008). Opportunity discovery, entrepreneurial action, and economic organization. Strategic Entrepreneurship Journal, 2(3):175-190.

Knight, R. T. (2007). Neural networks debunk phrenology. Science, 316(5831):15781579 . 
Komulainen, K., Korhonen, M., and Räty, H. (2009). Risk-taking abilities for everyone? Finnish entrepreneurship education and the enterprising selves imagined by pupils. Gender and Education, 21(6):631-649.

Kraaijenbrink, J., Spender, J.-C., and Groen, A. J. (2009). The resource-based view: A review and assessment of its critiques. Journal of Management, 36(1):349-372.

Lachmann, L. M. (1976). From Mises to Shackle: An essay on Austrian economics and the kaleidic society. Journal of Economic Literature, 14(1):54-62.

Lachmann, L. M. (1986). The market as an economic process. Blackwell, Oxford, United Kingdom.

Lakshmanan, A. and Krishnan, H. S. (2009). How does imagery in interactive consumption lead to false memory? A reconstructive memory perspective. Journal of Consumer Psychology, 19(3):451-462.

Lamm, C., Batson, C. D., and Decety, J. (2007). The neural substrate of human empathy: Effects of perspective-taking and cognitive appraisal. Journal of Cognitive Neuroscience, 19(1):42-58.

Larsen, R. and Kasimatis, M. (1990). Individual differences in entrainment of mood to the weekly calendar. Journal of Personality and Social Psychology, 58(1):164-171.

Laurenceau, J.-P. and Bolger, N. (2005). Using diary methods to study marital and family processes. Journal of Family Psychology, 19(1):86-97.

LeBreton, J. M. and Senter, J. L. (2007). Answers to 20 questions about interrater reliability and interrater agreement. Organizational Research Methods, 11(4):815-852.

Lewis, P. (2006). The quest for invisibility: Female entrepreneurs and the masculine norm of entrepreneurship. Gender, Work and Organization, 13(5):453-469. 
Liao, S.-y. and Gendler, T. S. (2011). Pretense and imagination. Wiley Interdisciplinary Reviews: Cognitive Science, 2(1):79-94.

Loasby, B. J. (2001). Cognition, imagination and institutions in demand creation. Journal of Evolutionary Economics, 11(1):7-21.

Locke, K., Golden-Biddle, K., and Feldman, M. S. (2008). Making doubt generative: Rethinking the role of doubt in the research process. Organization Science, 19(6):907918.

Lumpkin, G. T. and Dess, G. G. (1996). Clarifying the entrepreneurial orientation construct and linking it to performance. Academy of Management Review, 21(1):135172.

MacLeod, A. K., Byrne, A., and Valentine, J. D. (1996). Affect, emotional disorder, and future-directed thinking. Cognition \& Emotion, 10(1):69-86.

Markman, K. D., Gavanski, I., Sherman, S. J., and McMullen, M. N. (1993). The mental simulation of better and worse possible worlds. Journal of Experimental Social Psychology, 29(1):87-109.

Markman, K. D., Klein, W. M. P., and Suhr, J. A., editors (2009). Handbook of imagination and mental simulation. Psychology Press, New York, NY.

Mathews, J. A. (2010). Lachmannian insights into strategic entrepreneurship: Resources, activities and routines in a disequilibrium world. Organization Studies, 31(2):219-244.

Maurya, A. (2012). Running lean: Iterate from plan A to a plan that works. O'Reilly, Sebastopol, CA, $2^{\text {nd }}$ edition.

McBane, D. A. (1995). Empathy and the salesperson: A multidimensional perspective. Psychology \& Marketing, 12(4):349-370. 
McMullen, J. S. (2010). Perspective taking and the heterogeneity of the entrepreneurial imagination. In Horwitz, S., Desrochers, P., and Koppl, R., editors, Advances in Austrian economics, pages 113-143. Edward Elgar, London, United Kingdom.

McMullen, J. S., Plummer, L. A., and Acs, Z. J. (2007). What is an entrepreneurial opportunity? Small Business Economics, 28(4):273-283.

McMullen, J. S. and Shepherd, D. A. (2006). Entrepreneurial action and the role of uncertainty in the theory of the entrepreneur. Academy of Management Review, 31(1):132-152.

McVea, J. F. (2009). A field study of entrepreneurial decision-making and moral imagination. Journal of Business Venturing, 24(5):491-504.

Mehta, C. R. and Patel, N. R. (1983). A network algorithm for performing Fisher's exact test in $r \times c$ contingency tables. Journal of the American Statistical Association, 78(382):427-434.

Mehta, C. R. and Patel, N. R. (1986). ALGORITHM 643: FEXACT: A FORTRAN subroutine for Fisher's exact test on unordered $r \times c$ contingency tables. ACM Transactions on Mathematical Software, 12(2):154-161.

Miles, M. B. and Huberman, A. M. (1994). Qualitative data analysis: An expanded sourcebook. Sage, Thousand Oaks, CA, 2nd edition.

Mills, C. W. (1959). The sociological imagination. Oxford University Press, Oxford, United Kingdom.

Mitchell, J. R., Friga, P. N., and Mitchell, R. K. (2005). Untangling the intuition mess: Intuition as a construct in entrepreneurship research. Entrepreneurship Theory and Practice, 29(6):653-679. 
Mitchell, J. R. and Shepherd, D. A. (2010). To thine own self be true: Images of self, images of opportunity, and entrepreneurial action. Journal of Business Venturing, 25(1):138-154.

Mitchell, R. K. (1997). Oral history and expert scripts: Demystifying the entrepreneurial experience. International Journal of Entrepreneurial Behaviour $\mathcal{E}$ Research, 3(2):122139.

Mitchell, R. K., Busenitz, L. W., Bird, B. J., Gaglio, C. M., McMullen, J. S., Morse, E. A., and Smith, J. B. (2007). The central question in entrepreneurial cognition research 2007. Entrepreneurship Theory and Practice, 31(1):1-27.

Mitchell, R. K., Busenitz, L. W., Lant, T., McDougall, P. P., Morse, E. A., and Smith, J. B. (2002). Toward a theory of entrepreneurial cognition: Rethinking the people side of entrepreneurship research. Entrepreneurship Theory and Practice, 27(2):93-104.

Mitchell, R. K., Busenitz, L. W., Lant, T., McDougall, P. P., Morse, E. A., and Smith, J. B. (2004). The distinctive and inclusive domain of entrepreneurial cognition research. Entrepreneurship Theory and Practice, 28(6):505-518.

Mullally, S. L. and Maguire, E. A. (2014). Memory, imagination, and predicting the future: A common brain mechanism? The Neuroscientist, 20(3):220-234.

Mumford, M. D. (2003). Where have we been, where are we going? Taking stock in creativity research. Creativity Research Journal, 15(2-3):107-120.

Mustar, P. (2009). Technology management education: Innovation and entrepreneurship at MINES ParisTech, a leading French engineering school. Academy of Management Learning and Education, 8(3):418-425.

Nasco, S. A. and Marsh, K. L. (1999). Gaining control through counterfactual thinking. Personality and Social Psychology Bulletin, 25(5):556-568. 
Oettingen, G. and Mayer, D. (2002). The motivating function of thinking about the future: Expectations versus fantasies. Journal of Personality and Social Psychology, 83(5):1198-1212.

Oettingen, G., Schnetter, K., and Pak, H.-j. (2001). Self-regulation of goal setting: Turning free fantasies about the future into binding goals. Journal of Personality and Social Psychology, 80(5):736-753.

ogilvie, d. (1998). Creative action as a dynamic strategy: Using imagination to improve strategic solutions in unstable environments. Journal of Business Research, 41(1):4956.

Olson Jr, M. (1996). Distinguished lecture on economics in government: Big bills left on the sidewalk: Why some nations are rich, and others poor. Journal of Economic Perspectives, 10(2):3-24.

O'Reilly, K., Paper, D., and Marx, S. (2012). Demystifying Grounded Theory for business research. Organizational Research Methods, 15(2):247-262.

Pelaprat, E. and Cole, M. (2011). "Minding the gap": Imagination, creativity and human cognition. Integrative Psychological and Behavioral Science, 45(4):397-418.

Phillips, D. M. (1996). Anticipating the future: The role of consumption visions in consumer behavior. In Corfman, K. P. and Lynch Jr., J. G., editors, Advances in consumer research, volume 23, pages 70-75. Association for Consumer Research, Provo, UT.

R Core Team (2014). R: A language and environment for statistical computing. Vienna, Austria. 
Read, S., Dew, N., Sarasvathy, S. D., Song, M., and Wiltbank, R. (2009). Marketing under uncertainty: The logic of an effectual approach. Journal of Marketing, 73(3):118.

Revelle, W. (2015). psych: Procedures for psychological, psychometric, and personality research. Northwestern University, Evanston, IL. R package version 1.5.6.

Roco, M. C. and Bainbridge, W. S. (2003). Converging technologies for improving human performance. National Science Foundation, Dordrecht, The Netherlands.

Roese, N. J. (1994). The functional basis of counterfactual thinking. Journal of Personality and Social Psychology, 66(5):805-818.

Roese, N. J. (1997). Counterfactual thinking. Psychological Bulletin, 121(1):133-148.

Roos, J. and Victor, B. (1999). Towards a new model of strategy-making as serious play. European Management Journal, 17(4):348-355.

Rye, M. S., Cahoon, M. B., Ali, R. S., and Daftary, T. (2008). Development and validation of the counterfactual thinking for negative events scale. Journal of Personality Assessment, 90(3):261-269.

Sanna, L. J. (1996). Defensive pessimism, optimism, and simulating alternatives: Some ups and downs of prefactual and counterfactual thinking. Journal of Personality and Social Psychology, 71(5):1020-1036.

Sanna, L. J. (1998). Defensive pessimism and optimism: The bitter-sweet influence of mood on performance and prefactual and counterfactual thinking. Cognition $\mathscr{G}$ Emotion, 12(5):635-665.

Sanna, L. J. (1999). Mental simulations, affect, and subjective confidence: Timing is everything. Psychological Science, 10(4):339-345. 
Sanna, L. J. (2000). Mental simulation, affect, and personality: A conceptual framework. Current Directions in Psychological Science, 9(5):165-173.

Sanna, L. J. and Turley-Ames, K. J. (2000). Counterfactual intensity. European Journal of Social Psychology, 30(2):273-296.

Sanna, L. J., Turley-Ames, K. J., and Meier, S. (1999). Mood, self-esteem, and simulated alternatives: Thought-provoking affective influences on counterfactual direction. Journal of Personality and Social Psychology, 76(4):543-558.

Sarasvathy, S. D. (2001). Causation and effectuation: Toward a theoretical shift from economic inevitability to entrepreneurial contingency. Academy of Management Review, 26(2):243-263.

Sarasvathy, S. D. (2002). Entrepreneurship as economics with imagination. The Ruffin Series of the Society for Business Ethics, 3:95-112.

Sarasvathy, S. D. (2008). Effectuation: Elements of entrepreneurial expertise. New Horizons in Entrepreneurship. Edward Elgar, Cheltenham, United Kingdom.

Sarasvathy, S. D., Dew, N., Velamuri, S. R., and Venkataraman, S. (2003). Three views of entrepreneurial opportunity. In Acs, Z. J. and Audretsch, D. B., editors, Handbook of entrepreneurship research, pages 141-160. Springer, New York, NY.

Schacter, D. L., Addis, D. R., and Buckner, R. L. (2007). Remembering the past to imagine the future: The prospective brain. Nature Reviews Neuroscience, 8(9):657661.

Schau, H. J. (2000). Consumer imagination, identity and self-expression. In Hoch, S. J. and Meyer, R. J., editors, Advances in consumer research, pages 50-56. Association for Consumer Research, Provo, UT. 
Schlegel, A., Kohler, P. J., Fogelson, S. V., Alexander, P., Konuthula, D., and Tsa, P. U. (2013). Network structure and dynamics of the mental workspace. Proceedings of the National Academy of Sciences of the United States of America, 110(40):16277-16282.

Schumpeter, J. A. (1934). The theory of economic development: An inquiry into profits, capital, credit, interest and the business cycle. Harvard University Press, Cambridge, MA.

Schumpeter, J. A. (1942). Capitalism, Socialism and Democracy. Routledge, London, United Kingdom.

Seelig, T. (2015). Insight out: Get your ideas out of your head and into the world. HarperOne, New York, NY.

Shadish, W. R., Cook, T. D., and Campbell, D. T. (2002). Experimental and QuasiExperimental Designs for Generalized Causal Inference. Houghton Mifflin Company, Boston, MA.

Shane, S. A. (2000). Prior knowledge and the discovery of entrepreneurial opportunities. Organization Science, 11(4):448-469.

Shane, S. A. (2001). Technological opportunities and new firm creation. Management Science, 47(2):205-220.

Shane, S. A. (2003). A general theory of entrepreneurship: The individual-opportunity nexus. Edward Elgar, Northampton, MA.

Shane, S. A. and Venkataraman, S. (2000). The promise of entrepreneurship as a field of research. Academy of Management Review, 25(1):217-226.

Shapiro, S. and Spence, M. T. (1997). Managerial intuition: A conceptual and operational framework. Business Horizons, 40(1):63-68. 
Shepherd, D. A. (2015). Party On! A call for entrepreneurship research that is more interactive, activity based, cognitively hot, compassionate, and prosocial. Journal of Business Venturing, 30(4):489-507.

Shepherd, D. A., McMullen, J. S., and Jennings, P. D. (2007). The formation of opportunity beliefs: Overcoming ignorance and reducing doubt. Strategic Entrepreneurship Journal, 1(1-2):75-95.

Simon, H. A. (1956). Rational choice and the structure of the environment. Psychological Review, 63(2):129-138.

Strauss, A. L. and Corbin, J. M. (1990). Basics of qualitative research: Grounded theory procedures and techniques. Sage, Newbury Park, CA.

Szulanski, G. and Amin, K. (2001). Learning to make strategy: Balancing discipline and imagination. Long Range Planning, 34(5):537-556.

Taylor, S. E., Pham, L. B., Rivkin, I. D., and Armor, D. A. (1998). Harnessing the imagination: Mental simulation, self-regulation, and coping. American Psychologist, 53(4):429-439.

Teece, D. J., Pisano, G., and Shuen, A. (1997). Dynamic capabilities and strategic management. Strategic Management Journal, 18(7):509-533.

Thompson, E. R. (2008). Development and validation of an International English BigFive Mini-Markers. Personality and Individual Differences, 45(6):542-548.

Tversky, A. and Kahneman, D. (1973). Availability: A heuristic for judging frequency and probability. Cognitive Psychology, 5(2):207-232.

Tversky, A. and Kahneman, D. (1986). Rational choice and the framing of decisions. Journal of Business, 59(4):S251-S278. 
U2 (2014). California (there is no end to love). In Songs of Innocence. Island Records / Interscope Records.

Van Boven, L., Kane, J., and McGraw, A. P. (2009). Temporally asymmetric constraints on mental simulation: Retrospection is more constrained than prospection. In Markman, K. D., Klein, W. M. P., and Suhr, J. A., editors, Handbook of imagination and mental simulation, pages 131-150. Psychology Press, New York, NY.

van de Ven, A. H. (2007). Engaged scholarship: A guide for organizational and social research. Oxford University Press, Oxford, United Kingdom.

van de Ven, A. H. and Johnson, P. E. (2006). Knowledge for theory and practice. Academy of Management Review, 31(4):802-821.

Van Maanen, J. (1979). The fact of fiction in organizational ethnography. Administrative Science Quarterly, 24(4):539-550.

Venables, W. N. and Ripley, B. D. (2002). Modern applied statistics with S. Springer, New York, NY, $4^{\text {th }}$ edition.

Venkataraman, S. (1997). The distinctive domain of entrepreneurship research. In Katz, J. A. and Brockhaus Sr., R. H., editors, Advances in entrepreneurship, firm emergence and growth, pages 119-138. JAI Press, Greenwich, CT.

Venkataraman, S. (2003). Foreword. In A general theory of entrepreneurship: The individual-opportunity nexus, pages xi-xii. Edward Elgar, Northampton, MA.

Ward, T. B. (1994). Structured imagination: The role of category structure in exemplar generation. Cognitive Psychology, 27(1):1-40.

Ward, T. B. (2008). The role of domain knowledge in creative generation. Learning and Individual Differences, 18(4):363-366. 
West III, G. P. (2007). Collective cognition: When entrepreneurial teams, not individuals, make decisions. Entrepreneurship Theory and Practice, 31(1):77-102.

Wheeler, M. A., Stuss, D. T., and Tulving, E. (1997). Toward a theory of episodic memory: The frontal lobes and autonoetic consciousness. Psychological Bulletin, 121(3):331-354.

Wiley, J. (1998). Expertise as mental set: The effects of domain knowledge in creative problem solving. Memory \& Cognition, 26(4):716-730.

Wiltbank, R., Read, S., Dew, N., and Sarasvathy, S. D. (2009). Prediction and control under uncertainty: Outcomes in angel investing. Journal of Business Venturing, 24(2):116-133.

Witt, U. (1998). Imagination and leadership: The neglected dimension of an evolutionary theory of the firm. Journal of Economic Behavior \& Organization, 35(2):161-177.

Witt, U. (2007). Firms as realizations of entrepreneurial visions. Journal of Management Studies, 44(7):1125-1140.

Witt, U. and Foster, J. (1992). Turning Austrian economics into an evolutionary theory. In Austrian economics: Tensions and new directions, pages 215-243. Springer, Dordrecht, The Netherlands.

Woehr, D. J., Loignon, A. C., Schmidt, P. B., Loughry, M. L., and Ohland, M. W. (2015). Justifying aggregation with consensus-based constructs: A review and examination of cutoff values for common aggregation indices. Organizational Research Methods, pages $1-34$.

Zahra, S. A. (2008). The virtuous cycle of discovery and creation of entrepreneurial opportunities. Strategic Entrepreneurship Journal, 2(3):243-257. 
Zeileis, A., Kleiber, C., and Jackman, S. (2008). Regression models for count data in R. Journal of Statistical Software, 27(8):1-25.

Zhao, M., Hoeffler, S., and Dahl, D. W. (2009). The role of imagination-focused visualization on new product evaluation. Journal of Marketing Research, 46(1):46-55.

Zhao, M., Hoeffler, S., and Dahl, D. W. (2012). Imagination difficulty and new product evaluation. Journal of Product Innovation Management, 29(S1):76-90.

Zhao, M., Hoeffler, S., and Zauberman, G. (2011). Mental simulation and product evaluation: The affective and cognitive dimensions of process versus outcome simulation. Journal of Marketing Research, 48(5):827-839.

Zhou, J. (2008). New look at creativity in the entrepreneurial process. Strategic Entrepreneurship Journal, 2(1):1-5. 


\section{Summary: On the Use of Imagination by Entrepreneurs}

In this dissertation we study the use of imagination by entrepreneurs. Many scholars state that entrepreneurs use their imagination for, among others, identifying opportunities and developing strategies. Nevertheless, what imagination is, how entrepreneurs use their imagination, and how they use it effectively, remain unknown. In this dissertation we address these issues. The present dissertation comprises four studies (one conceptual and three empirical) to address the use of imagination by entrepreneurs.

In the first study we aim to provide more clarity on what imagination is from a business perspective, and to explain how entrepreneurs can use imagination effectively. We review the concept of imagination in the literature and conceptualize imagination as a combination of three mental simulation processes: prospective thinking, counterfactual thinking, and perspective taking. Additionally, we differentiate imagination from related concepts such as creativity. Subsequently, we develop a conceptual model and propositions on the effective use of imagination by entrepreneurs. We argue that individual factors, the type of imagination task, and environmental dynamism influence the effective use of imagination by entrepreneurs. Based on our conceptual model and propositions we study the use of imagination in the subsequent empirical studies.

In the second study, using a grounded theory approach, we study how thirty-one high- 
technology entrepreneurs use their imagination in opportunity identification processes and strategic decision-making processes. We find that entrepreneurs are aware that they use their imagination, although they call it differently (e.g., creating a vision). They consider imagination to be an important factor that contributes to their business success. Additionally, we find that the use of imagination is more important in highuncertainty environments than low-uncertainty environments. Subsequently we find that the use of imagination is more important earlier in the entrepreneurial process, where information is often unknown, than later in the process when more information was already gathered. Based on our findings we develop propositions for further research.

In the third study, we study the use of imagination by differentiating between distinct imagination processes and business related uses of imagination in the venture creation process. Additionally, we link the use of imagination to the pursuit of the business idea. Based on the previous finding that imagination is important for both opportunity identification and strategic decision-making processes, we study these processes by analyzing 5,803 weekly entries of diaries that were kept by 164 nascent entrepreneurs. We found that entrepreneurs tend to use prospective thinking when identifying business opportunities, and counterfactual thinking strategic decision-making processes.

In the fourth study, we design and execute an experimental study based on the findings of the previous studies. We test the effect of the use of the three imagination processes (prospective thinking, counterfactual thinking, and perspective taking) on the quality of a business opportunity identified by the participants. We conduct two studies with an experimental design where we compare three experimental groups and a control group. In each experimental condition, we stimulate the use of one of the three imagination processes using manipulation techniques. We do not stimulate the use of imagination in the control group. The manipulations that we use in the two studies differ, but we find the same result: participants of whom the use of prospective thinking 
is stimulated identify business opportunities of a higher quality than the participants of whom the use of counterfactual thinking, perspective taking was stimulated or of whom the use of imagination is not stimulated at all. This study provides empirical support that the use of imagination - more specifically the use of prospective thinking - is beneficial for identifying business opportunities.

The results of this dissertation contribute to both theory and practice of entrepreneurship. Whereas many entrepreneurship scholars write that entrepreneurs use their imagination, this dissertation makes clear that imagination is a concept that consists of three processes: prospective thinking, counterfactual thinking, and perspective taking. Additionally, we show that these three imagination processes are used for different entrepreneurial tasks. Prospective thinking is more effective for identifying opportunities, whereas counterfactual thinking is more effective for creating new strategies. This dissertation also offers practical implications for both entrepreneurs, entrepreneurship educators, and entrepreneurship support organizations. Furthermore, we offer a research agenda for further research on the use of imagination by entrepreneurs, which focuses on opportunity identification, entrepreneurship strategies, and expertise. 



\section{Samenvatting: Over het gebruik}

\section{van voorstellingsvermogen door}

\section{ondernemers}

In dit proefschrift bestuderen wij het gebruik van voorstellingsvermogen (imagination) door ondernemers. Veel onderzoekers stellen dat ondernemers hun voorstellingsvermogen gebruiken om, onder andere, mogelijkheden te identificeren om een bedrijf te starten (business opportunity) en passende strategieën te ontwikkelen. Desalniettemin, wat voorstellingsvermogen is, hoe ondernemers hun voorstellingsvermogen gebruiken, en hoe zij dit effectief kunnen inzetten, blijven in eerdere onderzoeken onbekend. In dit proefschrift behandelen wij deze kwesties. Dit proefschrift omvat vier studies (een conceptuele en drie empirische) en behandelt het gebruik van voorstellingsvermogen door ondernemers.

Het doel van de eerste onderzoek is om meer duidelijkheid te verschaffen over wat voorstellingsvermogen is vanuit een bedrijfskundig perspectief, en om uit te leggen hoe ondernemers hun voorstellingsvermogen effectief kunnen gebruiken. We bespreken het concept voorstellingsvermogen in de literatuur en conceptualiseren dit begrip als een combinatie van drie mentale simulatieprocessen: prospectief denken (prospective thinking), contrafeitelijk denken (counterfactual thinking), en perspectief nemen (perspective taking). Daarnaast onderscheiden we voorstellingsvermogen van verwante concepten zo- 
als creativiteit. Vervolgens ontwikkelen we een conceptueel model en proposities over het effectief gebruik van voorstellingsvermogen door ondernemers. Wij stellen dat individuele factoren, de aard van de voorstellingstaken, en omgevingsdynamiek het effectief gebruik van voorstellingsvermogen door ondernemers beïnvloeden. Op basis van ons conceptueel model en de hierbij behorende proposities, onderzoeken wij de toepassing van voorstellingsvermogen in de daaropvolgende empirische studies.

In de tweede studie, waarin we gebruik maken van een grounded theory-benadering, bestuderen wij hoe eenendertig high-techondernemers hun voorstellingsvermogen gebruiken in de opportunity-identificatie- en strategischebesluitvormingsprocessen. Wij vinden dat ondernemers zich ervan bewust zijn dat ze gebruik maken van hun voorstellingsvermogen, ondanks dat ze het anders noemen (bijvoorbeeld, het creëren van een visie). Zij beschouwen voorstellingsvermogen als een belangrijke factor die bijdraagt aan hun zakelijk succes. Daarnaast blijkt dat het gebruik van voorstellingsvermogen belangrijker is in situaties met grote onzekerheid, dan in situaties met weinig onzekerheid. Vervolgens komt naar voren dat het gebruik van voorstellingsvermogen belangrijker is vroeger in het ondernemingsproces, waar informatie vaak onbekend is, dan later in het proces, als er al meer informatie is verzameld. Op basis van onze bevindingen ontwikkelen wij proposities voor vervolgonderzoek.

In de derde studie besturen wij het gebruik van voorstellingsvermogen door onderscheid te maken tussen verschillende voorstellingsprocessen en de bedrijfskundiggerelateerde toepassingen van voorstellingsvermogen in het ondernemerschapsproces. Bovendien koppelen we het gebruik van voorstellingsvermogen aan het voortzetten van het bedrijfsidee. Op basis van de eerdere constatering dat voorstellingsvermogen belangrijk is voor zowel de identificatie van opportunities en strategische besluitvorming, bestuderen we deze processen door 5.803 wekelijkse dagboekberichten, die door 164 startende ondernemers werden ingevuld, te analyseren. Uit de analyse kwam naar voren 
dat ondernemers prospectief neigen te denken wanneer zij opportunties identificeren, en contrafeitelijk denken bij strategischebesluitvormingsprocessen.

In de vierde studie ontwerpen wij een experiment op basis van de bevindingen in eerdere studies en voeren dit experiment uit. Wij testen het effect van het gebruik van de drie voorstellingsprocessen (prospectief denken, contrafeitelijk denken, en perspectief nemen) op de kwaliteit van een bedrijfs-opportunity, die de deelnemers identificeerden. Wij voeren twee experimenten uit waarbij we de drie interventiegroepen en de controlegroep vergelijken. In elke experimentele conditie stimuleren wij het gebruik van een van de drie voorstellingsprocessen met behulp van manipulatietechnieken. Het gebruik van voorstellingsprocessen stimuleerden wij niet in de controlegroep. De manipulaties die wij in de twee studies gebruiken verschillen, maar wij vinden hetzelfde resultaat: deelnemers waarbij prospectief denken is gestimuleerd identificeren bedrijfs-opportunities van een hogere kwaliteit dan deelnemers waarbij contrafeitelijk denken of perspectief nemen is gestimuleerd, of waarbij het gebruik van voorstellingsvermogen niet is gestimuleerd. Deze studie geeft empirische ondersteuning dat het gebruik van voorstellingsvermogen of preciezer, het gebruik van prospectief denken - gunstig kan zijn voor het identificeren van opportunities.

De resultaten van dit proefschrift leveren een bijdrage aan zowel de ondernemerschapstheorie als de -praktijk. Terwijl veel ondernemerschapsonderzoekers schrijven dat ondernemers gebruik maken van hun voorstellingsvermogen, maakt dit proefschrift duidelijk dat het voorstellingsvermogen een concept is dat bestaat uit drie processen: prospectief denken, contrafeitelijk denken, en perspectief nemen. Daarnaast laten we zien dat deze drie voorstellingsprocessen worden gebruikt voor verschillende ondernemerschapstaken. Prospectief denken is effectiever voor het identificeren van opportunities, terwijl contrafeitelijk denken effectiever is voor het creëren van nieuwe strategieën. Dit proefschrift biedt ook praktische implicaties voor ondernemers, ondernemerschapson- 
SAMENVATTING: OVER HET GEBRUIK VAN VOORSTELLINGSVERMOGEN DOOR ONDERNEMERS

derwijzers en ondernemerschapsondersteuningsorganisaties. Daarnaast leveren wij voor vervolgonderzoek naar het gebruik van voorstellingsvermogen door ondernemers een onderzoeksagenda die zich richt op opportunity-identificatie, ondernemerschapsstrategieën en expertise. 


\section{About the Author}

Arjan Frederiks' research focuses on entrepreneurial cognition and entrepreneurial strategy. Arjan has published some of his research in the Frontiers of Entrepreneurship Research and has presented his research at top-tier academic conferences in the field, such as the Annual Meeting of the Academy of Management (AOM), and the Babson College Entrepreneurship Research Conference (BCERC).

Arjan obtained a Bachelor of Science in Industrial Engineering \& Management degree, and a Master of Science degree in Business Administration with a specialization in Innovation \& Entrepreneurship from the University of Twente, the Netherlands. Additionally, he obtained a Master of Science degree in Innovation, Knowledge \& Entrepreneurial Dynamics from Aalborg University, Denmark.

Before he started a career in academia, Arjan gained entrepreneurial experience for more than three years as a co-founder of a technology-driven marketing company in the Netherlands. 


\section{ON THE USE OF IMAGINATION BY ENTREPRENEURS}

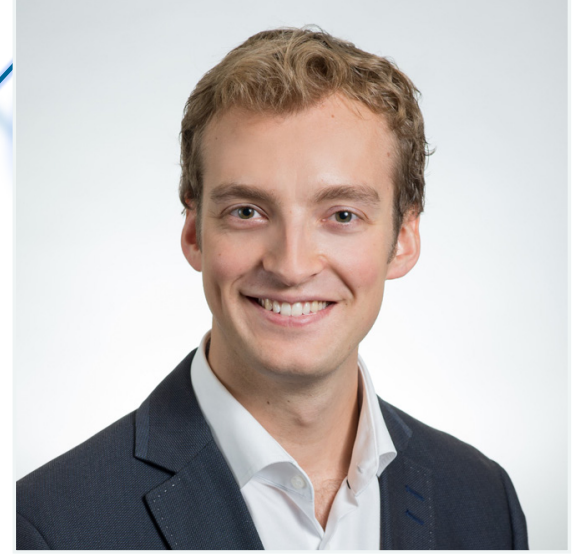

Arjan Frederiks' research focuses on entrepreneurial cognition and entrepreneurial strategy. Arjan has published some of his research in the Frontiers of Entrepreneurship Research and he has presented his research at top-tier academic conferences in the field, such as the Annual Meeting of the Academy of Management (AOM), and the Babson College Entrepreneurship Research Conference (BCERC). Arjan gained entrepreneurial experience for more than three years as a co-founder of a technology-driven marketing company in the Netherlands.

ISBN: 978-90-365-4003-2
Many scholars acknowledge that entrepreneurs use their imagination. What entrepreneurs use their imagination for is known. However, what imagination is, and how entrepreneurs can use their imagination most effectively remain unknown. The goal of this research is to increase our understanding of the use of imagination by entrepreneurs.

We conceptualize, demarcate and define the concept of imagination based on social and cognitive psychology literature. Subsequently, we theorize how certain factors influence the effective use of imagination by entrepreneurs.

Based on the literature and the interviews we conducted with entrepreneurs, we developed propositions that guide us in our research. We analyzed the use of imagination by entrepreneurs by studying their diaries and conducting experiments.

Among other results, we find that prospective thinking, which is future-oriented imagination, is effective for entrepreneurs to identify business opportunities. Additionally, we find that counterfactual thinking, which is alternatives-oriented imagination, is effective for entrepreneurs to develop business strategies.

Our research contributes to the entrepreneurship literature by offering a theoretical lens to study the use of imagination by entrepreneurs. Furthermore, our research informs practice by suggesting that entrepreneurs should train the use of their imagination and that entrepreneurship support organizations could include such trainings in their programs. 